\title{
INVESTIGATION OF PULLOUT STRENGTH OF PRE-INSTALLED GLASS FIBRE REINFORCED POLYMER BARS IN HIGH-PERFORMANCE CONCRETE
}

\author{
By \\ Jennifer Lu \\ B.Eng, Toronto, Ontario \\ Ryerson University \\ A report \\ Presented to Ryerson University \\ in partial fulfillment of the \\ requirements for the degree of \\ Master of Engineering \\ In the Program of \\ Civil Engineering \\ Toronto, Ontario, Canada, 2015 \\ (C) Jennifer Lu 2015
}




\section{Author's Declaration}

I hereby declare that I am the sole author of this project. This is a true copy of the project, including any required final revisions as accepted by examiner.

I thereby authorize Ryerson University to reproduce or lend this project by photocopying or by other means, in total or in part, at the request of other institutions or individuals for the purpose of scholarly research.

I understand that this project may be made electronically available to the public. 


\begin{abstract}
Fibre reinforced polymer (FRP) bars are rapidly becoming an alternative to conventional steel reinforcing bars in bridge construction. This research investigated the bond behaviour of glass fiber reinforced polymer (GFRP) bars embedded in high-performance concrete (HPC). Sand-coated and ribbed-surface GFRP bars of 16 and $20 \mathrm{~mm}$ diameters were considered in this study. Concrete blocks were cast with embedded GFPR bars to conducted pullout tests to examine the effect of varying parameters on their pullout and bond strengths, namely: embedment length, bar diameter, surface treatment, and concrete cover. In addition, bond characteristic were analyzed between straight and head-ended sand-coated GFRP bars. The experimental results were used to evaluate the development lengths specified in design codes. It was determined that the development lengths for straight GFRP bars provided by the codes are conservative. Also, the development length for head-end bar is shorter than that for similar bar with straight end.
\end{abstract}




\section{Acknowledgements}

I am grateful to my project supervisor, Professor Khaled Sennah, for his patience throughout this project. I am also thankful to the many undergraduate students, concrete lab technicians and friends for their time spent in the lab and their moral support. 


\section{Dedication}

This report is dedicated to my family and friends for their patience and endless support. 


\section{Table of Contents}

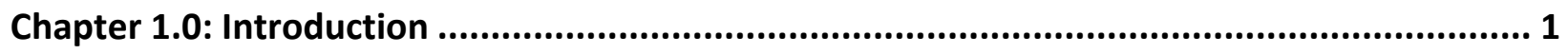

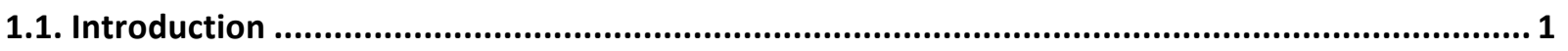

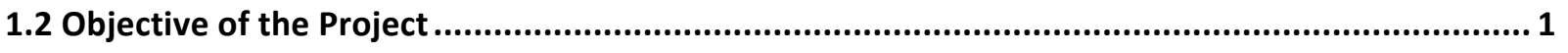

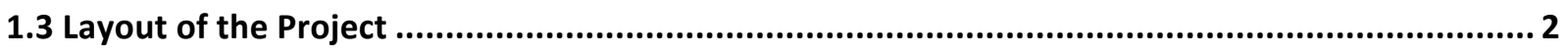

Chapter 2: Background, Literature Review and Design Equations......................................... 4

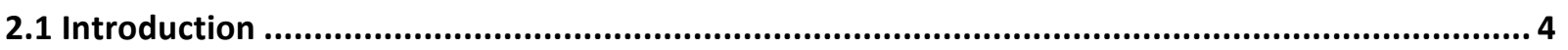

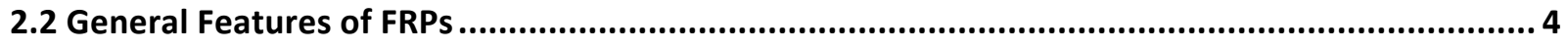

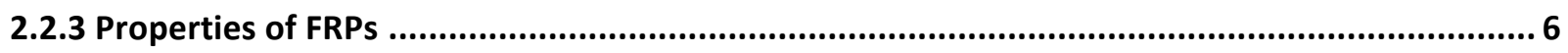

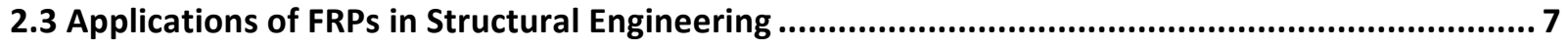

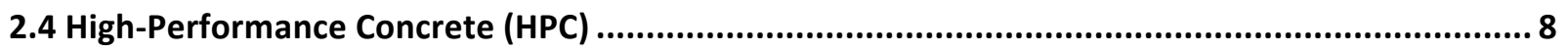

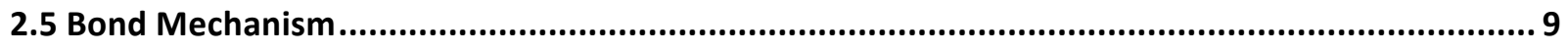

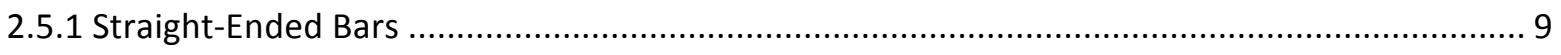

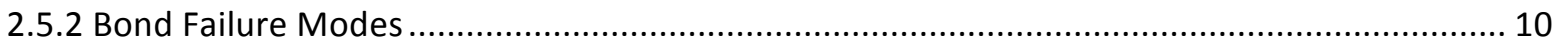

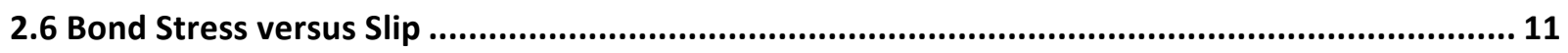

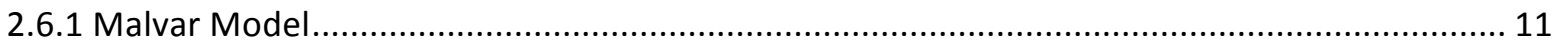

2.6.2 Eligehausen, Popov, and Bertero Model (BPE Model) ..................................................... 12

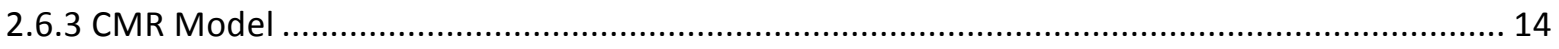

2.7 Controlling Variables Affecting Bond Behaviour of FRP bar Embedded in Concrete.................. 14

2.7.1 Effect of Fibre Type on Bond Action ................................................................................. 14

2.7.2 Effect of Surface Treatment and Configuration on Bond Action ............................................ 14

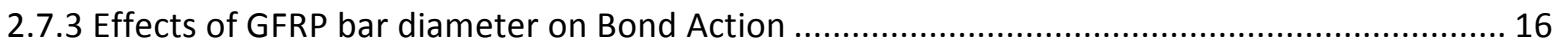

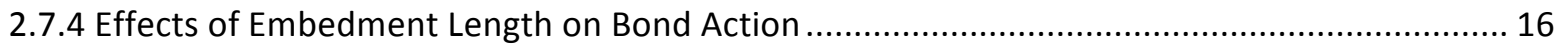

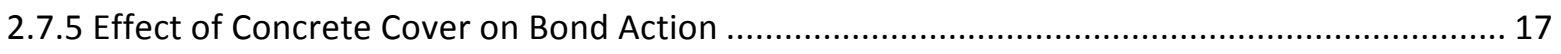

2.7.6 Effect of Concrete Properties on Bond Action .................................................................. 17

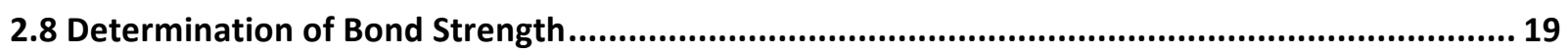

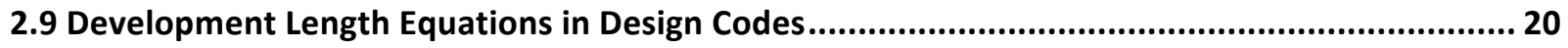

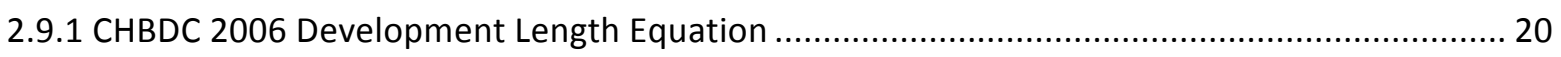

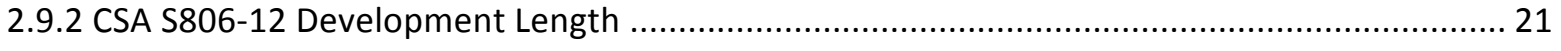

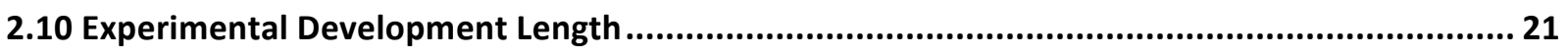

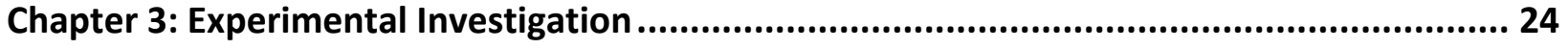

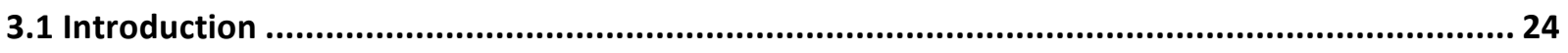

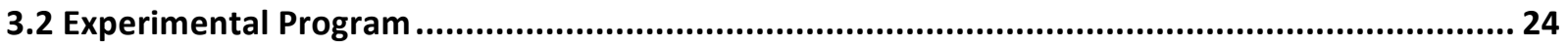

3.3 Pullout Test Specimen Matrix and Configuration ........................................................... 26

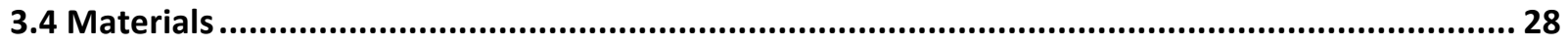

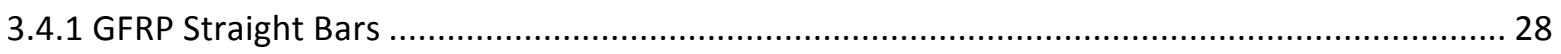

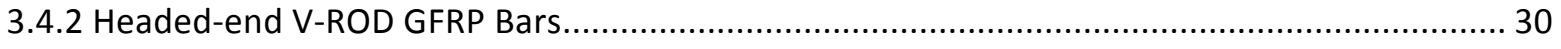

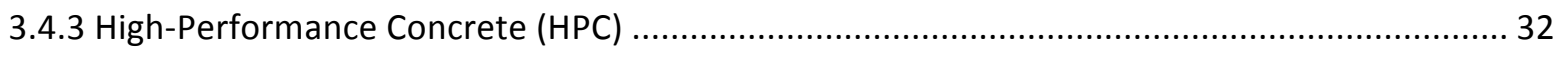

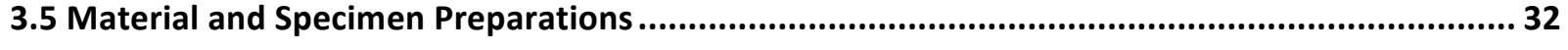

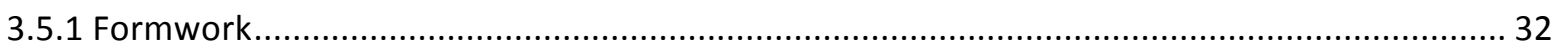




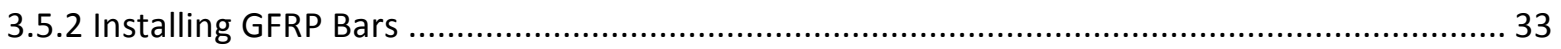

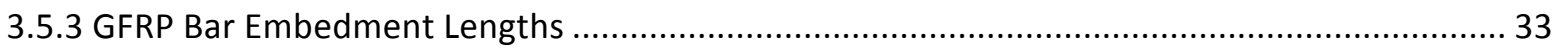

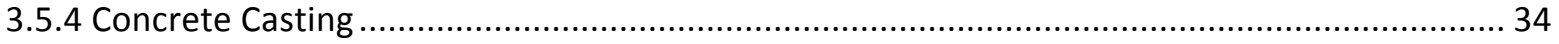

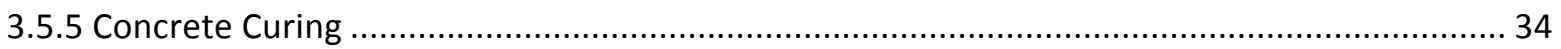

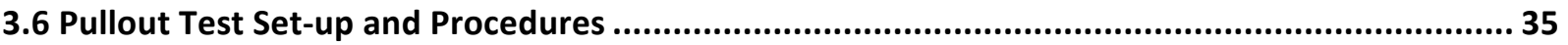

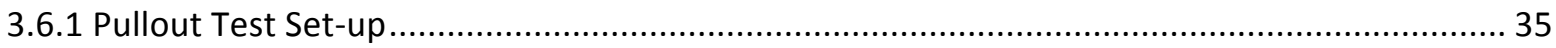

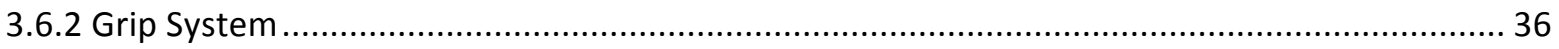

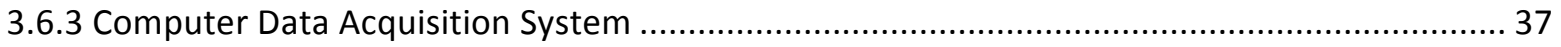

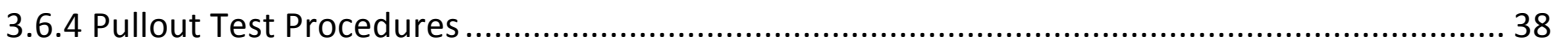

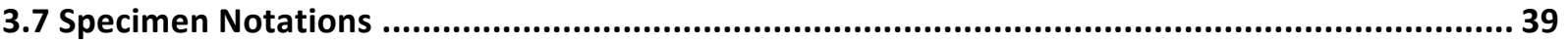

Chapter 4: Experimental Results and Analysis........................................................ 40

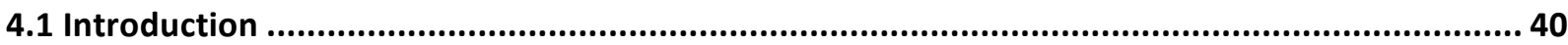

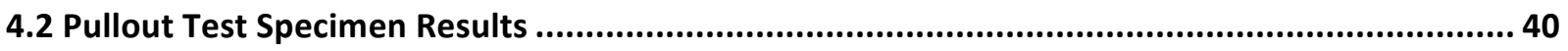

4.2.1 Pullout Test Specimen Results for Straight-End GFRP bars .................................................. 40

4.2.2 Pullout Test Specimen Results for the Headed GFRP bars................................................. 45

\subsection{Experimental Results for Straight-Ended Specimens: Effect of Controlling Parameters on Bond}

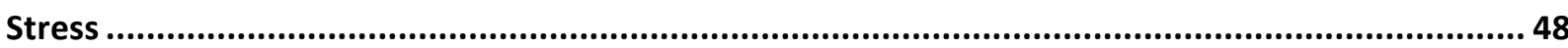

4.3.1 Experimental Results: Effect of GFRP Bar's Surface Treatment on Ultimate Load and Bond

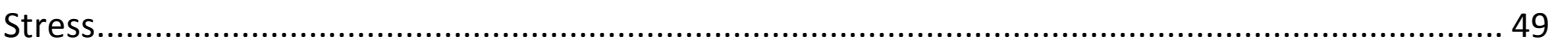

4.3.2 Experimental Results: Effect of Embedment Length on Ultimate Load and Bond Stress ......... 49

4.3.3 Experimental Results: Effect of GFRP Bar Diameter on Ultimate Load and Bond Stress .......... 51

4.3.4 Experimental Results: Effect of Concrete Cover on Ultimate Load...................................... 52

4.3.5 Summary of the Variables' Influence on Ultimate Load and Bond Stress for Straight-Ended

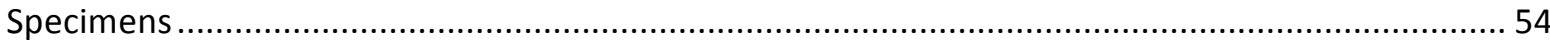

4.4 Experimental Results for Headed Specimens: Effect of Controlling Parameters on Bond Stress. 55

4.4.1 Effect of Embedment Length on Ultimate Load and Bond Stress......................................... 55

4.4.2 Effect of Bar Diameter on Ultimate Load and Bond Stress ..................................................... 56

4.4.3 Effect of Concrete Cover on Ultimate Load and Bond Stress................................................ 56

4.4.4 Summary of the Variables' Influence on Ultimate Load and Bond Stress for Headed bar

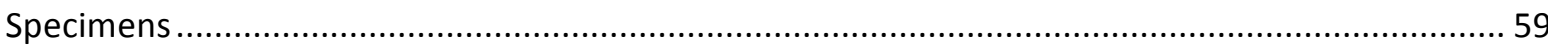

4.5 Bond Behaviour Comparison: Straight-End Versus Headed-End Specimens............................59



Chapter 5: Comparative Analysis of Experimental Development Length and Code

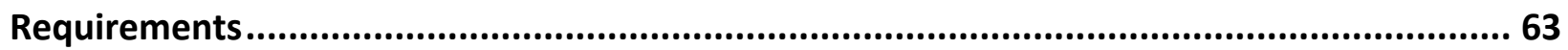

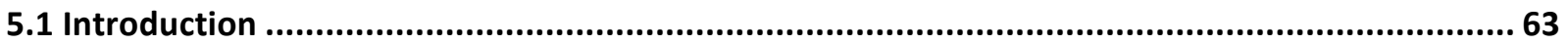

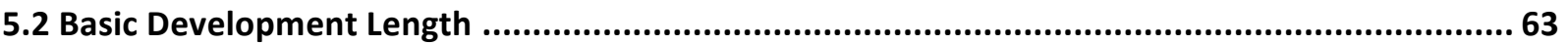

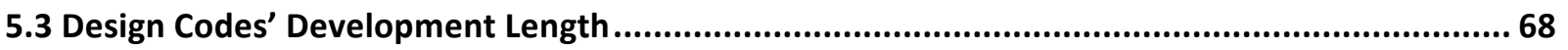

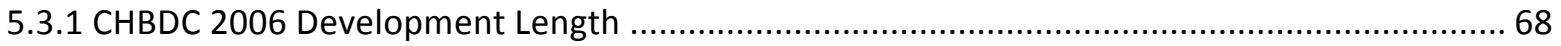

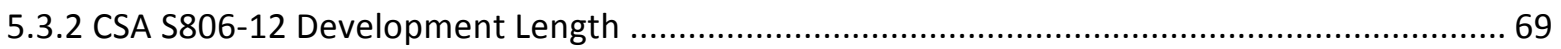

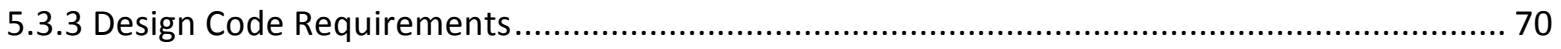

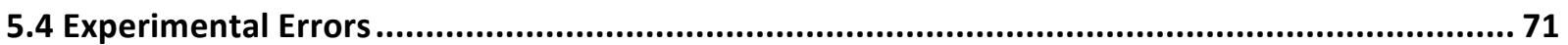




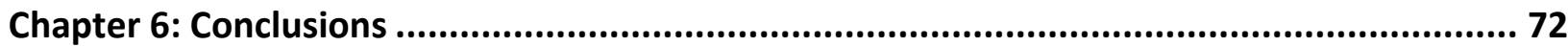

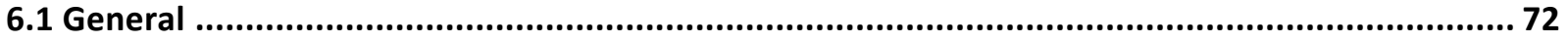

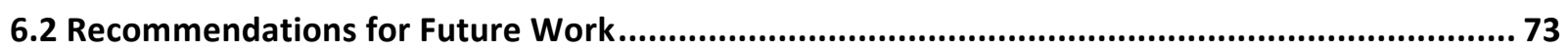

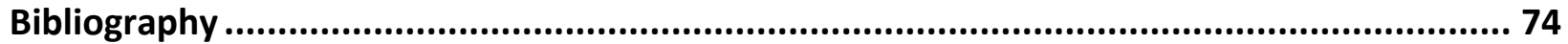

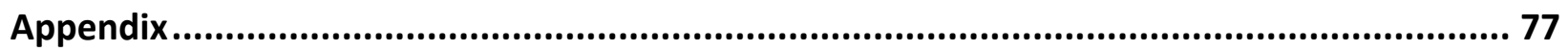




\section{List of Tables}

Table 2.1: General Properties of High-Performance Concrete.....................................................................

Table 3.1: Investigated Parameters Summary: For Straight Bars..............................................................25

Table 3.2: Investigated Parameters Summary: For Headed Bars................................................................25

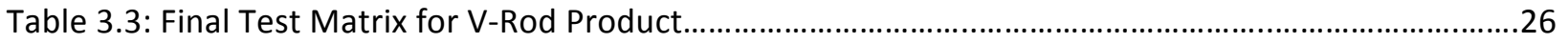

Table 3.4: Final Test Matrix for Schöck ComBAR Product..........................................................................26

Table 3.5a: Nominal Diameter and Section Area of GFRP V-Rod................................................................28

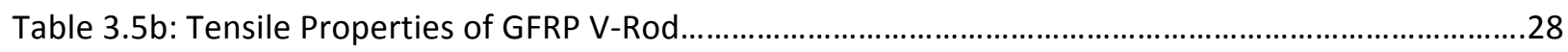

Table 3.6a: Nominal Diameter and Sectional Area of GFRP Schöck ComBAR...........................................29

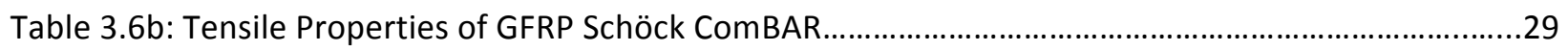

Table 3.7: Dimension \& Characteristic Values Anchorage Forces of GFRP V-Rod with Headed

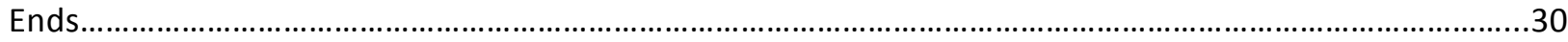

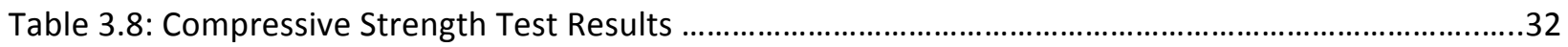

Table 5.1: Bond Factor Parameter, $\mathrm{C}_{2}$, and Experimental Development Length for Straight

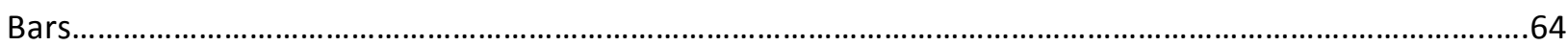

Table 5.2: Bond Factor Parameter, $\mathrm{C}_{2}$, and Experimental Development Length for Headed

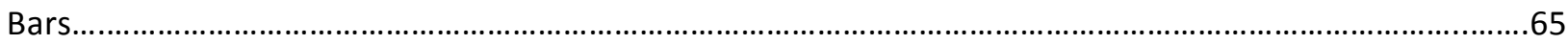

Table 5.3: Experimental Development Length Calculation........................................................................67

Table 5.4: Parameters for CHBDC Development Length Equation for Schöck ComBAR

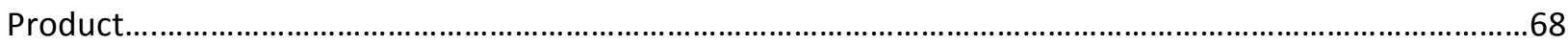

Table 5.5: Parameters for CHBDC Development Length Equation for V-Rod Product................................68

Table 5.6: CHBDC 2006 Development Length Requirement...................................................................69

Table 5.7: Parameters for CSA S806-12 Development Length Equation for Schöck ComBAR

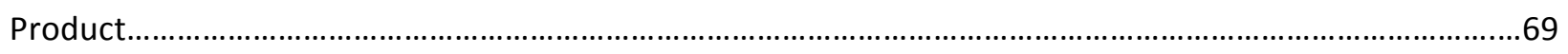

Table 5.8: Parameters for CSA S806-12 Development Length Equation for V-Rod Product........................70

Table 5.9: CSA S806-12 Development Length Requirement....................................................................70

Table 5.10: Comparison of Development Length between CSA S806-12 and CHBDC 2006.......................70 


\section{List of Figures}

Figure 2.1: Two-Component Composite Materials of FRP Materials (Bisby, 2006).....................................4

Figure 2.2: Stress-Strain Relationship of Various FRP Reinforcements (Bisby, 2006).................................6

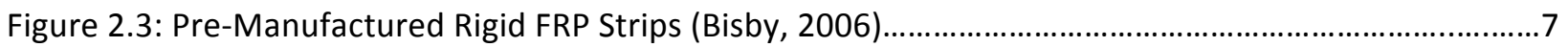

Figure 2.4: Bond Mechanism- Forces on Typical Rebar (ACl 408R-03) ........................................................

Figure 2.5: Side View of Shear Cracking due to Bar Pullout Failure (Ametrano, 2011).............................10

Figure 2.6: Bond-Slip Relationship (M. Baena et al., 2009) .....................................................................11

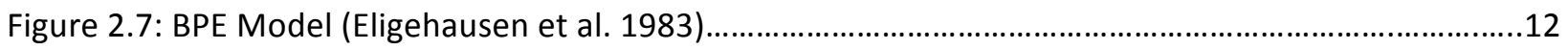

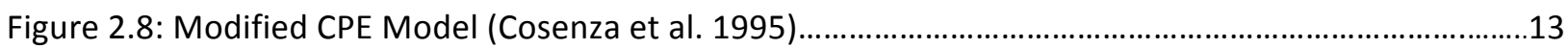

Figure 2.9: Linear Regression Analysis for a) Straight Bars and

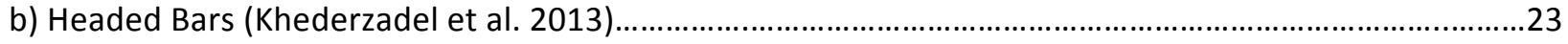

Figure 3.1: Pullout Specimen Configuration with Concentric Concrete Cover...........................................27

Figure 3.2: Pullout Specimen Configuration with Eccentric Concrete Cover...............................................27

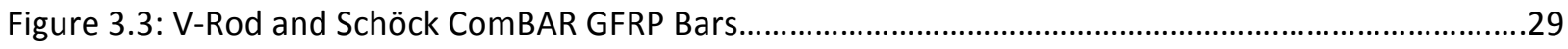

Figure 3.4: Overview of V-ROD GFRP Bar with Anchorage Head (Mohamed, 2012)...................................30

Figure 3.5: Overview of the Anchorage Head and Ribbed Grooves on the End of GFRP Bar (Mohamed,

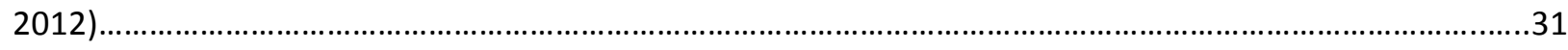

Figure 3.6: AutoCAD Drawing of Bar and Anchorage Head Interface (Mohamed, 2012)...........................31

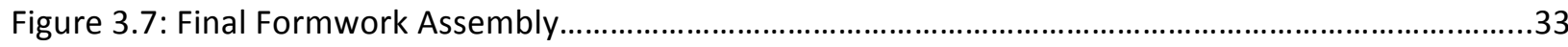

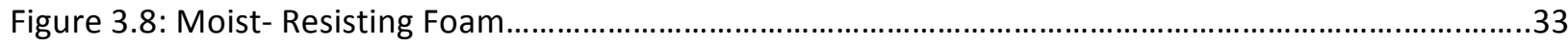

Figure 3.9: Formwork Configuration with Moisture-Resistant Foam Installed for

a) Straight Bars, b) Headed Bars and c) Magnified Foam Design for Achieving Specific Embedment

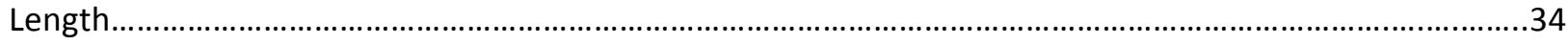

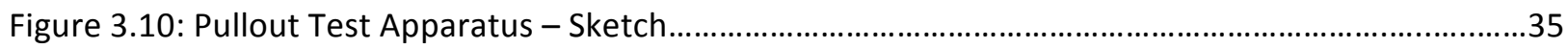

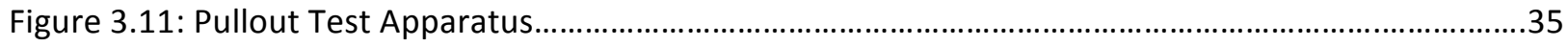

Figure 3.12: Schematic View of Distributed Compression Forces on Specimen........................................36

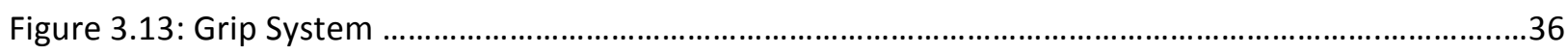

Figure 3.14: SmartStrain Micro-Measurement Computer Data Acquisition System...................................37 
Figure 3.15: LVDT's Position for a) Free-end and b) Loaded-end.

Figure 4.1: Failure Modes for Concrete Blcoks with Concentric GFRP Bar .............................................41

Figure 4.2: Failure Modes for Concrete Blocks with 40 mm Eccentric GFRP Bars.....................................42

Figure 4.3: Failure Modes for Concrete Blocks with 60 mm Eccentric GFRP Bars .....................................43

Figure 4.4: Concrete Splitting Failure for Straight Bars.............................................................................45

Figure 4.5: Failure Modes for Concrete Blocks with Concentric GFRP Bars with Sand-Coated Surface and

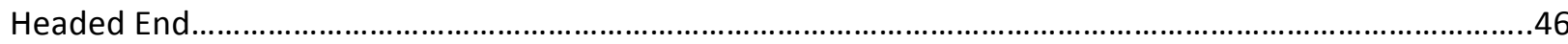

Figure 4.6: Failure Modes for Concrete Blocks with Eccentric GFRP Bars with Sand-Coated Surface and Headed

End..

Figure 4.7: Effect of Surface Treatment on

a) Ultimate Load and b) Bond Stress

Figure 4.8: Effect of Embedment Length on Average Ultimate Load for

a) Shock ComBAR Specimens and b) VROD Specimens

Figure 4.9: Effect of Embedment Length on Bond Stress for

a) Shock ComBAR Specimens and b) VROD Specimen. .50

Figure 4.10: Effect of Bar Diameter ( $\mathrm{mm}$ ) on Average Ultimate Load for

a) VROD Specimens b) Schöck ComBAR Specimens. .51

Figure 4.11: Effect of Bar Diameter ( $\mathrm{mm}$ ) on Average Bond Stress for Straight GFRP bars

Figure 4.12: Effect of Concrete Cover on Average Ultimate Load for a) $16 \mathrm{~mm}$ Schöck ComBAR Specimens and b) 15.9 mmVROD Specimens...

Figure 4.13: Effect of Concrete Cover on Average Ultimate Load for a) $20 \mathrm{~mm}$ Schöck ComBAR Specimens b) $19.050 \mathrm{~mm}$ VROD Specimens

Figure 4.14: Effect of Concrete Cover on Bond Stress for

a) 16 mm Schöck ComBAR Specimens b) 15.9 mm VROD Specimens .53

Figure 4.15: Effect of Concrete Cover on Bond Stress for

a) $20 \mathrm{~mm}$ Schöck ComBAR Specimens b) $19.050 \mathrm{~mm}$ VROD Specimens.

Figure 4.16: Total Embedment Length of Headed Bars .55

Figure 4.17: Effect of Embedment Length on a) Average Ultimate Load and

b) Average Bond Stress for Headed Specimens. .56

Figure 4.18: Effect of Bar Diameter on a) Average Ultimate Load and

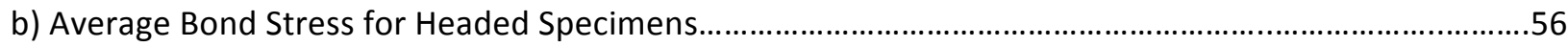

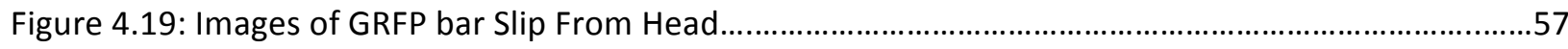

Figure 4.20: Effect of Concrete Cover on Average Ultimate Load for Specimens with a) $d_{b}=15.875 \mathrm{~mm}$ and $\left.b\right) d_{b}=19.050 \mathrm{~mm}$ .58 
Figure 4.21: Effect of Concrete Cover on Average Bond Stress for Specimens with

a) $d_{b}=15.875 \mathrm{~mm}$ and b) $d_{b}=19.050 \mathrm{~mm}$...

Figure 4.22: Bond Stress (MPa) vs. Free-End Slip (mm) for

Concentric, Straight-Ended Specimens for a) Schöck ComBAR and b) VROD.

Figure 4.23: Bond Stress (MPa) vs. Free-End Slip (mm) for

Schöck ComBAR Specimens with Concrete Cover of $60 \mathrm{~mm}$.

61

Figure 4.24: Bond Stress -Slip Graph for Headed V-ROD Specimens with

Concrete Cover of a) $125 \mathrm{~mm}$ Concentric and b) $40 \mathrm{~mm}$.

Figure 4.25: Bond Stress-Slip for Headed V-ROD Specimens with

Concrete Cover of a) $40 \mathrm{~mm}$ and b) $60 \mathrm{~mm}$.

Figure 5.1: Bond Factor Coefficient, C2, for

a) Straight Schöck ComBAR Bars and b) Straight VROD Bars and c) Headed Bars.

.66 


\section{Notation}

\begin{tabular}{|c|c|c|}
\hline$A_{b}$ & $=$ & Cross-sectional area of the bar \\
\hline$C_{1}$ & $=$ & Constant that relates other effects on the bond stress \\
\hline$C_{2}$ & $=$ & Bond factor constant \\
\hline$d_{b}$ & $=$ & Bar diameter \\
\hline$d_{c s}$ & $=$ & $\begin{array}{l}\text { is the smaller of distance from the closest concrete surface to } \\
\text { the centre of the bar being developed, or two-thirds the } \\
\text { centre-to-centre spacing of the bars being developed, but not } \\
\text { greater than } 2.5 d_{b}\end{array}$ \\
\hline$E$ & $=$ & Concrete cover \\
\hline$E_{F R P}$ & $=$ & Mean modulus of elasticity of FRP bars \\
\hline$E_{t}$ & $=$ & Tensile modulus of elasticity \\
\hline$E_{S}$ & $=$ & Modulus of elasticity of steel \\
\hline$f_{c}^{\prime}$ & $=$ & Compressive strength of concrete \\
\hline$f_{F}$ & $=$ & $\begin{array}{l}\text { Design stress in FRP tension reinforcement at ultimate limit } \\
\text { state }\end{array}$ \\
\hline$f_{F R P}$ & $=$ & Stress in tension FRP reinforcement \\
\hline$f_{f k 1000 h}$ & $=$ & 1000 hours tensile strength for Schock ComBAR \\
\hline$F_{f u}$ & $=$ & Guaranteed design tensile strength \\
\hline$F_{S}$ & $=$ & Shear Strength \\
\hline$F_{u}$ & $=$ & Ultimate tensile strength \\
\hline$f_{c r}$ & $=$ & Cracking strength of concrete \\
\hline$K_{t r}$ & $=$ & Transverse index \\
\hline$k_{1}$ & $=$ & Bar location factor \\
\hline$k_{2}$ & $=$ & Concrete density factor \\
\hline$k_{3}$ & $=$ & Bar size factor \\
\hline$k_{4}$ & $=$ & Bar surface factor \\
\hline$k_{5}$ & $=$ & Bar surface profile factor \\
\hline$L_{d}$ & $=$ & Development length \\
\hline$l_{d b}$ & $=$ & Embedment length \\
\hline$T$ & $=$ & Applied tension force \\
\hline$u$ & $=$ & Poisson's Ratio \\
\hline$\tau$ & $=$ & Bond strength of Schock ComBAR \\
\hline$\mu$ & $=$ & Average bond stress \\
\hline
\end{tabular}




\section{Chapter 1.0: Introduction}

\subsection{Introduction}

In Canada, the majority of bridges were built throughout the 1950s and 1960s, and many of these bridges are located in Ontario (Ametrano, 2011). Bridges built within this period of time did not use proper air-entrained concrete and are deteriorating due to repetitive freeze-thaw cycles. The reinforcing steel is also corroding due to repetitive penetration of winter de-icing salts over the years. According to Weber et al. (1998) over $40 \%$ of all bridges in Canada require significant maintenance, rehabilitation, and replacement, which amounts to an estimated value of $\$ 10$ billion. However, current bridge rehabilitation procedures are costly and time-consuming, and Canada is in desperate needs to develop an alternative solution to provide durable, sustainable bridges to avoid the high rehabilitation costs.

Currently, two design codes in Canada permit the use of FRP bars as internal reinforcement in concrete structures and are used to completely replace the role of conventional reinforcing steel. There are several types of existing FRP technology being used today, such as carbon fibre reinforced polymer (CFRP), aramid fibre reinforced polymer (AFRP), and glass fibre reinforced polymer (GFRP). However, GFRP bars are more frequently used due to its inexpensive cost relative to the other products. FRPs have many advantages that can be considered as an excellent alternative to reinforcing steel in bridge decks, including its non-corrodible composition, electromagnetic neutrality, high durability and high strengthto-weight ratio. This advanced reinforcing technology has high potential of improving the durability of bridges; however, FRP bars are fairly new products in North America, and there is still a lot of development and understanding of how it will endure and perform as it replaces conventional reinforcing steel. One critical aspect that still needs more development is the bond performance of FRP in concrete. It is vital to study the bond behaviour of FRP bars embedded in concrete to develop a design standards that can be utilized by engineers.

\subsection{Objective of the Project}

The main objectives of this research project are to:

- Evaluate the controlling variables that affect the bond stress and bond mechanism between HPC and GFRP bars which included:

- surface treatment

$\bigcirc$ embedment length 
$\begin{array}{ll} & \text { bar diameter } \\ & \text { concrete cover } \\ & \text { bar's end condition (straight or headed) }\end{array}$

- Conduct comparative analysis of the bond stress vs. slip relationship between the different types of GFRP bars pre-installed in HPC

- Determine the development length and verify if the calculated values based on prescribed design codes can potentially be used in prefabricated deck panels

\subsection{Layout of the Project}

The layout of the project includes a literature review and experimental investigation on the bond performance and mechanisms that exist for different GFRP bars embedded in HPC. The focus of the study was to investigate the potential usage of different type of GFRP bars, namely sand-coated surface bars (V-Rod) and ribbed-surface bars (Schöck ComBAR), in the joints of precast bridge decks. The study also focused on how the controlling factors, such as bar diameter, surface treatment, concrete cover and embedment length, influenced the variability of the results.

Chapter 2 provides background, literature review and introduces the design equations that are used in the research. The background and literature review covers previous research studies relevant to the bond behaviour and mechanism relevant to GFRP and FRP in varies concrete mix. This chapter also includes information on the different controlling variables that plays a role in the variability of the results.

Chapter 3 presents the experimental program. All materials, software and methodologies used for the experimental procedures are also covered in this chapter.

Chapter 4 presents the experimental results and a full parametric study of the effects of embedment length, bar diameter, concrete cover, surface treatments, and bar's end conditions on the bond characteristics of GFRP bars embedded in high performance concrete. Comparative analysis and discussions of different GFRP products are conducted in terms of performance and bond failure mode. Also, the design equations are used in this chapter to determine the basic experimental development length. 
Chapter 5 presents the conclusions drawn from the results that are used to provide a comparative analysis regarding the bond performance of the two different GFRP bar. Recommendations are also included to better enhance this research and future studies that can potentially branch off from this research. 


\section{Chapter 2: Background, Literature Review and Design Equations}

\subsection{Introduction}

It is a fact that the majority of bridges across Canada are deteriorating due to the nonuse of airentrained concrete and repetitive cycles of freeze-thaw, and corroding steel due to the penetration of winter de-icing salts, and it is costing our country billions of dollars to rehabilitate and replace these bridges. However, with current technology and research, new productions such as FRP reinforcing bars are receiving more acknowledgements in the industry and they are being accepted as an alternative to reinforcing steel in bridge decks.

There have been growing numbers of researchers eager to learn more about the new technology and study the bond behaviour of FRP bars embedded in concrete, which has allowed us to develop a design standard that can be utilized by engineers in the near future. Thus, this chapter presents a few broad overview studies conducted that relate to GFRP and other FRP reinforcing bars used with several types of concrete mixes.

\subsection{General Features of FRPs}

Fibre reinforced polymers (FRPs) are composite materials that consist of fibres in a polymer matrix (Bisby, 2006). The matrix consists of a binding material that is used to bind the fibres together and protect the fibres from any abrasion and environmental degradations. This bond is essential and is the main component that provides FRPs' advantageous mechanical properties when used as reinforcing material. Figure 2.1 demonstrates an elementary composition of FRPs.

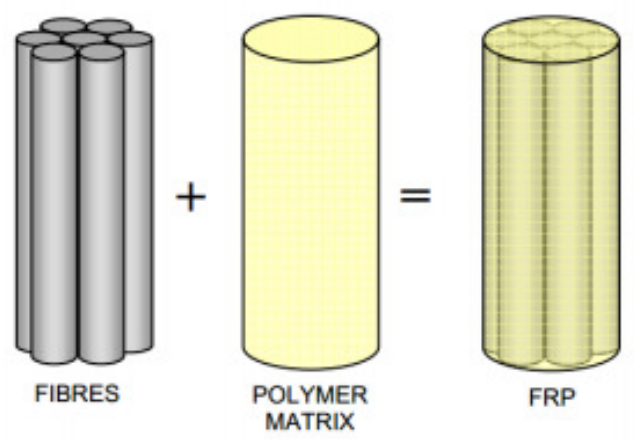

Figure 2.1: Two-Component Composite Materials of FRP Materials (Bisby, 2006) 


\subsubsection{Fibres}

There is a wide selection of fibres used in FRPs; however, when used in current structural engineering practices, the most commonly used fibres are glass (GFRP), carbon (CFRP), and aramid (AFRP). By standard procedures, fibres must be treated with coupling agents to effectively bond with the resin matrix.

Glass fibres are processed from glass composed of silica oxide from silica sand and some may consist of raw materials, such as limestone, fluorspar, boric acid and clay. The glass fibres are manufactured by melting the oxides into fine particles, with particle sizes ranging from 3 to $24 \mu \mathrm{m}$. In the current civil engineering applications, GFRP bars are most commonly used due to their high strength with their relatively lower cost. The most common use of glass fibre in the industry is E-glass.

Carbon fibre is manufactured from a pyrolysis process, which is a procedure that requires processing temperatures above $1500^{\circ} \mathrm{C}$. Carbon fibres are known for their high elastic modulus and fatigue strength relative to glass fibres, thus they are widely used in prestressing tendons and structural FRP wraps for restoration projects.

Aramid is the third type of fibre. It is manufactured from a solution of aromatic polyamide through an extrusion procedure at temperature ranges between $-50^{\circ} \mathrm{C}$ to $-80^{\circ} \mathrm{C}$, then placed in a cylinder of temperature $200^{\circ} \mathrm{C}$. From the manufacturing process, the aramid fibres exhibit anisotropic properties, and results in a relatively lower compressive and shear strengths.

\subsubsection{Resins}

The selection of the matrix that bonds the fibres is crucial, as the physical properties of the matrix significantly affect the final mechanical properties of the FRPs. The main role of the matrix is to help transfer stresses between the fibres. In order to obtain the optimal strength of the fibres, the matrix must have the ability to produce higher ultimate strain than the fibres (Philips, 1989). Additionally, coating of the fibres is highly recommended to protect the fibres from abrasion and friction. The matrix materials are categorized into two groups depending on the manufacturing process, and they are thermoplastic and thermosetting polymer. Thermoplastic polymers are commonly nylon, polyetheretheketine (PEEK), polyesters and epoxies. The thermoplastics matrix polymers are produced by aligning molecules in a linear formation (Ametrano, 2011). As for thermosetting matrix polymers, they are produced from semi-solid precursors (Tuakta, 2004). At the final manufacturing process, the resin hardens and cannot be reformed or reshaped by applying heat or pressure. Thermosetting resins

offer high rigidity, and thermal and dimensional stability at service temperature relative to thermoplastic matrix polymer (Ametrano, 2011), which can be advantageous. 


\subsubsection{Properties of FRPs}

FRP materials are isotropic; therefore, the mechanical and physical properties of FRP vary differently in the longitudinal and transverse direction. Based on Bisby's paper (2006), the transverse properties depend on the resin of the FRP bar, whereas the fibres dominate the longitudinal properties. All FRPs produce a similar linear elastic tensile stress-strain relationship and when used in concrete reinforcing applications, they exhibit this trend up to failure, whereas the conventional steel reinforcement exhibits a plateau relationship. FRP reinforcements have high strength-to-weight ratios and have an elastic linear behaviour in tensile strength that can be achieved with one fifth of the weight of steel (Tuakta, 2005). The stress-strain relationship between different FRP bars and conventional steel bars is shown in Figure 2.2. Yielding in the FRP does not exist, indicating that failure is brittle, when the tensile strength of the material is exceeded. The properties of each FRP vary depending on the type and proportions of fibre, the matrix used, and the manufacturing process. The different branches of stressstrain curves in the graph for each different FRP bars demonstrate this.

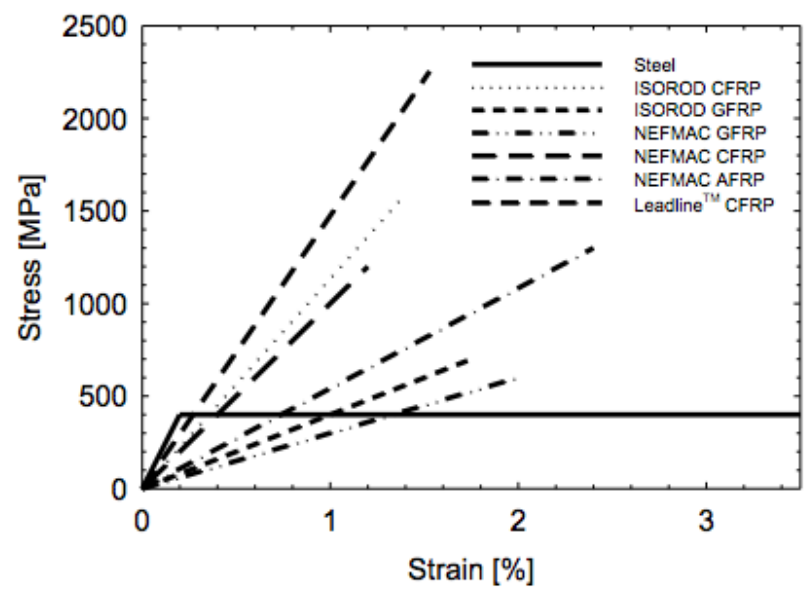

Figure 2.2: Stress-Strain Relationship of Various FRP Reinforcements (Bisby, 2006) 


\subsection{Applications of FRPs in Structural Engineering}

FRPs are used in current civil engineering practices in different forms. FRP reinforcing bars entered into the North American construction industry in the late 1970's and, since then, have been used in many rehabilitation projects, such as restoring pedestrian and highway bridges, deck panels, and even concrete highway barriers. FRPs can also be used as internal reinforcing bars and prestressing tendons. In Canada, one of the first concrete bridge deck slabs that solely used FRP reinforcing bars was constructed in 1995 over the Salmon River in Nova Scotia. Since then, there have been numerous amounts of bridges that have incorporated the use of FRP bars. In addition, FRP reinforcing bars have various surface treatments, which aid the bond between the bars and the surrounding concrete. Such surface treatments include sand-coating, wound surface and ribbed-surface. Another application of FRPs is FRP shear strengthening strips. FRPs have prominent shear and flexural strengthening abilities and are mainly used in rehabilitation projects. Materials used for these projects are pre-manufactured rigid FRP strips, which bond to the surface of elements that exhibit inadequate shear strength (Bisby, 2006). An example of such application is shown in Figure 2.3. This photograph illustrates a bridge in Maryland in Winnipeg, which was constructed in 1969. This bridge was investigated in accordance with current codes and it was discovered that the L-shaped concrete girder lacked the shear strength to withstand the current truckloads. As a solution, four girders were strengthened using FRP sheets and to this day, strain gauges are attached to the girders for ongoing basis monitoring.

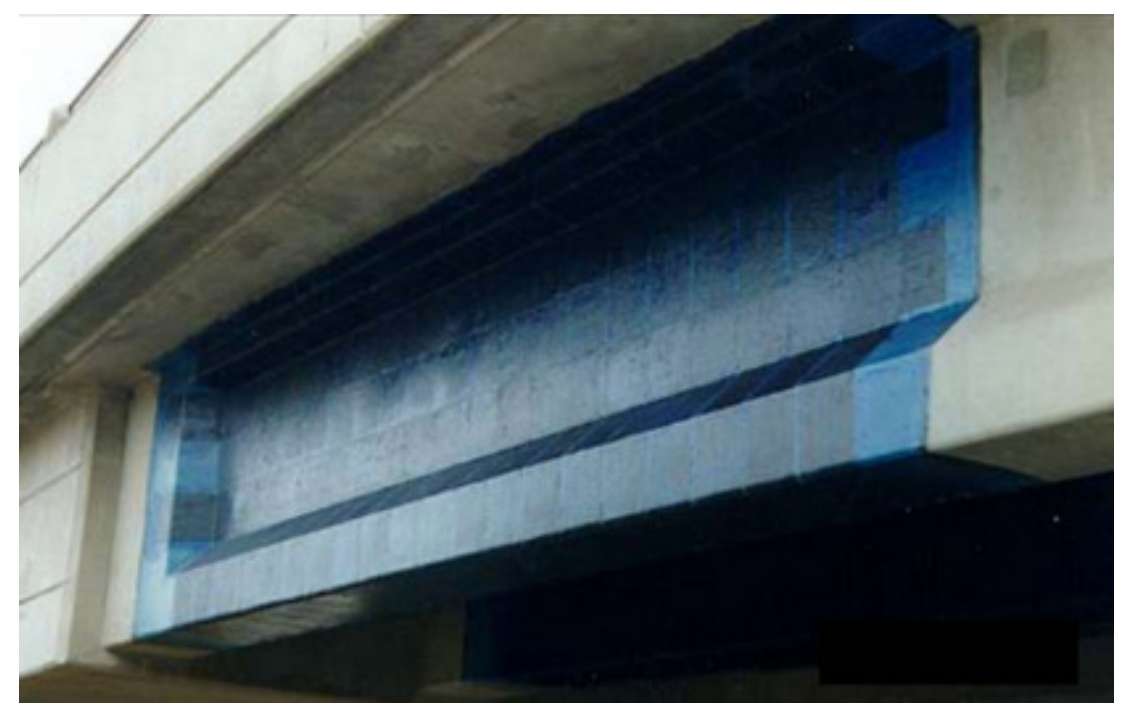

Figure 2.3: Pre-Manufactured Rigid FRP Strips (Bisby, 2006) 
Over the past few years, FRP applications have gradually been implemented in many structural engineering projects and are now fully recognized by design codes and provisions, such as CHBDC 2006, and CSA S806-12. Full chapter of standards, minimum requirements, and guides on the use of FRPs materials have fully been developed in the standards.

\subsection{High-Performance Concrete (HPC)}

High-performance concrete (HPC) exceeds the properties of normal concrete. In current construction practices, HPC is used in tunnels, bridges, and tall buildings due to its strength, durability, and high modulus of elasticity. HPC has an average compressive strength between $70 \mathrm{MPa}$ and 140 $\mathrm{MPa}$, and is made with selected high quality ingredients. HPC provides many advantageous characteristics relative to normal concrete including:

- High early strength

- High modulus of elasticity

- High durability

- Resistance to chemical attack

- Volume stability

- High resistance to frost and deicer scaling damage

Tables 2.1 highlight the general properties of HPC, respectively.

\begin{tabular}{|l|l|}
\hline \multicolumn{2}{|l|}{ Table 2.1: General Properties of High-Performance Concrete } \\
\hline High strength & $70-140 \mathrm{MPa}$ \\
\hline High-early compressive strength & $20-28$ days \\
\hline High-early flexural strength & $2-4 \mathrm{MPa}$ \\
\hline Abrasion resistance & $0-1 \mathrm{~mm}$ depth of wear \\
\hline Low permeability & $500-200$ coulombs \\
\hline Chloride penetration & Less than $0.07 \%$ at 6 months \\
\hline Sulfate attack & $0.10 \%$ max. (from sulfate testing) \\
\hline High modulus of elasticity & More than $40 \mathrm{GPa}$ \\
\hline High resistance to freezing and thawing damage & Durability factor of 95 to 100 at 300 to 1000 cycles \\
\hline Low shrinkage & Less than 400 millionths \\
\hline Low creep & Less than normal concrete \\
\hline
\end{tabular}

(Source: PCI Manual, Chapter 17, 2003) 


\subsection{Bond Mechanism}

\subsubsection{Straight-Ended Bars}

The bond mechanism of FRP bars performs differently than conventional steel reinforcement due to the different manufacturing procedures and difference in material properties in both longitudinal and transverse directions (Cosenza et al., 1997). In Cosenza et al.'s research (1997), experimental results suggested that the bond between FRP reinforcement and concrete is controlled by several factors including chemical bond, friction due to surface roughness of FRP bars, mechanical interlock, and expansion of the FRP bar due to temperature change and moisture absorption. The bond action between FRP and surrounding concrete reaches maximum tensile strength, adequate flexural capacity, and shear resistance only when there is tight bond between the concrete and the FRP bar. In Figure 2.4, the three bond mechanisms are shown on a typical bar. The forces applied to the bar are counteracted by the compressive and shear stresses in the surrounding concrete, and these forces result in tensile stresses which are released in the form of cracks in the concrete. Thus, it can be seen that the bond mechanism of FRP bars differ from the conventional steel reinforcing bars. To fully characterize the mechanism of load and stress transfer along the surface of the FRP bar and the surrounding concrete, the anisotropic nature of FRP needs to be understood. FRP's mechanical and physical properties differ in the longitudinal and transverse direction. Based on Bisby's paper (2006), the transverse properties depend on the resin of the FRP bar, whereas the fibres dominate the longitudinal properties. It is also found that the strength of the resin is lower than the compressive strength of the concrete. Thus, this results in a different bond interaction from that of conventional steel reinforcements and, also, demonstrates that the bond strength greatly depends on the failure stresses and strains in FRP's longitudinal and transverse directions (Cosenza et al. 1997). Although the bond behaviour and mechanism of FRP bars depend on various factors, the factors discussed above demonstrate that by understanding FRP's properties, it will aid researchers to understand more on its effect on bond behaviour and strength.

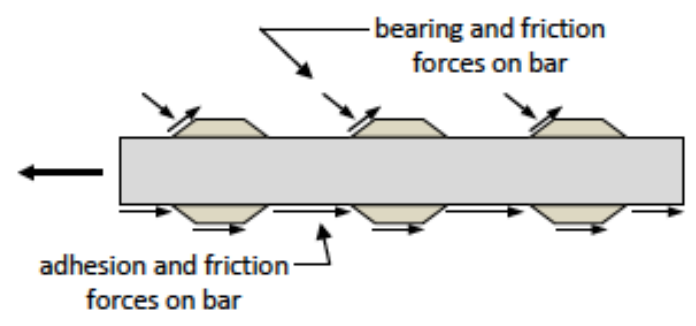

Figure 2.4: Bond Mechanism - Forces on Typical Rebar (ACl 408R-03) 


\subsubsection{Bond Failure Modes}

Typically, there are three types of failures that occur when pullout tests are conducted. These failure types are dependent on bond properties between the concrete and the FRP bars. The failure types are as follows:

- Bar rupture

- Bar pullout

- $\quad$ Concrete splitting

Bar rupture occurs when the full tensile strength of the bar is reached or exceeded during the bond test. This type of failure is classified as a premature failure of the bar and is not recommended as it provides limited information on the required bar development length and insignificant input in the analysis of the bond behavior of the system.

A bar pullout failure occurs when the bond between the FRP bar and the concrete cannot resist the load applied on the test bar with adequate confinement and the concrete cover is sufficient to prevent a splitting failure. This failure is usually associated with shearing of the surrounding concrete around the bar when the bar slips out (Ametrano, 2011), which is schematically shown in Figure 2.5.

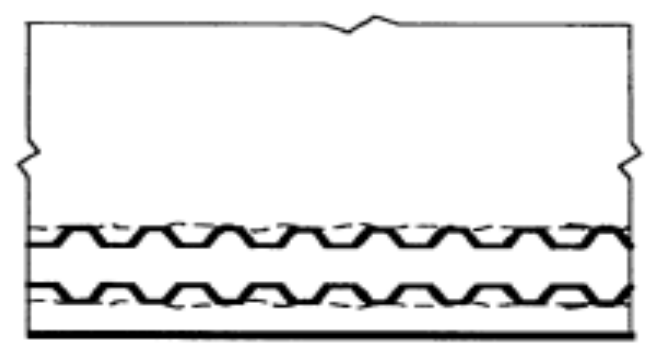

Figure 2.5: Side View of Shear Cracking due to Bar Pullout Failure (Ametrano, 2011)

Concrete splitting is the type of failure that represents a well-confined bond between the FRP bar and the concrete and is able to withstand the splitting stresses. As the bar is under tension, cracks are typically formed around the bar, which propagate to the surface and, when there is sufficient cracking, the embedded bar will be exposed. Splitting failure is characterized by the concrete splitting along the bar length. 


\subsection{Bond Stress versus Slip}

The bond characteristics between reinforcement and concrete can be graphically described by means of a bond stress-slip relationship and can also be used to calculate the development and splice lengths (Cosenza et al. 1996). An example of a bond-slip graph is illustrated in Figure 2.6 for sand-coated CFRP specimens. The two graphs demonstrate the bond stress plotted against the loaded-end slip and the unloaded-end slip. Typically, the bond stress-slip graphs compose of an initial steep curve, indicating the increasing of bond strength with a small slip up to the ultimate bond stress. This point on the graph demonstrates that the frictional force and chemical adhesion between the concrete and reinforcing bar are fully contributing in attaining this bond of the entire system (Baena et al. 2009).
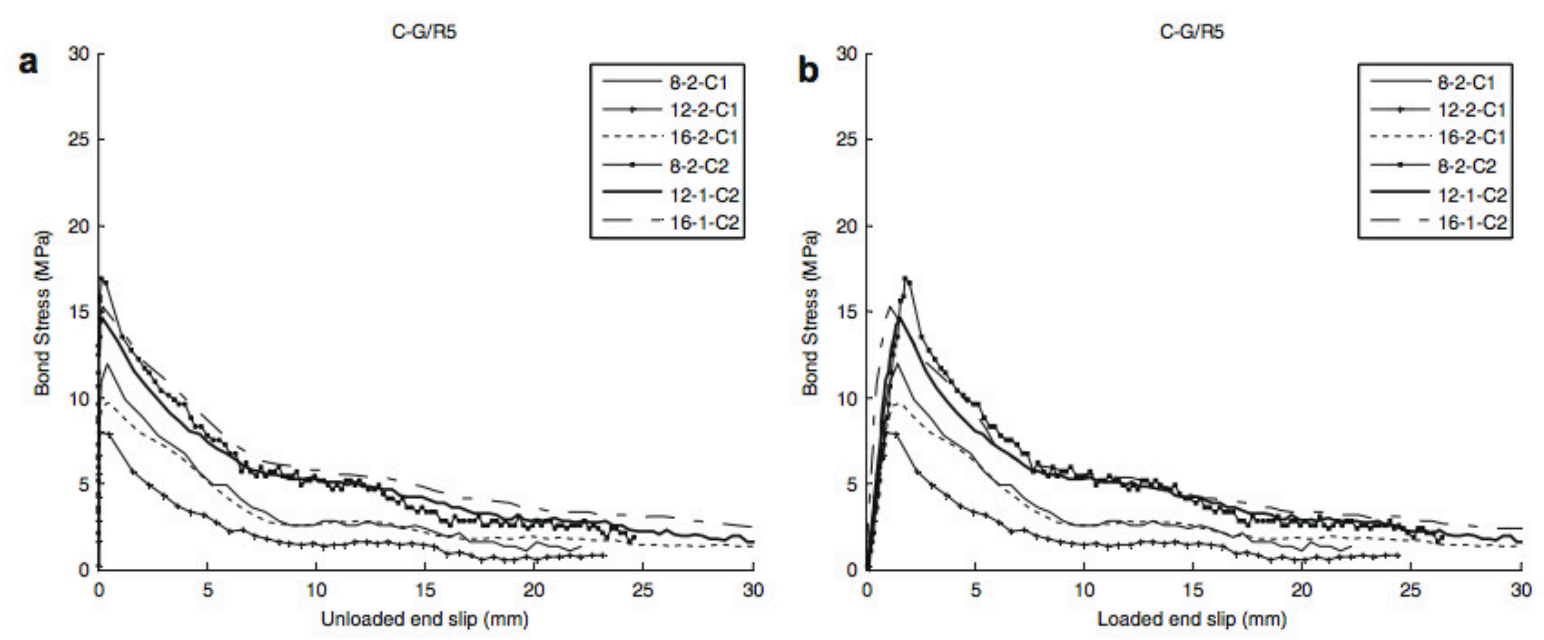

Figure 2.6: Bond-Slip Relationship (M. Baena et al., 2009)

Despite the numerous existing formulations for steel reinforcing bars, extensive research efforts are still required to establish a consistent analytical model of the bond stress-slip behaviour for FRP bars. In the following subsections, an overview of a number of available models for FRP bars is presented.

\subsubsection{Malvar Model}

The Malvar Model, developed by Malvar (1994), was one of the first models created to explain the bond characteristics of FRP bars with concrete. The experimental research was carried out with GFRP bars composed of different outer surface shapes and a fixed tensile strength of the concrete. Based on the experimental results, Malvar (1994) proposed a refined model for the overall bond behaviour and it is represented by the following relationship: 
$\tau=\tau_{m} \frac{F\left(\frac{\delta}{\delta_{m}}\right)+(G-1)\left(\frac{\delta}{\delta_{m}}\right)^{2}}{1+(F-2)\left(\frac{\delta}{\delta_{m}}\right)+G\left(\frac{\delta}{\delta_{m}}\right)^{2}}$

where:

$\tau_{m}$ is the peak bond stress

$\sigma$ is the confining axisymmetric radial pressure

$\delta_{m}$ is the slip at peak bond stress

$\mathrm{F}, \mathrm{G}$ is empirical constants for each bar type

\subsubsection{Eligehausen, Popov, and Bertero Model (BPE Model)}

The BPE model is a well-known bond stress-slip law developed in 1983 by Eligehausen et al. by failing deformed steel bars through pullout experimentation. The BPE model, shown in Figure 2.7, shows 4 different curves. The initial curve on the bond stress-slip relationship ascends to the point $\left(s_{1}, \tau_{1}\right)$, indicating the maximum bond stress, $\tau$, is achieved at a slip of $s_{1}$, for $s<s_{1}$. The second curve is a plateau, demonstrating that the maximum bond stress is attained while the slip is increasing up to $s_{2}$ until failure. A gradual descending line follows this from points $\left(s_{2}, \tau_{1}\right)$ to $\left(s_{3}, \tau_{3}\right)$ and a horizontal trend line is developed with a value of $\tau=\tau_{3}$ and with the slip $s>s_{3}$.

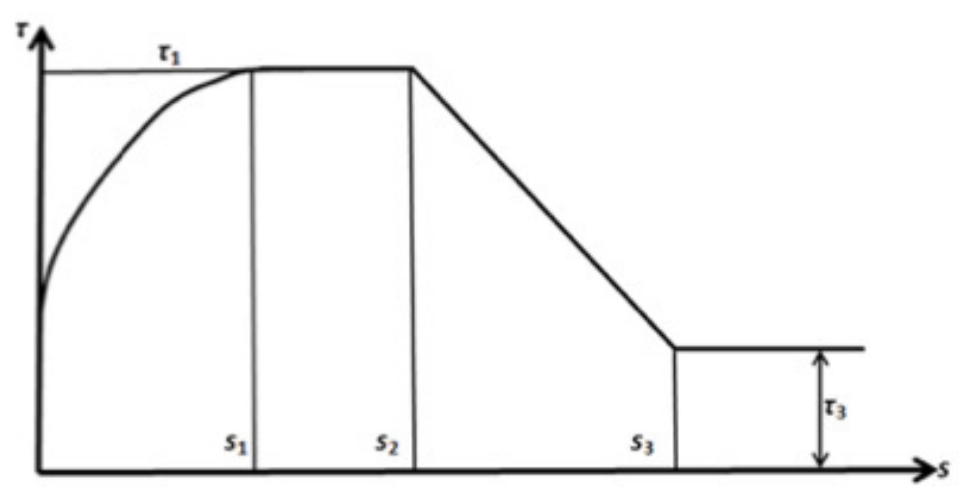

Figure 2.7: BPE Model (Eligehausen et al., 1983) 
The initial ascending curve was then modeled in the following expression:

$\frac{\tau}{\tau_{1}}=\left(\frac{s}{s_{1}}\right)^{\alpha}$

where:

$\tau_{1}$ is the maximum bond stress

$S_{1}$ is the slip corresponding to the maximum bond stress

$\alpha$, is a curve-fitting parameter and must not be greater than 1

(Ametrano, 2011)

Researchers, including Cosenza et al. (1996), have successfully applied this model to FRP bars with minor modifications to the BPE model to represent the FRP bond stress-slip relationship. From the experimental results by Cosenza et al. (1996), the second trend line, as illustrated in Figure 2.7, was nonexistent for FRP bars, thus the team proposed the modified BPE model with a different expression for the same initial ascending trend line, which is given by:

$\frac{\tau}{\tau_{1}}=1-p\left(\frac{s}{s_{1}}-1\right)$

where:

$p \cdot \frac{\tau_{1}}{s_{1}}$, is the slope from points $\left(s_{1}, \tau_{1}\right)$ to $\left(s_{3}, \tau_{3}\right)$.

Which resulted in the following model shown in Figure 2.8.

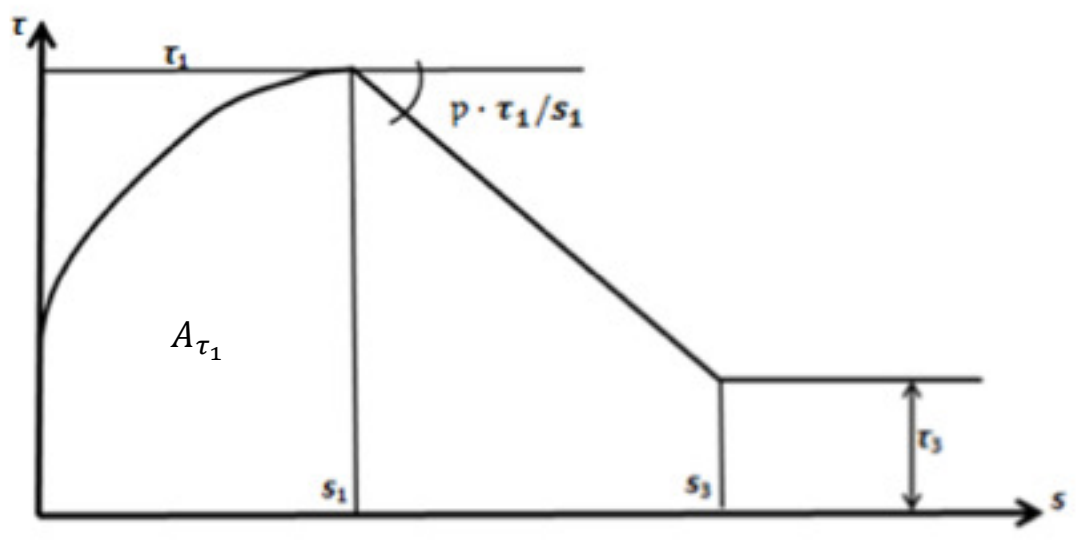

Figure 2.8: Modified BPE Model (Cosenza et al., 1995) 


\subsubsection{CMR Model}

A refined model of the bond stress-slip model was developed by Cosenza et al (1997) to remodel the ascending branch of the BPE model to captivate the bond stress-slip behaviour for FRP bars. This model represents an alternative to the BPE model and the modified expression is given as:

$\frac{\tau}{\tau_{m}}=\left(1-e^{-\frac{s}{s_{r}}}\right)^{\beta}$

where:

$\tau_{m}$ is the peak bond stress

$s_{r}$ and $\beta$ are parameters used for curve-fitting purposes for the actual data

\subsection{Controlling Variables Affecting Bond Behaviour of FRP bar Embedded in Concrete}

There are several factors that affect the bond between FRP bars and concrete. The factors include fibre type, surface treatment, bar diameter, embedment length, concrete cover and the concrete properties. These factors each play a significant role in the bond behaviour and it is essential to understand how each parameter affect the bond mechanism and bond strength.

\subsubsection{Effect of Fibre Type on Bond Action}

Two design codes that are used in this research project are the CHBDC 2006 and CSA S806-12 and they are used to determine the minimum required development length for the FRP bars. Only the CSA S806-12 design code takes into account the bar fibre, which influences the development length and the bond strength. The bar fibre factor of 1.0 corresponds to CFRP and GFRP bars and a factor of 1.25 is assigned to AFRP bars. Thus, CSA S806-12 recognizes that AFRP bars produce lower bond strength relative to CFRP and GFRP bars. The research conducted by Achillides et al. (2004) validates CSA S80612 's notion. The research consisted of beam tests to evaluate the bond strength between GFRP, CFRP, and traditional steel reinforcing bars. It was concluded that specimens with GFRP and CFRP bars produced a bond strength of $72 \%$ of the bond strength of the traditional steel reinforcing bars, which validated that glass and carbon fibres have a similar effect on the bond strength.

\subsubsection{Effect of Surface Treatment and Configuration on Bond Action}

GFRP bars can be manufactured with various surface configurations and surface treatments to improve the bond action with the surrounding concrete to optimize load transfer. The different surface configurations and treatments include ribbed, spiraled wrapped, helical, and sand-coated surfaces. These are used to improve the bond between the reinforcing bar and the surrounding concrete. 
Similarly, in conventional steel reinforcing bar practices, the deformation on the bar results in a higher bond relative to a plain, smooth bar, as it provides mechanical interlocking between the surface of the rebar and concrete (Alunno Rossetti et al., 1995). In the research conducted by Al-Zahrani (1995), the experimental program was set up to investigate the behaviour of smooth glass-vinyl ester bars with the removal of the resin-rich layer. The experimental results demonstrated an increase of bond strength due to the bar's surface condition. It shows that the surface condition affects the adhesion and friction bond mechanisms. In CSA S806-12, Clause 9.9.3 (e), the bar surface profile factor is provided for different types of surface treatments, such as 1.0 for sand-coated surfaces, 1.05 for spiral pattern, 1.0 for braided pattern, 1.05 for ribbed surfaces and 1.80 for indented surfaces. Thus, it can be seen that CSA S806-12, listed both sand-coated surface and braided pattern FRP bars to produce relatively higher bond strength. The study conducted by Morales Arias et al. (2012) supports this statement. Morales et al. (2012) studied the influence of sand granulometry on the bond strength between sand-coated GFRP bars and concrete. Two different bar sizes of $9 \mathrm{~mm}$ and $16 \mathrm{~mm}$ were used, and for each size, the bar was coated with fine and coarse sand with the mean grain size of $1.2 \mathrm{~mm}$ and $300 \mu \mathrm{m}$ respectively. In addition, two different types of concrete were used, including conventional concrete and high resistance concrete (HRC) with a mean 7 day strength of $23.5 \mathrm{MPa}$ and $56 \mathrm{MPa}$, respectively. The pullout specimens were prepared in cylinder molds with a diameter of $100 \mathrm{~mm}$ and a height of $200 \mathrm{~mm}$. Embedment lengths of $5 d_{b}$ and $10 d_{b}$ were also used for investigation. The experimental results concluded that GFRP bars coated with the coarser sand resulted in higher bond strength due to increased friction and interlocking forces.

As for the GFRP bars with a finer sand coat, this group of specimens resulted in a lower bond strength due to the stripping of the sand particles, although the research conducted by Morales et al. (2012) suggests that sand-coated surface profile provides higher bond strength. Makitanit et al. (1993) also noted that the sand-covered FRP bars demonstrate good bond performance due to the increased chemical bond provided by the sand particles initially, but abrupt detachment of the sand particles led to a brittle bond failure. However, Hao et al. (2009) suggests differently. This research group studied the effect of bond action between GFRP bars and concrete with various ribbed patterned GFRP bars. The test included 24 different rib geometries of GFRP bars. The rib configurations included rib spacing, which is measured from center-to-center of the bar's ribs, rib angle, which is angle measured between the longitudinal axis to the inclined rib, and the rib height, which is the difference between the bar radius at the rib and radius at midpoint between the rib to the next one. The research showed that ribbed GFRP bars with rib spacing equal to the bar diameter exceeds the bond strength of the sand-coated bar and 
exhibits a better bond-slip relationship with the least end slip at failure. It can be seen that research conducted by both Morales et al. (2012) and Hao et al. (2009) led to different conclusions and essentially opposes each other. Therefore, the effect of FRP surface treatment still requires more investigation and is open to debate.

\subsubsection{Effects of GFRP bar diameter on Bond Action}

The relationship between bar diameter and bond strength of FRP bars embedded in concrete has been widely investigated by Larradle and Silva Rodriguez (1993), Benmokrane et al. (1996), Baena et al. (2008), Tighiouart et al. (1998 and 1999), Hao et al. (2009) and Morales et al. (2012). All researchers attained similar results and concluded that the bond strength increases as the diameter of the bar decreases. Benmokrane et al. (1996) conducted the experiment with GFRP bars with bar diameters of 12.7, 15.9, 19.1 and $25.4 \mathrm{~mm}$ and the resulting bond strengths were 10.6, 7.3, 6.6 and $6.4 \mathrm{MPa}$, respectively. Baena et al. (2008) studied both CFRP and GFRP with various diameter sizes with the largest being $19.55 \mathrm{~mm}$ for GFRP and $13.43 \mathrm{~mm}$ for CFRP. As a result, the larger diameter FRP bars resulted in lower bond strengths, which validates the preceding findings. This phenomenon can be explained by the peak bond stress gradually migrating from the loaded end towards the unloaded end, which results in the lower than average bond strength. Baena et al. (2008) also suggested that the Poisson effect may also be another reason that the pullout forces increase as the bar diameter gradually decreases. This demonstrates that the Poisson effect can potentially have greater influence on the bond properties for specimens with bars of larger diameter. Ultimately, this reduces the frictional forces and mechanical locking stresses. Additionally, Tigouart et al. (1998) concluded that this phenomenon is due to the bleed water trapped around the bar creating an interfacial transition zone that limits the contact surface between the bar and the surrounding concrete, and also reduces the frictional forces and mechanical interlocking. This was also the conclusion drawn from the research conducted by Sayed Ahmed et al. (2009).

\subsubsection{Effects of Embedment Length on Bond Action}

Embedment length is defined as the length that will bond with the surrounding concrete to transfer the loads and stresses. According to research conducted by, Benmokrane et al. (1996), Tigiouart et al. (1998 \& 1999) and Firas et al. (2009), the increase of embedment length results in a decrease in bond strength. This relationship can be explained by the non-linear distribution of bond stress along the FRP bar embedded in the concrete. In recent studies conducted by Firas et al. (2009), the experimental results demonstrated that the embedment length is a function of bar diameter and is directly 
proportional to it. Thus, with an increase of the GFRP bar diameter, a larger embedment length is needed to reach the same normal bond stress in order to avoid non-linear distribution of bond stresses along the FRP bar from bei ng so pronounced (Firas et al., 2009). Morales et al. (2012) presented similar results with sand-coated GFRP bars where the bond strength for shorter length is double that of the longer length. Sayed Ahmad et al. (2009) explained that friction reduction occurs from the elongation of the bar from the pullout force and concluded that shorter embedment lengths developed higher bond strength, which provides more frictional forces. Results obtained by Ametrano (2011) confirm the preceding findings. Ametrano (2011) conducted both beam and pullout tests with sand-coated GFRP bars embedded in high strength and ultra-high performance concrete, which both demonstrated a decrease in bond strength as the embedment length increased.

\subsubsection{Effect of Concrete Cover on Bond Action}

Research conducted by Ehsani et al. (1997) included a total of 102 specimens with three different diameter GFRP bars. It was observed that the mode of failure was greatly dependent on the concrete cover. Specimens with a concrete cover of one bar diameter, $1 d_{b}$, resulted in splitting failure, whereas specimens with a concrete cover of two bar diameter, $2 d_{b}$, resulted in either a pullout failure or bar rupture. Wambeke and Shield (2006) also presented similar results where splitting failures were accompanied by a clear cover between one and three bar diameter and half of the group of specimens resulted in pullout failures with a concrete cover of more than three bar diameter, $3 d_{b}$. From Ryerson University, Ametrano (2011) discovered that the effect of the concrete cover on bond behaviour was more pronounced with specimens casted with high strength concrete. From these specimens, Ametrano (2011) discovered that with a $19.1 \mathrm{~mm}$ bar diameter and a concrete cover of $60 \mathrm{~mm}$, stronger bond strength was achieved, relative to the group of specimens with a concrete cover of $40 \mathrm{~mm}$. As for specimens casted with a $15.9 \mathrm{~mm}$ bar diameter, an average increase of $9 \%$ in bond strength from $40 \mathrm{~mm}$ to $60 \mathrm{~mm}$ concrete cover was found. Therefore, the preceding findings suggest that the effect of concrete cover significantly affects the mode of bond failure and bond strength. Additionally, in CSA S806-12, a factor is incorporated to account for the effect of concrete cover in the development length and bond strength design equations.

\subsubsection{Effect of Concrete Properties on Bond Action}

Concrete compressive strength is another parameter that affects the bond action between FRP bar and the concrete. In design codes, such as CSA S806-12 and $\mathrm{ACl}$, the effect of concrete strength is taken into consideration using the square root of the compressive strength $\left(\sqrt{f^{\prime} c}\right)$. Stated earlier, the 
bond mechanism consists of adhesion, bearing, and friction when there is applied load on the bar. The forces subjected to the bar are counteracted by both compressive and shear stresses around the concrete, which can prompt bond failure due to either tensile splitting or shearing off concrete ( $\mathrm{ACl})$. To resist tensile splitting failure, the compressive strength of the concrete needs to be increased because of the proportional relationship between concrete's compressive strength and its tensile strength (ACI). In Ehasani et al.'s research (1997), the team casted specimens with concrete compressive strengths ranging from $28 \mathrm{MPa}$ and $56 \mathrm{MPa}$, the specimens were tested in pairs with all other factors remaining constant except for the concrete strengths. The ultimate bond stress for the specimens were $4.83 \mathrm{MPa}$ (700 psi) versus $5.46 \mathrm{MPa}$ (792 psi); and $3.91 \mathrm{MPa}(567 \mathrm{psi}$ ) and $4.08 \mathrm{MPa}$ (592 psi). The two pairs demonstrated a slight increase of bond stress with increasing concrete compressive strength. However, the increase was not proportional to the expected square root of concrete compressive strength, which is still implied in North American design codes. Ehasnai et al. (1997) also discovered that both splitting failure and pullout failure were dependent on the concrete strength, whereas bar fracture is controlled by tensile capacity of the GFRP bar only. In Ametrano's study (2011) specimens with sand-coated GFRP bars were casted with 4 different concrete strengths, ranging from $70 \mathrm{MPa}$ to $175 \mathrm{Mpa}$. The results also demonstrated a slight increase in bond strength with increasing concrete strength. The research conducted by Achillides et al. (2004) included concrete compressive strength of 15Mpa and $30 \mathrm{MPa}$. The findings demonstrated for the case of concrete strength greater than $30 \mathrm{MPa}$, bond failure occurred partly on the surface of the GFRP bar and in the concrete. Baena et al. (2009) explained that when this happens, it indicates that the bond strength of the FRP bar does not depend on the concrete strength, but rather on the GFRP bar's properties. As for specimens with a compressive strength of $15 \mathrm{MPa}$, crushing of the concrete away from the surface of the bar was noted, indicating the bond strength is dependent on the concrete strength (Achillides et al. 2004). The preceding finding was validated by Baena et al. (2009) with two different concrete strengths, $28.63 \mathrm{MPa}$ and $52.19 \mathrm{MPa}$, labelled as $C_{1}$ and $C_{2}$, respectively. The experimental results demonstrated that concrete with compressive strength greater than $30 \mathrm{MPa}$ caused bond failure to occur at the vicinity of the FRP bar, indicating that the bond strength depends on the bar's properties, rather than the concrete strength. However, for lower compressive strength concrete, around $15 \mathrm{MPa}$, the bond failure mode changes and failure was seen to take place at the concrete matrix interface. When $C_{1}$ concrete specimens were tested, all the specimens failed in a pullout mode with failure taking place in the concrete surface. Increasing the concrete strength above $C_{1}$ did not change the mode of failure; nevertheless, there was more damage on the GFRP bar surface (Baena et al. 2009). 


\subsection{Determination of Bond Strength}

$\mathrm{ACl}$ defines bond stress as the resultant stress at the surface of the FRP bar from the force component in the direction of the bar. Over the past two decades, the bond strength of FRP bar embedded in concrete has been extensively investigated by researchers, as mentioned in previous sections, through different types of tests, such as pullout tests, beam tests, splice tests, and cantilever beam tests to determine a conventional empirical formula that allow designers and other professionals to define bond strength. In earlier studies, bond strength was simply evaluated with the ultimate tensile load until failure from these tests. Ehasnai et al. (1997) defined bond stress as the shear force per unit surface area of the rebar, and has the following form:

$\mu=\frac{T}{\pi d_{b} l_{d b}}$

where $\mu$ is the bond stress, $T$ is the applied tension force, $d_{b}$ is the bar diameter and $l_{d b}$ is the embedment length. Equation 2.5 was developed with an assumption of a uniform distribution of stress and that the force on the bar is resisted by an average bond stress, $u$, which is acting along the surface of the bar (Ametrano, 2011). Although this equation is used to determine the bond stress, it is not enough to define the strength of FRP bars embedded in concrete. By solely measuring the ultimate bond strength, it only gives an average sense, and does not provide a good representation of, the actual bond properties. Slip-strain and bond stress-slip relationships also need to be established to fully understand the FRP bond strength along with the parameters Tighiouart et al. (2008) specifically discussed, such as embedment length, bar diameter, concrete cover and surface treatment. 


\subsection{Development Length Equations in Design Codes}

In current design codes, development and splice lengths are already implemented and they represent the length of embedded reinforcement requires to develop adequate strength of the reinforcement at any critical location (CSA S806-12). The development lengths provided by CSA S806-12 and CHBDC 2006 are presented in the following sections.

\subsubsection{CHBDC 2006 Development Length Equation}

In CHBDC 2006, the development length equation shown in Equation 2.6 is provided in section

16.8.4.1.

$L_{d}=\frac{0.45 k_{1} k_{4}}{\left[d_{c s}+K_{t r}\left(\frac{E_{F R P}}{E_{S}}\right)\right]}\left[\frac{f_{F R P u}}{f_{c r}}\right] A_{b}$

Where:

$k_{1}$ is the bar location factor

$k_{4}$ is the bar surface factor

$d_{c s}$ is the smaller of distance from the closest concrete surface to the centre of the bar being developed, or two-thirds the centre-to-centre spacing of the bars being developed, $\mathrm{mm}$

$K_{t r}$ is the transverse index, $\mathrm{mm}$

$E_{F R P}$ is the mean modulus of elasticity of FRP bars, $M P a$

$E_{S}$ is the modulus of elasticity of steel, $\mathrm{MPa}$

$f_{F R P}$ is the stress in the tension FRP reinforcement, $M P a$

$f_{c r}$ is the cracking strength of concrete, $M P a$

$A_{b}$ is the cross-sectional area of the bar, $\mathrm{mm}^{2}$

Some of the variables in the equation are in accordance with steel reinforcement, which is in Clause 8.15.2.2, while other variables are adjusted in accordance to FRP's properties. As described in Clause 16.8.4.1:

- $k_{4}$ is the bar surface factor, which resemble the ratio of the bond strength of the FRP bar to a deformed steel rebar with the same dimensions as the FRP, but not greater than 1.0in. Otherwise, $k_{4}$ is taken as 0.8 with absence of experimental data

- $E_{F E P}$ represents the modulus of elasticity of the FRP bar

- The denominator, $\left(d_{c s}+K_{t r}\left(\frac{E_{F R P}}{E_{S}}\right)\right)$, cannot be greater than $2.5 d_{b}$

- The bond strength is required to be determined by experimental testing or the bond strength specified by the manufacturer of the bar 


\subsubsection{CSA S806-12 Development Length}

The development length equation provided by CSA S806-12 is shown in Equation 2.7.

$L_{d}=\frac{1.15 k_{1} k_{2} k_{3} k_{4} k_{5}}{d_{c s}+K_{t r}}\left(\frac{f_{F}}{\sqrt{f_{c}^{\prime}}}\right) A_{b}$

Where:

$k_{1}$ is the bar location factor

$k_{2}$ is the concrete density factor

$k_{3}$ is the bar size factor

$k_{4}$ is the bar fibre factor

$k_{5}$ is the bar surface profile factor

$d_{c S}$ is the smaller of

(a) the distance from the closest concrete surface to the centre of the bar being developed; or

(b) two-thirds of the centre-to-centre spacing of the bars being developed

$f_{F}$ is the design stress in FRP tension reinforcement at ultimate limit state

$f_{c u}^{\prime}$ is the specified compressive strength of concrete

$A_{b}$ is the area of an individual bar

$K_{t r}$ is the ratio between total cross-section area of steel rebar and specific yield strength of transverse reinforcement

\subsection{Experimental Development Length}

The main derivation of the experimental development length is based on the methodology presented in the report by H.R. Khederzadeh et al. (2013). The basic development length is derived using the experimental results and with the assumption of constant bond stress along the embedded length of the FRP bar and for specimens that have experienced pullout failure. Specimens that experienced inconcrete splitting were omitted in the derivation process of the bond factor and the development length calculations. The basic equilibrium equation derived in a form of:

$\pi d_{b} L_{d b} \mu=A_{b} F_{f u}$

Isolating for the development length, $L_{d b}$ produces the following,

$L_{d b}=\frac{A_{b} F_{f u}}{\pi d_{b} \mu}=\frac{d_{b} F_{f u}}{4 \mu}$

Khederzadel et al. (2013) used the theorem of the average bond strength being a linear function of the square root of the concrete compressive strength and bar diameter. Thus, resulting to the following expression: 
$\mu=\frac{C_{1} \sqrt{f_{c}^{\prime}}}{d_{b}}$

$C_{1}$, is a constant, which was assigned to investigate the other parameters that may affect the bond stress. Substituting Equation 2.10 into Equation 2.9 provides the final equation used to determine the basic experimental development length. Substituting the equations yields the following:

$L_{d b}=\frac{d b^{2} F_{f u}}{4 C_{1} \sqrt{f_{c}^{\prime}}}$

A second constant, $C_{2}$, is assigned to represent the relationship between the bar diameter and the first constant, which can be represented in the following,

$C_{2}=\frac{d_{b}}{4 C_{1}}$

The purpose of the second constant, $C_{2}$, is to introduce a bond factor that reflects the effect of the bar diameter and concrete compressive strength when calculating the development length. Thus, by substituting Equation 2.12 to Equation 2.11, the development length then becomes,

$L_{d b}=\frac{C_{2} d_{b} F_{f u}}{\sqrt{f_{c u}^{\prime}}}$

And constants $C_{1}$ and $C_{2}$ can be related by substituting Equation 2.10 into Equation 2.12, which results in,

$C_{2}=\frac{\sqrt{f_{c u}^{\prime}}}{4 \mu}$

Khederzadel et al. (2013) determined the bond constant for all the specimens with Equation 2.14 for those specimens that experienced pullout bond failure. Bond factors of the lowest of 0.11 and highest of 0.173 were observed. In order to obtain an appropriate value for the $C_{2}$ factor, linear regression analysis was conducted to obtain a single bond factor that better represented the data and would be used to determine the basic experimental development length. Figure 2.9 illustrates the linear regression analysis that was carried out for both straight and headed bars, and the final modified bond factors were 0.175 and 0.161 for straight and headed V-ROD GFRP bars, respectively (Khederzadel et al. 2013). 


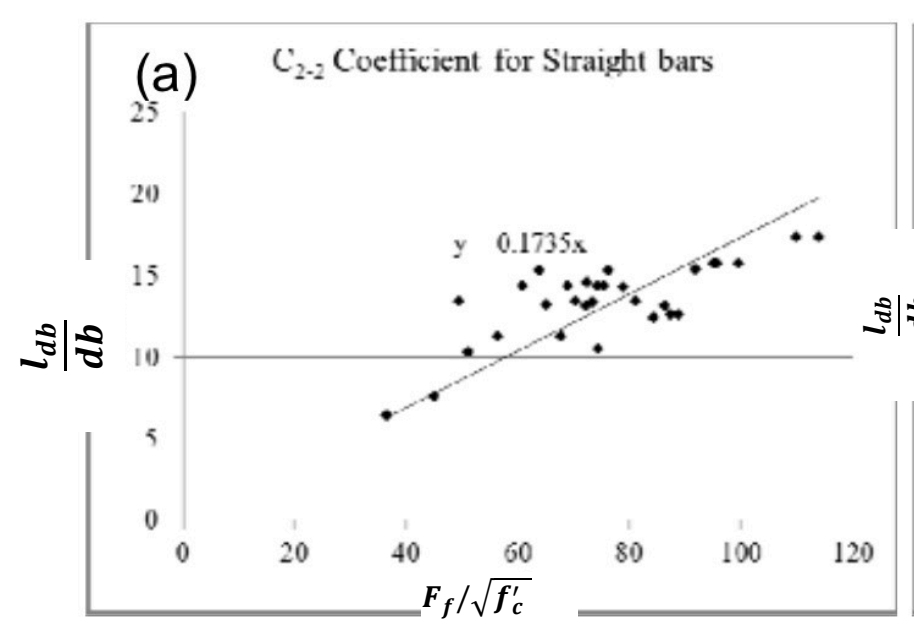

a)

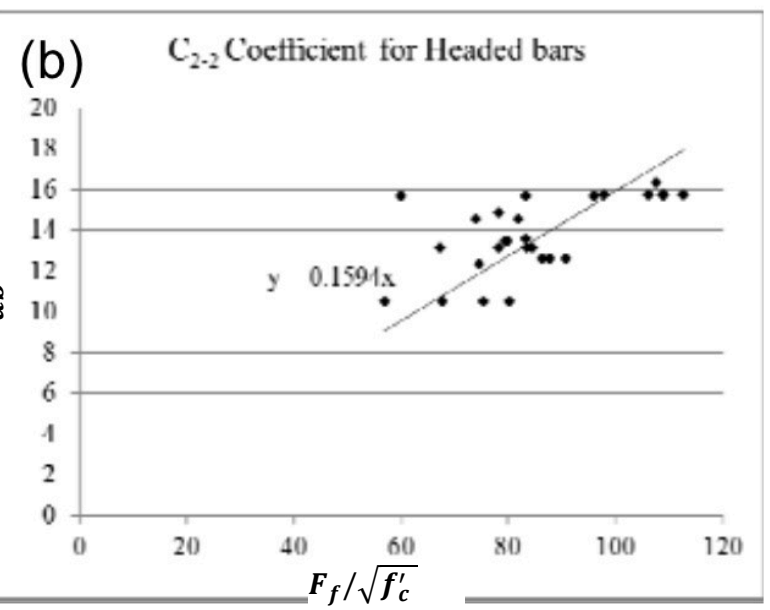

b)

Figure 2.9: Linear Regression Analysis for a) Straight Bars and

b) Headed Bars (Khederzadel et al., 2013) 


\section{Chapter 3: Experimental Investigation}

\subsection{Introduction}

This chapter outlines the scope of the research conducted and introduces the group of specimens and apparatus that were used to obtain the experimental results. The experimental program also provides details on the pullout test specimens, specimen configuration, material properties, pullout test procedures, apparatus set-up, and acquisition system used during the research process.

\subsection{Experimental Program}

The main objectives of this study were to conduct a parametric study of effect of different factors on bond characteristics of glass fibre reinforced polymer (GFRP) embedded in high performance concrete (HPC) and to determine experimental development lengths. The parametric study included factors such as surface treatment, bar diameter, embedment length and concrete cover. Two types of GFRP bars were included in this study: sand-coated GFRP bars and ribbed-surfaced bar. Specifically, for the sand-coated GFRP bars, an additional factor of the bar's end conditions, straight or with anchorage head, was included in the parametric study. In total, 145 specimens with straight-ended GFRP bars, both sand-coated and ribbed-surfaced, and 45 sand-coated specimens with an anchorage head were casted and tested. For the straight GFRP bars, the four parameters were investigated. The effect of surface treatment on bond strength is investigated with two different types of GFRP bars, which are sandcoated and ribbed-surfaced. The sand-coated GFRP bars were supplied by Trancels-Pultrall Canada Inc. (V-Rod) and the ribbed-coated GFRP bars were provided by Schöck Canada Inc. (ComBAR). For the straight-ended GFRP bars, the effect of bar diameter is investigated with two different bar diameters. For the sand-coated GFRP bars, nominal diameters of $15.875 \mathrm{~mm}$ and $19.05 \mathrm{~mm}$ were used and for the ribbed-surface GFRP bars, nominal diameters of $16 \mathrm{~mm}$ and $20 \mathrm{~mm}$ were used. The effect of embedment length is examined with three varying lengths, such as 4 times the bar diameter $\left(4 d_{b}\right), 6$ times the bar diameter $\left(6 d_{b}\right)$ and 8 times the bar diameter $\left(8 d_{b}\right)$. For the fourth factor, concrete cover of $40 \mathrm{~mm}$ and $60 \mathrm{~mm}$ were used in this study.

As for sand-coated GFRP bars with the anchorage head, only three parameters were investigated. The effect of bar diameter was examined with two separate bar diameters of $15.875 \mathrm{~mm}$ and $19.050 \mathrm{~mm}$, with anchorage heads of exterior diameters of $47.625 \mathrm{~mm}$ and $57.15 \mathrm{~mm}$, respectively. The effect of embedment length on bond strength was investigated with two different lengths of, firstly, the length of the anchorage head $\left(0 d_{b}\right)$ and, secondly, the length of the anchorage head and four times the bar diameter $\left(4 d_{b}\right)$. A final comparison of the bond strength was then conducted between the 
sand-coated GFRP straight bars and the headed bars. For all configurations, five duplicate specimens were casted and tested. Table 3.1 and Table 3.2 summarize the investigated parameters for both straight bars and headed bars.

\begin{tabular}{|c|c|c|c|c|}
\hline \multirow{3}{*}{$\begin{array}{c}\text { Surface } \\
\text { Treatment } \\
\text { Bar } \\
\text { Diameter, } d_{b} \\
(\mathrm{~mm})\end{array}$} & \multicolumn{4}{|c|}{ Varying Component } \\
\hline & \multicolumn{2}{|c|}{$\begin{array}{l}\text { Sand-Coated } \\
\text { (V-ROD) }\end{array}$} & \multicolumn{2}{|c|}{ Ribbed-Surface (ComBAR) } \\
\hline & 15.875 & 19.050 & 16 & 20 \\
\hline $\begin{array}{l}\text { Embedment } \\
\text { Length }(\mathrm{mm})\end{array}$ & \multicolumn{2}{|c|}{$4 d_{b}, 6 d_{b}, 8 d_{b}$} & \multicolumn{2}{|c|}{$4 d_{b}, 6 d_{b}, 8 d_{b}$} \\
\hline $\begin{array}{c}\text { Concrete } \\
\text { Cover* } \\
(\mathrm{mm})\end{array}$ & \multicolumn{2}{|c|}{40,60 , and concentric } & \multicolumn{2}{|c|}{40,60 , and concentric } \\
\hline
\end{tabular}

*Concrete cover measured from the edge of the GFRP bar

Table 3.2: Investigated Parameters Summary: For Headed Bar

\begin{tabular}{|c|c|c|}
\hline & \multicolumn{2}{|c|}{ Varying Component } \\
\hline $\begin{array}{c}\text { Surface } \\
\text { Treatment }\end{array}$ & \multicolumn{2}{|c|}{$\begin{array}{c}\text { Sand-Coated } \\
\text { (V-ROD) }\end{array}$} \\
\hline $\begin{array}{c}\text { Bar } \\
\text { Diameter, } \boldsymbol{d}_{\boldsymbol{b}} \\
(\boldsymbol{m m})\end{array}$ & 15.875 & 19.050 \\
\hline $\begin{array}{c}\text { Embedment } \\
\text { Length (mm) }\end{array}$ & $0 d_{b}, 4 d_{b}$ & $0 d_{b}, 4 d_{b}$ \\
\hline $\begin{array}{c}\text { Concrete } \\
\text { Cover* } \\
(\mathbf{m m})\end{array}$ & 40,60, and concentric & 40,60, and concentric \\
\hline
\end{tabular}

*Concrete cover measured from the edge of the anchorage head's exterior diameter 


\subsection{Pullout Test Specimen Matrix and Configuration}

The configuration of the pullout test specimens consisted of GFRP bars embedded into concrete blocks. For the straight-ended bars, the concrete specimens had a length and width of $200 \mathrm{~mm}$ by 200 $\mathrm{mm}$, essentially a square base, and the height of the specimen varied depending on the embedment length that needed to be installed. Concrete cover of $40 \mathrm{~mm}$ and $60 \mathrm{~mm}$ were investigated for each configuration of embedment length. As for the headed specimens, the concrete blocks had a base dimension of $300 \mathrm{~mm}$ by $300 \mathrm{~mm}$ with varying heights due to the varying embedment lengths. Concrete cover of $40 \mathrm{~mm}$ and $60 \mathrm{~mm}$ were investigated for each configuration of embedment length. Table 3.3 and Table 3.4 show the embedment lengths required in the pullout test specimens for sand-coated GFRP bars and ribbed-surfaced bars, respectively. Figure 3.1 and Figure 3.2 demonstrates the pullout test specimen configuration, which was referred to during the construction of the formwork and preinstallment of the GFRP bars.

\begin{tabular}{|c|c|c|c|c|c|c|}
\hline \multicolumn{2}{|c|}{ Table 3.3: Final Test Matrix for V-Rod Product } \\
\hline \multirow{3}{*}{ Bar Location } & $\begin{array}{c}d_{b} \\
(\mathrm{~mm})\end{array}$ & \multicolumn{3}{|c|}{$\begin{array}{c}l_{d b}(1) \\
(\mathrm{mm})\end{array}$} & \multicolumn{2}{c|}{$\begin{array}{c}L_{d b}(2) \\
(\mathrm{mm})\end{array}$} \\
\cline { 2 - 7 } & $4 d_{b}$ & $6 d_{b}$ & $8 d_{b}$ & $0 d_{b}$ & $4 d_{b}$ \\
\hline \multirow{2}{*}{\begin{tabular}{c} 
Concentric \\
\cline { 2 - 7 }
\end{tabular}} & 15.875 & 63.5 & 95.25 & 127.0 & 0 & 63.5 \\
\hline \multirow{2}{*}{$\begin{array}{c}\text { Eccentric } \\
\text { with 40mm } \\
\text { cover }\end{array}$} & 19.050 & 76.2 & 114.3 & 152.4 & 0 & 76.2 \\
\hline \multirow{2}{*}{$\begin{array}{c}\text { Eccentric } \\
\text { with 60 mm } \\
\text { cover }\end{array}$} & 15.875 & 63.5 & 95.25 & 127.0 & 0 & 63.5 \\
\cline { 2 - 7 } & 19.050 & 76.2 & 114.3 & 152.4 & 0 & 76.2 \\
\hline
\end{tabular}

\begin{tabular}{|c|c|c|c|c|}
\hline \multicolumn{2}{|c|}{ Table 3.4: Final Test Matrix for Schöck ComBAR Product } \\
\hline & & \multicolumn{3}{|c|}{ For Straight-Ended Bars } \\
\hline \multirow{2}{*}{ Bar Location } & $\begin{array}{c}d_{b} \\
(\mathrm{~mm})\end{array}$ & $4 d_{b}$ & $\begin{array}{c}L_{e 1} \\
(\mathrm{~mm})\end{array}$ \\
\hline Concentric & 16 & 64 & $6 d_{b}$ & $8 d_{b}$ \\
\cline { 2 - 5 } & 20 & 80 & 96 & 128 \\
\hline $\begin{array}{c}\text { Eccentric } \\
\text { with 40 mm } \\
\text { cover }\end{array}$ & 16 & 64 & 120 & 160 \\
\cline { 2 - 5 } $\begin{array}{c}\text { Eccentric } \\
\text { with 60 mm } \\
\text { cover }\end{array}$ & 20 & 80 & 96 & 128 \\
\cline { 2 - 5 } & 20 & 64 & 120 & 160 \\
\hline
\end{tabular}




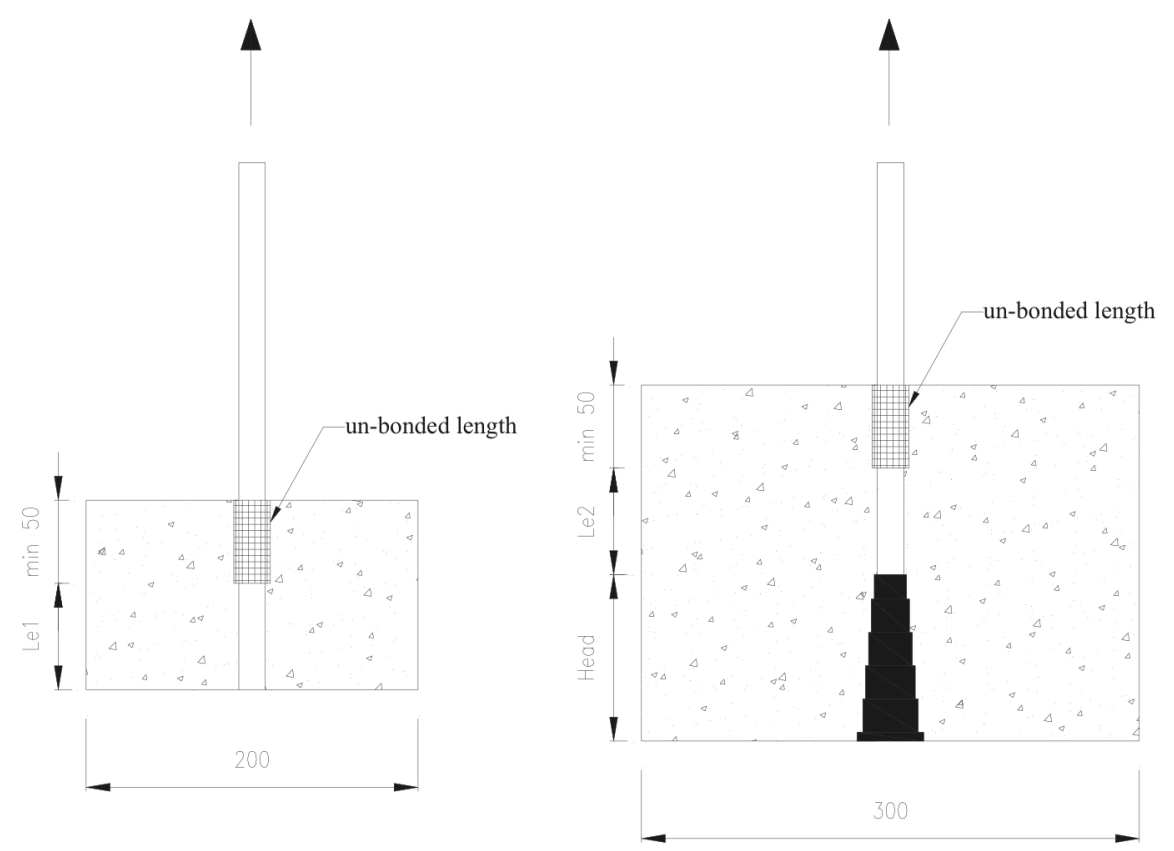

Figure 3.1: Pullout Specimen Configuration with Concentric Concrete Cover
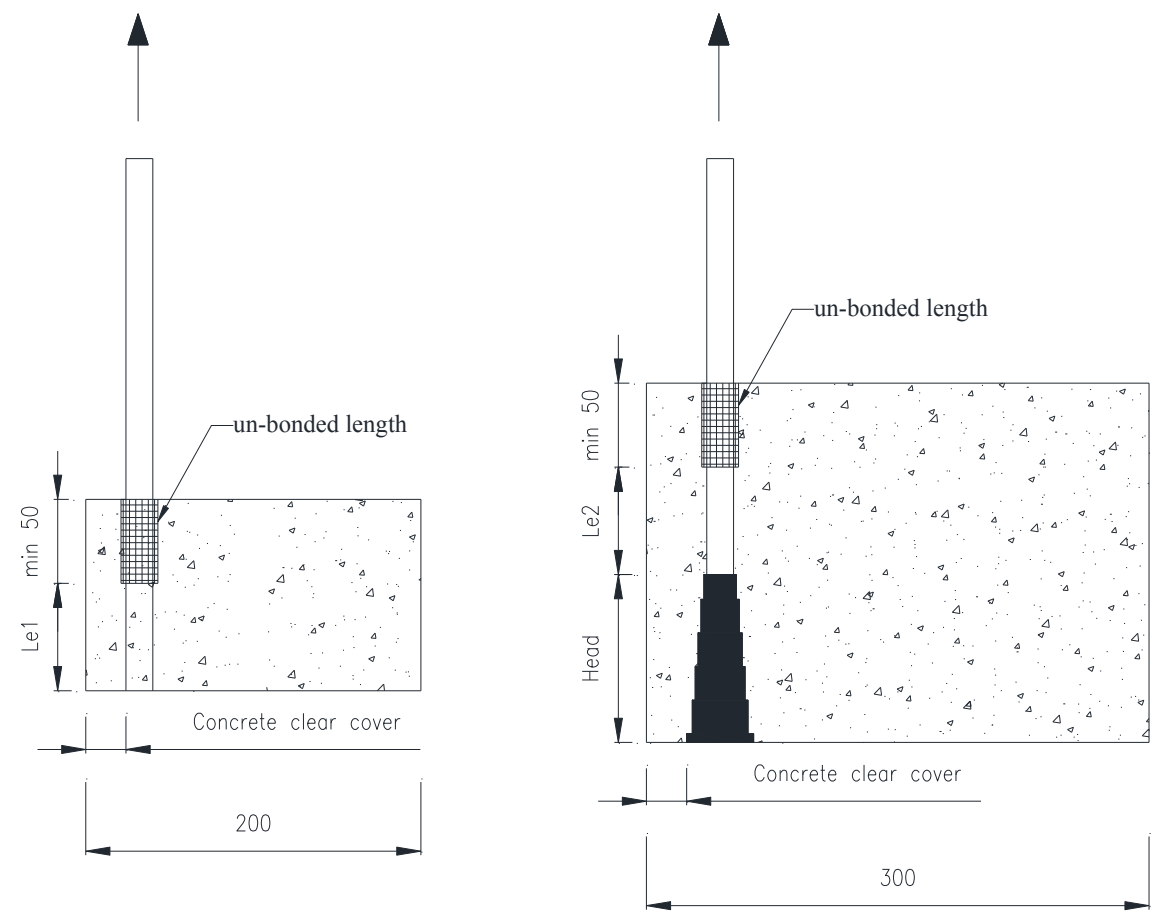

Figure 3.2: Pullout Specimen Configuration with Eccentric Concrete Cover 


\subsection{Materials}

This section discusses the materials and their properties used for this research and are divided into subsections to discuss the GFRP bars and HPC.

\subsubsection{GFRP Straight Bars}

Two types of GFRP bars were selected for this research project: sand-coated bars provided by Trancels-Pultrall Canada Inc. (V-Rod) and ribbed-coated bars provided by Schöck Canada Inc. (ComBAR). For the sand-coated GFRP bars provided by Trancels-Pultrall Canada Inc., V-ROD ${ }^{\circledR}$ HM type was used with a nominal tensile modulus of $60 \mathrm{GPa}$. \#5 GFRP and \#6 GFRP were the specific code names for the $15.875 \mathrm{~mm}$ and $19.050 \mathrm{~mm}$ diameter bars, respectively. All of the $\mathrm{V}-\mathrm{ROD}^{\circledR} \mathrm{HM}$ bars consisted of a glass content of $65 \%$ in volume. For ribbed-coated GFRP bars provided by Schöck Canada Inc., straight-ended ComBAR ${ }^{\circledR}$ bars were used, which have a nominal tensile modulus of $60 \mathrm{GPa}$. M15 and M20 were the specific code names for the $16 \mathrm{~mm}$ and $20 \mathrm{~mm}$ core diameter bars, respectively. For both GFRP bars, lengths of $1500 \mathrm{~mm}$ were used to allow installation of a grip system for testing the specimen. The technical information for each type of GFRP are presented in Table 3.5 and Table 3.6 and Figure 3.3 in below illustrates the photos of the different GFRP bars used for this research. Additionally, Table 3.7 shows the technical information on the anchorage head for the sand-coated GFRP bar.

Table 3.5a: Nominal Diameter and Sectional Area of GFRP V-Rod

\begin{tabular}{|c|c|c|c|}
\hline US Size & $\begin{array}{c}\text { Nominal Diameter } \\
(\mathrm{mm})\end{array}$ & $\begin{array}{c}\text { Area } \\
\left(\mathrm{mm}^{2}\right)\end{array}$ & $\begin{array}{c}\text { Weight } \\
(\mathrm{g} / \mathrm{m})\end{array}$ \\
\hline$\# 5$ & 15.875 & 197.9 & 425.5 \\
\hline$\# 6$ & 19.050 & 285.0 & 614.5 \\
\hline
\end{tabular}

(Source: Pultrall Inc., May 2011)

\begin{tabular}{|c|c|c|c|c|c|c|}
\hline \multicolumn{2}{|l|}{ Table 3.5b: Tensile Properties of GFRP V-Rod } \\
\hline \multirow{4}{*}{ US Size } & $\begin{array}{c}\text { Tensile } \\
\text { Modulus of } \\
\text { Elasticity } \\
E_{t},(\mathrm{GPa})\end{array}$ & $\begin{array}{c}\text { Ultimate } \\
\text { Tensile } \\
\text { Strength } \\
F_{u}(\mathrm{MPa})\end{array}$ & $\begin{array}{c}\text { Guaranteed } \\
\text { Design Tensile } \\
\text { Strength } \\
f_{f u}(\mathrm{MPa})\end{array}$ & $\begin{array}{c}\text { Shear } \\
\text { Strength }\end{array}$ & $\begin{array}{c}\text { Ultimate } \\
\text { Strain in } \\
\text { Tension }\end{array}$ & $\begin{array}{c}\text { Poisson's } \\
\text { Ratio }\end{array}$ \\
\hline$\# 5$ & 63.5 & 1184 & 1239 & $F_{S}(M P a)$ & $\varepsilon_{f u}(\%)$ & $u$ \\
\hline$\# 6$ & 60.2 & 1105 & 1196 & 127 & 1.89 & 0.25 \\
\hline
\end{tabular}

(Source: Pultrall Inc., May 2011) 


\begin{tabular}{|c|c|c|c|}
\hline \multicolumn{4}{|c|}{ Table 3.6a: Nominal Diameter and Sectional Area of GFRP Schöck ComBAR } \\
\hline US Size & $\begin{array}{c}\text { Nominal Diameter } \\
(\mathrm{mm})\end{array}$ & $\begin{array}{c}\text { Area } \\
\left(\mathrm{mm}^{2}\right)\end{array}$ & $\begin{array}{c}\text { Weight } \\
(\mathrm{g} / \mathrm{m})\end{array}$ \\
\hline$\# 5$ & 16.0 & 201.0 & 530.0 \\
\hline$\# 6$ & 20.0 & 314.0 & 800.0 \\
\hline
\end{tabular}

(Source: Schöck ComBAR , April 2013)

\begin{tabular}{|c|c|c|c|c|c|c|}
\hline \multicolumn{7}{|c|}{ Table 3.6b: Tensile Properties of GFRP Schöck ComBAR } \\
\hline $\begin{array}{c}\text { ComBAR } \\
\text { bar }\end{array}$ & $\begin{array}{c}\text { Tensile } \\
\text { Modulus } \\
\text { of } \\
\text { Notation } \\
\text { Elasticity } \\
E_{t},(\mathrm{GPa})\end{array}$ & $\begin{array}{c}\text { Ultimate } \\
\text { Tensile } \\
\text { Strength }\end{array}$ & $\begin{array}{c}1000 \mathrm{Hour} \\
\text { Tensile } \\
\text { Strength }\end{array}$ & $\begin{array}{c}\text { Shear } \\
\text { Strength } \\
F_{f k 1000 h}(\mathrm{MPA})\end{array}$ & $\begin{array}{c}\text { Ultimate Strain } \\
\text { in Tension }\end{array}$ & $\begin{array}{c}\text { Bond } \\
\text { Strength }\end{array}$ \\
\hline$\varnothing 5$ & $>63.5$ & $>1000$ & 950 & $\geq 150 \mathrm{MPa}$ & $\varepsilon_{f u}(\%)$ & $\tau_{F}(\mathrm{MPa})$ \\
\hline$\varnothing 6$ & $>63.5$ & $>1000$ & 950 & $\geq 150 \mathrm{MPa}$ & 1.67 & $>12.2$ \\
\hline
\end{tabular}

(Source: Schöck ComBAR , April 2013)

1 Values for determination of design value of tensile strength according to durability concept of fibre defining time-to-failure lines
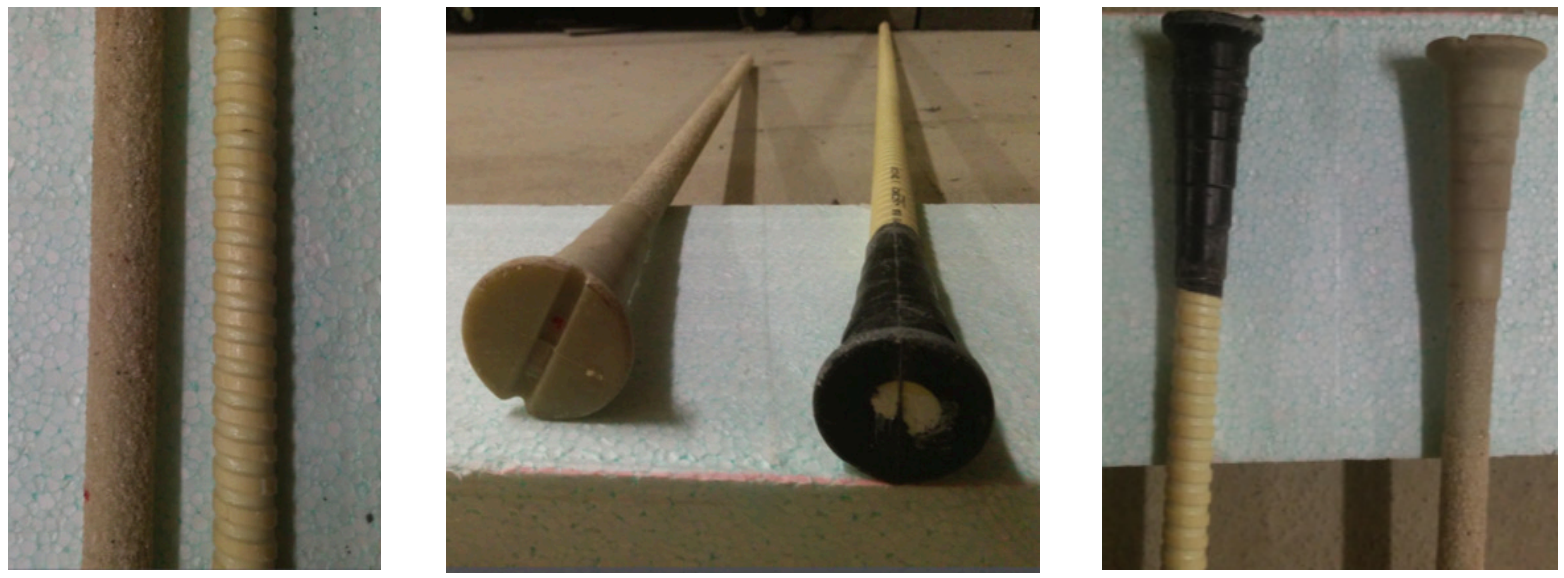

Figure 3.3: V-Rod and Schöck ComBAR GFRP Bars 


\subsubsection{Headed-end V-ROD GFRP Bars}

V-ROD ${ }^{\circledR} \mathrm{HM}$ GFRP bars with pre-installed anchorage heads are supplied from Trancels-Pultrall Canada Inc. The headed V-ROD GFRP bars with diameter size of \#5 GFRP and \#6 GFRP were used with a nominal tensile modulus of $60 \mathrm{GPa}$. The maximum exterior diameters of the anchorage heads are 3 times the diameter of the bar, with the head length of approximately $100 \mathrm{~mm}$. This information is summarized in Table 3.7. Figure 3.4 shows an overview of a V-ROD GFRP bar with a pre-installed anchorage head and it can be seen that the head tapers in five steps to the exterior anchorage head diameter. The purpose of the anchorage head is to provide a strong anchoring system and avoid splitting mechanism around the anchorage head. During the manufacturing process, the length of the GFRP bar to be installed inside the anchorage head is prepared with grooves around its circumference, which is shown in Figure 3.5, with the ribbed-bar in the middle. This process enables the bar and the anchorage head to achieve an adequate bond and to increase the mechanical interlocking (Mohamed, 2012). Figure 3.6 shows an AutoCAD drawing of the bar and anchorage head interface.

\begin{tabular}{|c|c|c|}
\hline \multicolumn{3}{|c|}{ Table 3.7: Dimension \& Characteristic Values Anchorage Forces of GFRP V-Rod with Headed Ends } \\
\hline $\begin{array}{c}\text { Nominal Diameter } \\
(\mathrm{mm})\end{array}$ & $\begin{array}{c}\text { Bar Length } \\
(\mathrm{mm})\end{array}$ & $\begin{array}{c}\text { Ext. Head Diameter } \\
(\mathrm{mm})\end{array}$ \\
\hline 15.875 & 100 & 47.63 \\
\hline 19.050 & 100 & 57.15 \\
\hline
\end{tabular}

(Source: Pultrall Inc., May 2011)

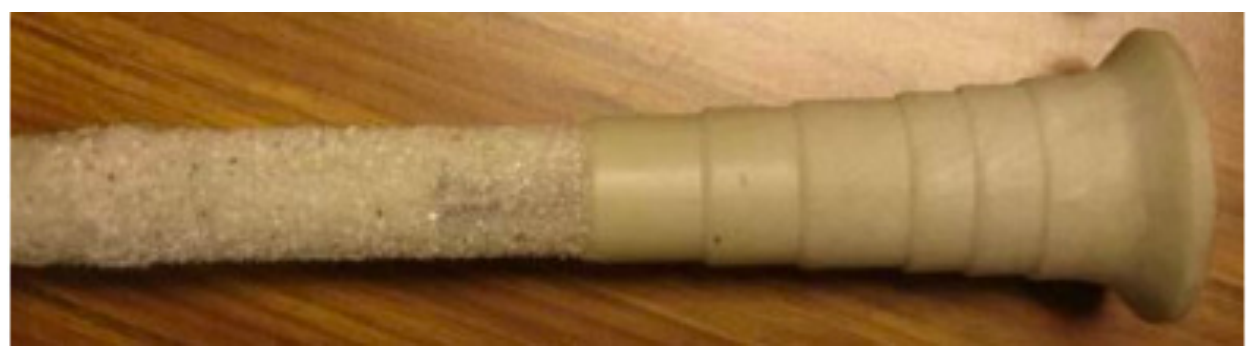

Figure 3.4: Overview of V-ROD GFRP Bar with Anchorage Head (Mohamed, 2012) 


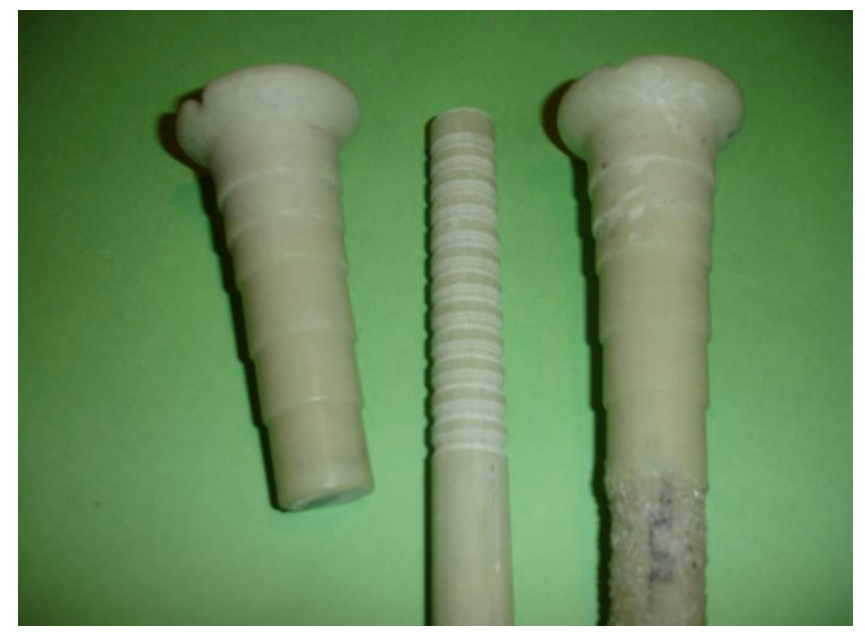

Figure 3.5: Overview of the Anchorage Head and Ribbed Grooves on the End of GFRP Bar (Mohamed, 2012)

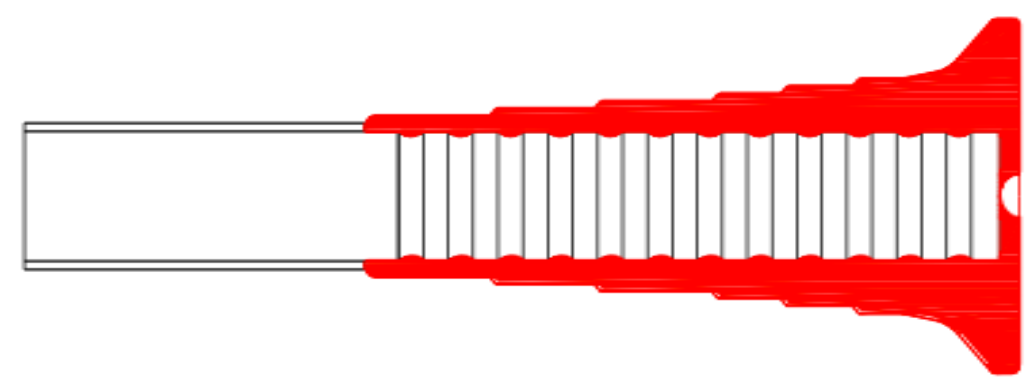

Figure 3.6: AutoCAD Drawing of Bar and Anchorage Head Interface (Mohamed, 2012) 


\subsubsection{High-Performance Concrete (HPC)}

High Performance Concrete (HPC) was used to cast the samples, which was supplied as a readymix from St. Mary Canada. Due to the confidentiality agreement with St. Mary's Canada, only minimal information is provided. The HPC specifically used for this project has a compressive strength of $70 \mathrm{MPa}$. Three cylinders with the dimensions of 4 inches in diameter and 8 inches in length were also cast at the beginning of the concrete pour. Compressive strength tests were conducted after the curing period with specifications outlined by ASTM C900-13, Standard Test Method for Pullout Strength of Hardened Concrete. The compressive strength test results are shown in Table 3.8 and the average concrete compressive strengths was calculated as $79.10 \mathrm{MPa}$.

\section{Table 3.8: Compressive Strength Test Results}

\begin{tabular}{|c|c|}
\hline Cylinder Sample & Compressive Resistance (MPa) \\
\hline 1 & 82.18 \\
\hline 2 & 73.49 \\
\hline 3 & 81.62 \\
\hline
\end{tabular}

\subsection{Material and Specimen Preparations}

This section provides detailed procedures taken to construct the formwork and pre-install the GFRP bars with the proper embedment lengths and concrete cover for the final product used to perform the pullout tests.

\subsubsection{Formwork}

The formwork for the concrete specimens was fabricated from 3/4-inch plywood with a standard dimension of 4 inches by 8 inches. All pieces were assembled together with screws. Proper care was taken to ensure that the screws secured the connecting formwork pieces together to prevent voids in the formwork for the concrete pour. Before assembling the formwork, holes were drilled in the plywood so that the longitudinal GFRP bars could be positioned accurately. Proper measurements were marked on all of the plywood pieces to ensure that all of the GFRP bars were installed accurately and precisely to match the proposed sketches. Wood boring drill bit sizes of $3 / 4$ inch and 1 inch were used for $16 \mathrm{~mm}$ and $20 \mathrm{~mm}$ diameter GFRP bars respectively to ensure the bars did not move during the concrete pour. Figure 3.7 below illustrates the final formwork assembly. 


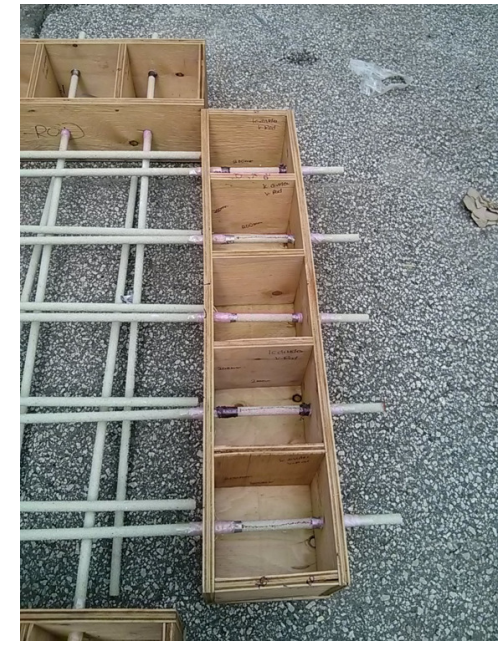

Figure 3.7: Final Formwork Assembly

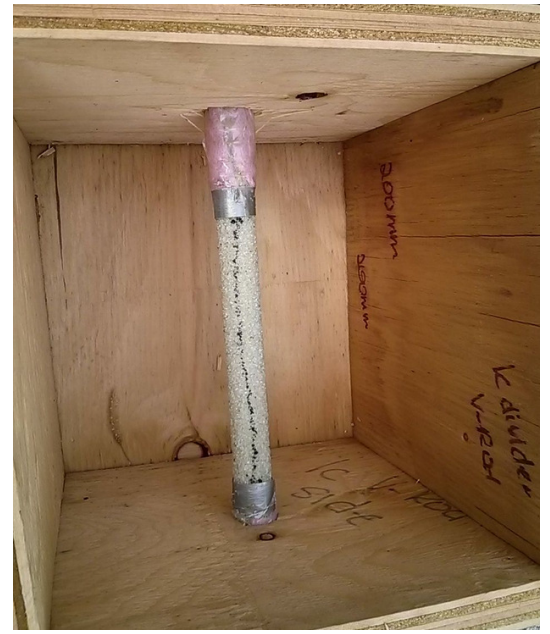

Figure 3.8: Moist- Resisting Foam

\subsubsection{Installing GFRP Bars}

Prior to the concrete pour, the GFRP bars had to be inserted into the formwork, and there were various specific instructions that needed to be followed. It was required that GFRP bars protrude from the formwork at least $100 \mathrm{~mm}$ to ease in handling the specimen and also the extended length allows a LVDT to be placed at the end (loaded end) to measure the slip of the GFRP bars. All GFRP bars installed have a length of $1500 \mathrm{~mm}$ to allow the gripping system to be installed in the pullout apparatus set up. The different embedment lengths were achieved by taping moisture-resistant foam on the bar before inserting the bars in the formwork. The foam also acted as a seal and filled in the gap between the GFRP bars and the drilled hole in the formwork, which can be seen in Figure 3.8.

\subsubsection{GFRP Bar Embedment Lengths}

As discussed in previous sections, the embedment lengths of $0 d_{b}$ and $4 d_{b}$ were investigated for the sand-coated GFRP bars with the anchorage heads, and embedment lengths of $4 d_{b}, 6 d_{b}$ and $8 d_{b}$ were investigated for straight-ended GFRP bars. Different embedment lengths were achieved by taping the moisture-resistance foam on both sides of the GFRP bars. As seen in Figure 3.9, $50 \mathrm{~mm}$ of moistureresistant foam is installed above the required embedment length. Casting the concrete specimen with just its required embedment length would introduce more human error and the $50 \mathrm{~mm}$ coverage aids in eliminating uncontrollable errors during the concrete pour and ensures that the exact embedment length was achieved for each specimen. Figure 3.9c illustrates the detailed design of the placement of the foam to achieve the required embedment length for the specimens. 


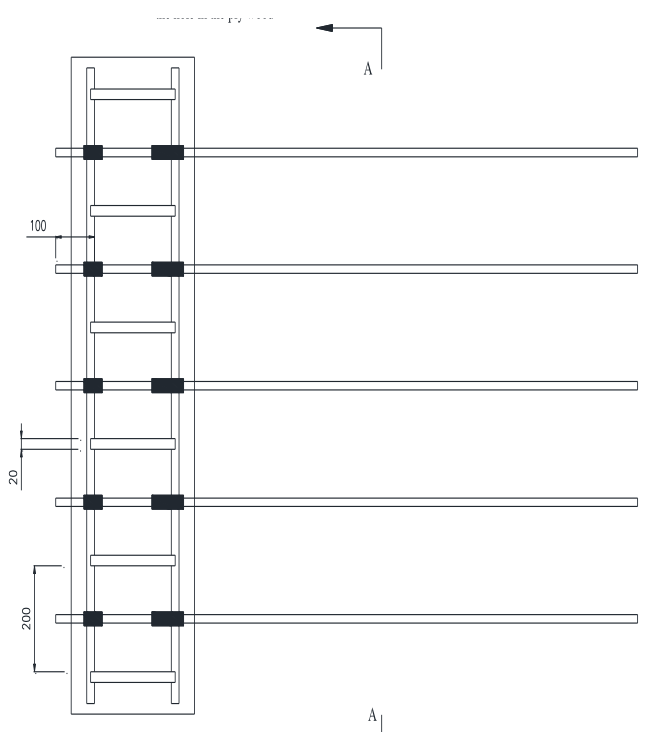

a)

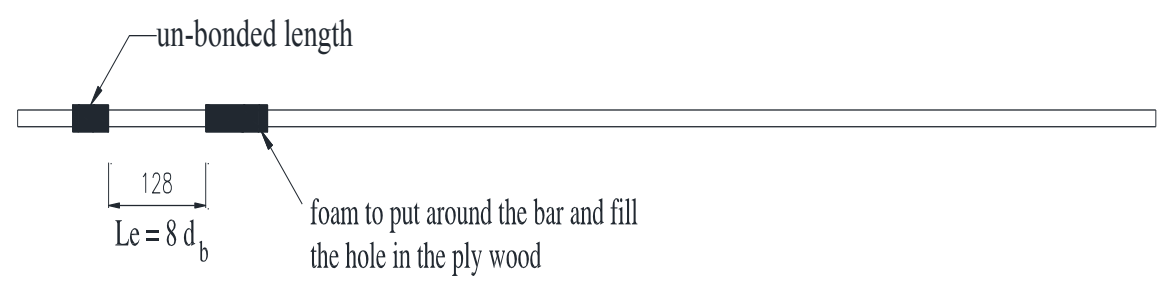

c)

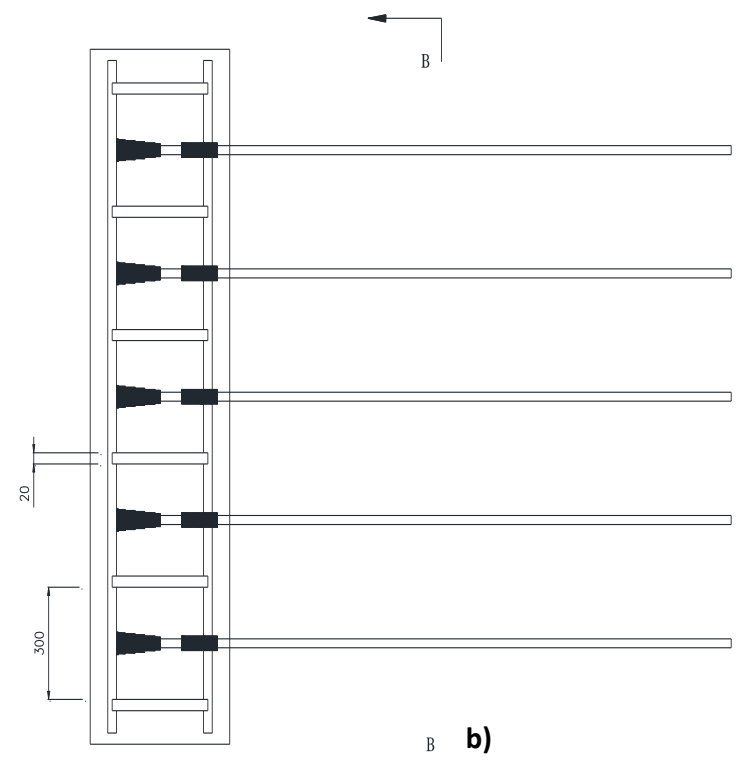

Figure 3.9: Formwork Configuration with Moisture-Resistant Foam Installed for a) Straight Bars, b) Headed bars and c) Magnified Foam Design for Achieving Specific Embedment Length

\subsubsection{Concrete Casting}

The specimens were cast after the final assembly of the formwork and proper installment of the GFRP bars in the formwork. Concrete was poured into each of the five specimens for each block, and each specimen was then vibrated to ensure adequate consolidation of the concrete and eliminate any voids below or around the GFRP bar. After the vibration, the top of the specimens was smoothed out. This procedure was carried out swiftly and with care to ensure that the ready-mix concrete did not dry out and lose its slump. All of the specimens were casted on September $3^{\text {rd }}, 2013$ during the afternoon.

\subsubsection{Concrete Curing}

All of the specimens were cured under the same conditions and for the same duration. The specimens were placed outdoors, exposed to a temperature range of 20-27 degrees Celsius. Thus, burlap sheets were placed over the specimens and were wet twice a day, once in the morning and once in the evening, to ensure minimum loss of moisture content and to avoid undesirable early stages of 
drying shrinkage. Plastic sheets were placed on top of the specimens after every wetting process of the burlap sheets. This procedure was followed for 10 days to allow for proper curing of the concrete. All of the specimens were transferred into the lab by mid-October and the groups of specimens were stripped from the forms on a bi-weekly basis. All of the specimens were organized in the lab in the order of testing.

\subsection{Pullout Test Set-up and Procedures}

The pullout tests were performed once the concrete cylinders had reached the desired compressive strength. The following section presents the pullout test set up, apparatus, and procedures used to conduct the tests to collect the required data for analysis, which is presented in the next chapter.

\subsubsection{Pullout Test Set-up}

The pullout test apparatus can be seen in a sketch in Figure 3.10, and an actual photo of the setup can be seen Figure 3.11. The apparatus consisted of 4 steel plates, a loading cell, and the grip system. The steel plates have a thickness of $2.5 \mathrm{in}$. and they were placed in a position to distribute the compression reaction on the specimen face. This reaction is shown in the sketch in Figure 3.12. The loading cell is attached to a computer data acquisition system. An aluminum hollow plunger cylinder is the main component used to exert the tensile force on the specimen's GFRP bar and the grip system is a standard wedge type grip system. The wedges have specific grooving patterns to allow full contact with the GFRP bars, which help minimize localized transverse stress and reduce the chances of premature failure in the bar itself.

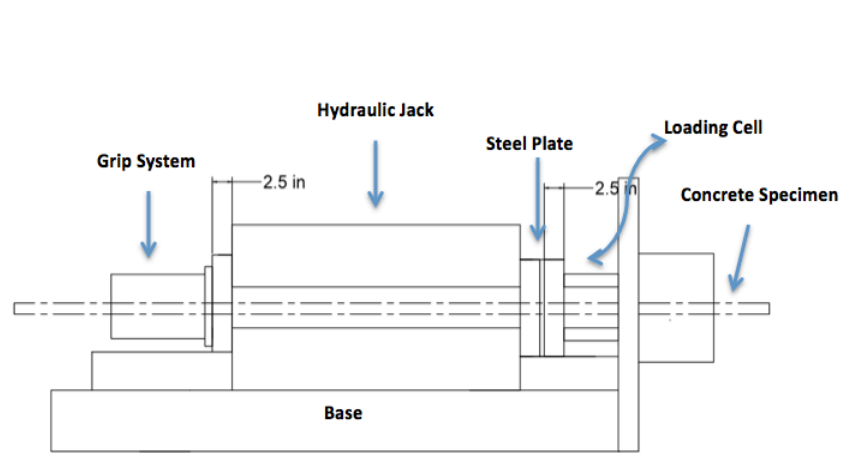

Figure 3.10: Pullout Test Apparatus - Sketch

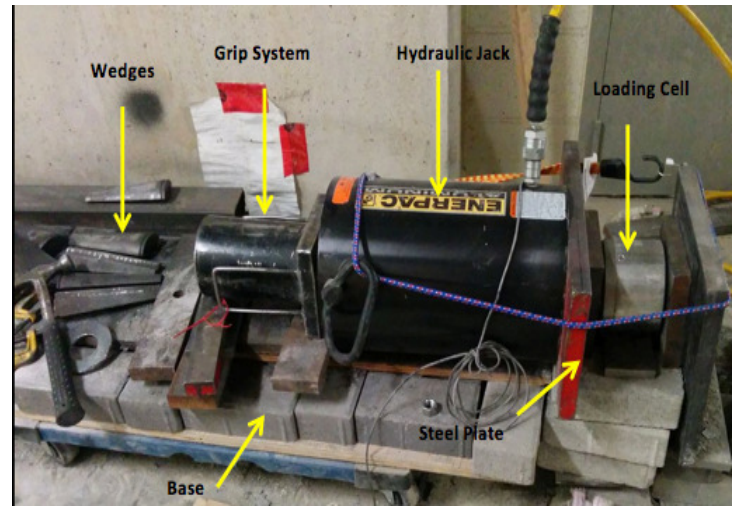

Figure 3.11: Pullout Test Apparatus 


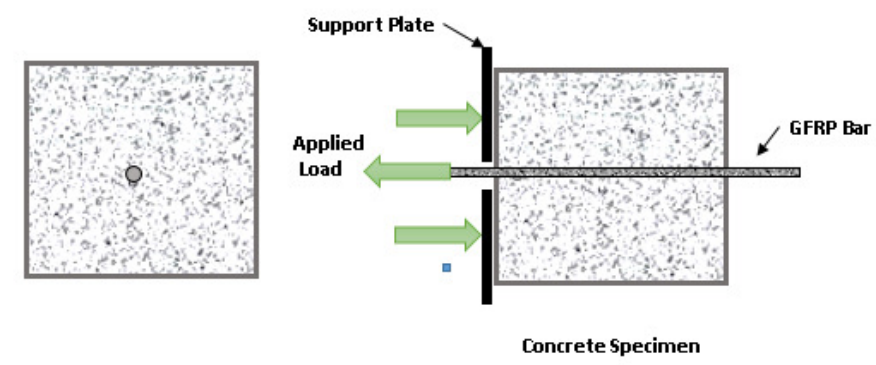

Figure 3.12: Schematic View of Distributed Compression Forces on Specimen

\subsubsection{Grip System}

The grip system is a standard wedge type setup and is shown in Figure 3.13. The black hollow aluminum tube is the support system for the three wedges that are used to grip the GFRP bar. For this research, wedges \#5 and \#6 are specifically used for 16/15.875 mm and 20/19.05 mm GFRP bars, respectively. As mentioned in the previous section, the wedges are grooved so that full contact with the GFRP bars is achieved. For each specimen, the hollow tube was sprayed with graphite as lubricate for easy insert and removal of the three wedges at the beginning and end of the pullout test. The steel wedges were then carefully hammered into place, surrounding the bar. It was important that the bar was in the center and that the steel wedges were equally spaced out so that the bar will experience equal stress all around its circumference. After each test, the residue on the wedges from the previous bar was cleaned off to ensure proper grip was achieved for the next test.

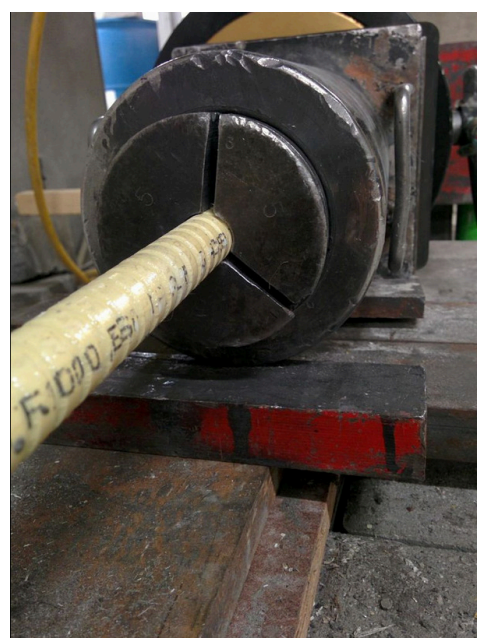

Figure 3.13: Grip System 


\subsubsection{Computer Data Acquisition System}

All measurements were recorded using System 8000's SmartStrain from Micro-Measurement. Two measurements, free-end slip and loaded-end slip, were recorded with Linear Variable Differential Transformers (LVDTs), whereas the load measurement was recorded with a load cell. The free-end slip and loaded-end slip measurements were recorded with the acquisition system at an excitation of $2 \mathrm{~Hz}$, while the loading cell scanner was excited with $10 \mathrm{~Hz}$. In Figure 3.14, the highlighted red box shows the LVDTs used to measure the free-end slip, which was labelled as "Free End on 2", and the load-end slip, which was labelled as "Elongation of Bar on 3". The load cell used for recording the pullout load was labelled as "Load Cell on 1". The numbering in the labels represents the channel assigned for each data acquisition.

The LVDTs had to be carefully positioned at the center of the GFRP bar. A steel bracket and a 16 in. deep-throat bar clamp were used to clamp the LVDT in position and this is shown in Figure 3.15a. As for the loaded-end slip measurement, the LVDT was placed parallel to the grip system and the measurements were taken with the end of the hollow plunger cylinder as the reference, as shown in Figure 3.15b.

Before starting the test, the LVDTs had to be calibrated and checked to determine if they would present accurate results. A reference object with a known length of $16.6 \mathrm{~mm}$ was placed between the tip of the LVDT and the relative point, and the SmartStrain software should yield out an indicated output of $16.6 \mathrm{~mm}$ and this is shown in Figure 3.14 with a highlighted blue box. This procedure was followed for every specimen. There were several occasions when the software yielded out an unacceptable value, and it was discovered that LVDTs lost its functionality due to wiring issues or the LVDTs had simply worn out. Thus, this step was very crucial to ensure all data was recorded accurately.

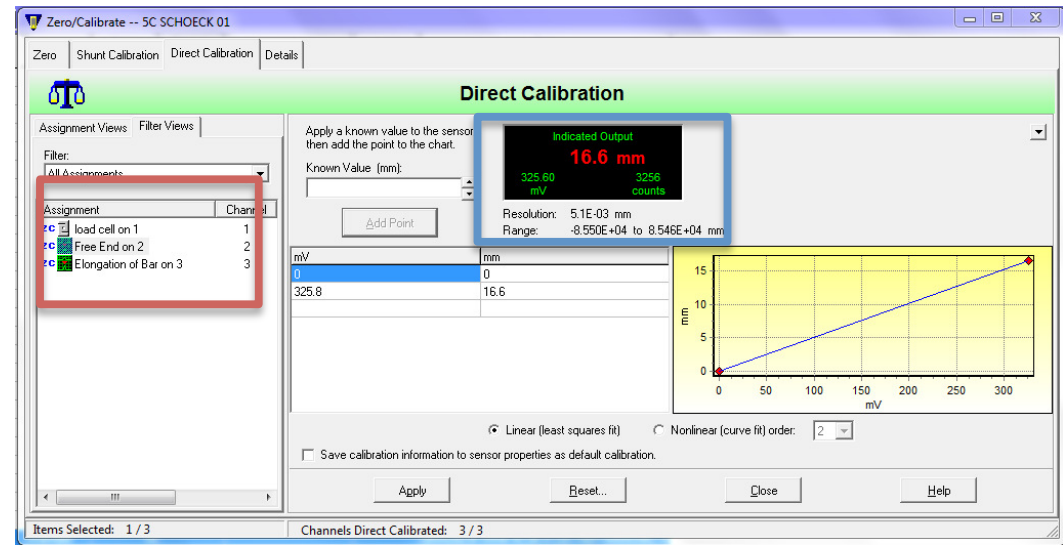

Figure 3.14: SmartStrain Micro-Measurement Computer Data Acquisition System 


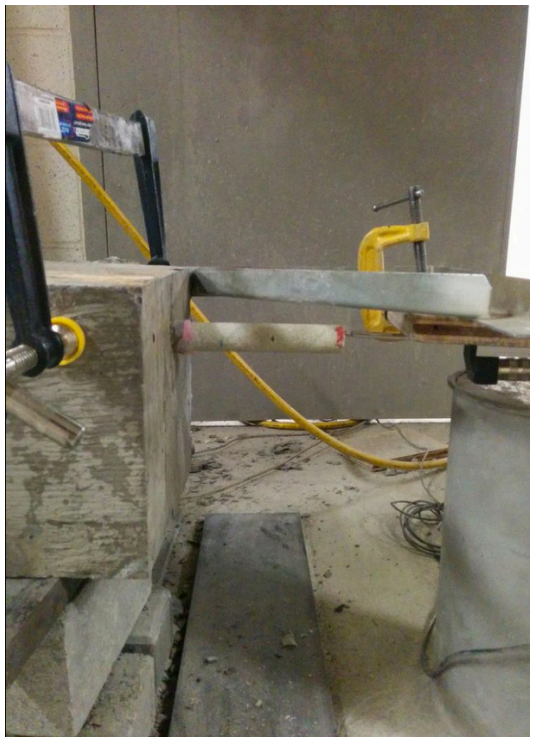

a)

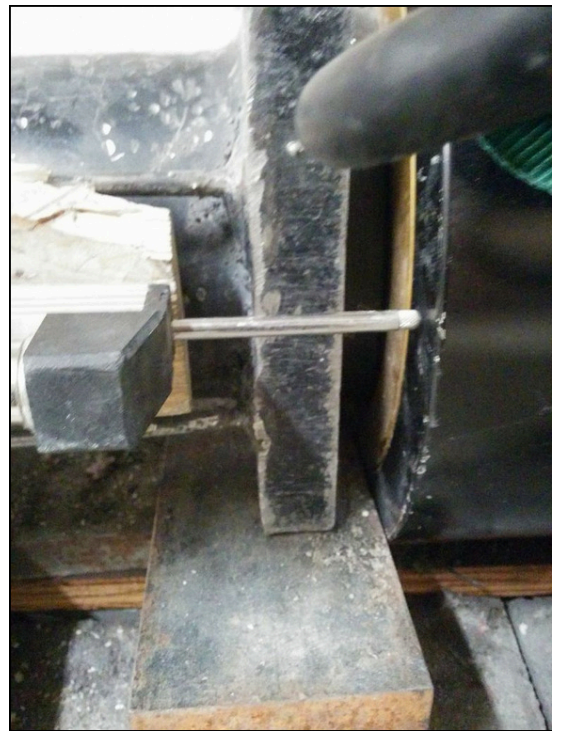

b)

Figure 3.15: LVDT's Position for a) Free-end and b) Loaded-end

\subsubsection{Pullout Test Procedures}

The entire pullout test was conducted according to the procedures outlined in this section. The concrete specimen was horizontally inserted into the experimental setup with the GFRP bar aligned in the center of the hollow steel tubes, ready for the steel wedges to be inserted in. A flush surface had to be established between the face of the concrete specimen and the supporting steel plate, and this automatically centered the bar. These alignments were very important, as it allowed the GFRP bars to be pulled straight out from the concrete specimen. The grip system was lubricated with graphite to allow the wedges to be inserted with ease, and the spaces between the wedges were equally spaced to allow constant stress to be applied on the bar when the specimen was being pulled out. The LVDTs were then secured in placed and the acquisition system was calibrated before the commencement of the experimental testing.

After application of $1-5 \mathrm{kN}$ of load, the concrete specimen had positioned itself against the steel plate. This position was maintained until the ultimate tensile load. After failure, any surface cracks on the concrete specimen were marked with a marker. As for the samples where the bar experienced 
slippage, they were placed aside and later cut in half to permit a visual review of the slippage within the concrete specimen.

After each failure, the type of bond failure was recorded and photos were taken. After every completed test, the bond failure mode was visually inspected and recorded.

\subsection{Specimen Notations}

The specimens were labeled with ascending letters and numbers that represented the varying embedment lengths and the different cover lengths. For the sake of simplicity and future referencing in the report, the specimens were labeled with the same notation format as presented in the tables in the Appendix. For example, for the specimen notation of S5-C-64-SCHOCK:

- The letter S, represents the GFRP bar's straight end

- The number 5, represents the diameter of the GFRP bar, where " 5 " represents $15.875 \mathrm{~mm}$ for VROD and $16 \mathrm{~mm}$ for Schöck bars and "6" represents $19.05 \mathrm{~mm}$ for V-ROD and $20 \mathrm{~mm}$ for Schöck bars.

- C, represents the bar position, which is placed concentrically

- " 64 " in the third position represents the embedment length 


\section{Chapter 4: Experimental Results and Analysis}

\subsection{Introduction}

This chapter presents the pullout test results attained from the experiments on GFRP bars embedded in high-performance concrete blocks. The effects of a few parameters on the bond properties of GFRP are also discussed in this section. For the specimens with the straight-end GFRP bars, four parameters are analyzed to evaluate their influences on the bond strength, namely: bar size, type of bar surface, concrete cover to the bar and bar embedment length. As for the sand-coated specimens with anchorage heads, the effects of bar size, concrete cover to the bar and bar embedment length on the bond strength is presented. Bond-slip relationships are presented to elaborate on the bond properties. In the final sections, the experimental development length is determined and is compared with the minimum required development length provided by design codes.

\subsection{Pullout Test Specimen Results}

In total, 145 specimens with straight-end GFRP bars, both sand-coated and ribbed-surfaced, and 45 sand-coated specimens with an anchorage head, were cast and tested to failure. For the specimens with straight-end GFRP bars, four modes of bond failure occurred. For the sand-coated specimens with the anchorage heads, two modes of bond failure and three types of anchorage head damage were experienced. The modes of bond failure are separated into subsections for the specimens with straightend and with headed end. Table A in Appendix A summarizes the failure modes, pullout force and calculated bon stress for all tested specimens.

\subsubsection{Pullout Test Specimen Results for Straight-End GFRP bars}

Test results showed that GFRP bars located at the center of the concrete blocks experienced two failure modes, namely: pure bar pullout of concrete (BP) and bar slippage followed by concrete block splitting (BS-CS). Figure 4.1 shows the photos of these failure modes after testing. Most of the specimens experienced concrete splitting after initial bar slip, which is an indication of adequate bond between the GFRP bar and the surrounding concrete inside the specimen. For example, specimens with the bar positioned concentrically with a diameter of $20 \mathrm{~mm}$ and embedment length of $6 d_{b}, \mathrm{~S} 6-\mathrm{C}-114-\mathrm{V}$, experienced a bar pullout initially and the pullout load swiftly dropped to $0 \mathrm{kN}$. When loaded again, the load reached to a value $10 \%$ lower than the first applied load and was able to sustain this load for a short period of time before concrete splitting failure occurred. 

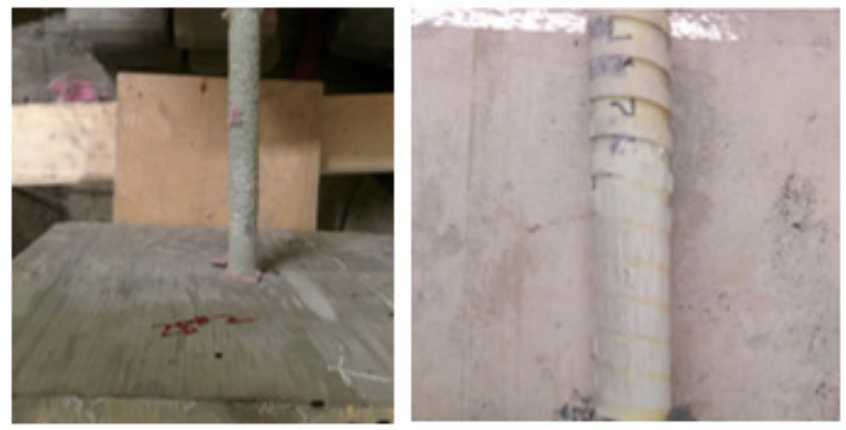

a) Pure Bar Pullout Failure (BP)

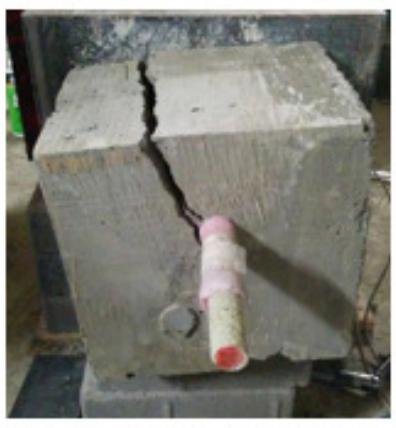

b) Bar Slippage followed by Concrete Block Splitting (BS-CS)

Figure 4.1: Failure Modes for Concrete Blocks with Concentric GFRP Bar

For concrete blocks with concentrically positioned GFRP ribbed-surface bar of $16 \mathrm{~mm}$ diameter, concrete blocks with embedment length of $4 \mathrm{~d}_{\mathrm{b}}$ experienced pure bar pullout failure, whereas specimens with embedment length of $6 \mathrm{~d}_{\mathrm{b}}$ and $8 \mathrm{~d}_{\mathrm{b}}$ experienced bar slippage followed by concrete block splitting. The specimens that experienced pure bar pullout failure required the most time to reach to its ultimate load. Once the ultimate load was reached, the load immediately drops to zero due to the shearing of the ribs and the core bar as depicted in Figure 4.1(a). Specimens of embedment length of $4 \mathrm{~d}_{\mathrm{b}}$ and $8 \mathrm{~d}_{\mathrm{b}}$ for sand-coated GFRP bars failed due to bar slippage, followed by concrete splitting (BS-CS) as depicted in Figure 4.1(b), except one specimen with $4 d_{b}$ embedment length as depicted in Table A-1a. For specimens with embedment length of $6 d_{b}$, pure bar pullout occurred at failure (BP) with shear failure at the interface between the sand-coating and the core diameter of the bar which can be seen in Figure 4.1(a). As for the 20-mm diameter bars, results reported in Table A-1b showed that specimens with different embedment lengths for the ribbed-surface and sand-coated bars failed due to bar slippage followed by concrete splitting. The only exception was the case of embedment length of $4 d_{b}$ for the ribbed-surface bar on which the failure mode was pure bar pullout. 

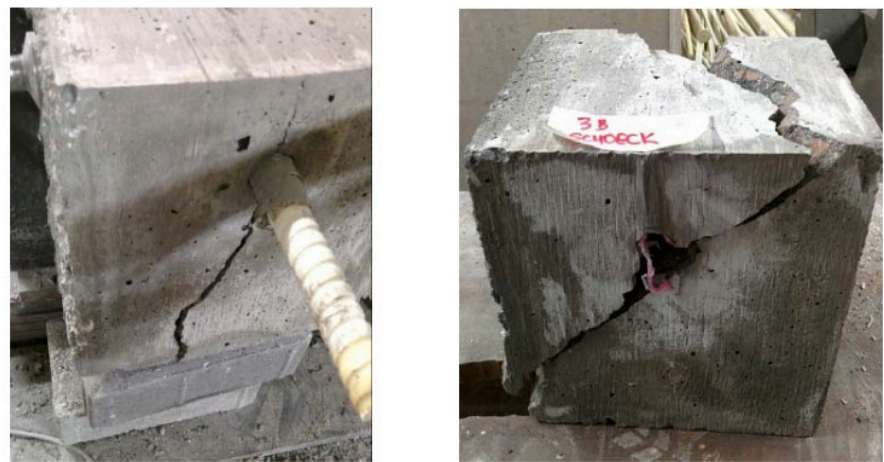

a) Bar Slippage followed by Diagonal Concrete Crack (BS-DCC)
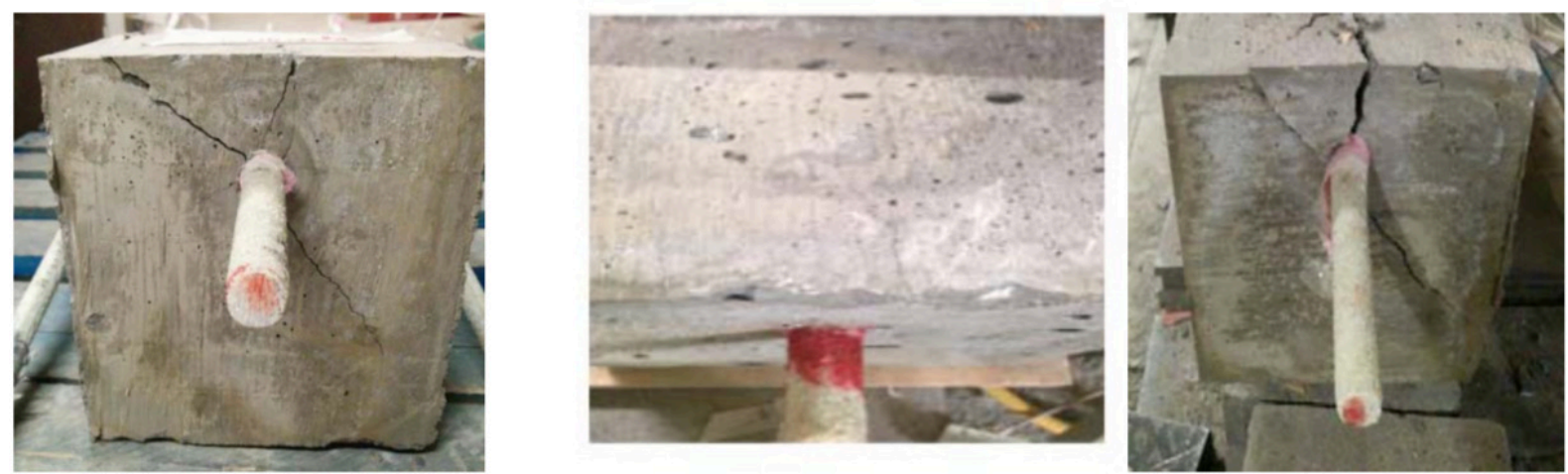

b) Bar Slippage followed by V-notch Concrete Cover Crack (BS-VCCC)
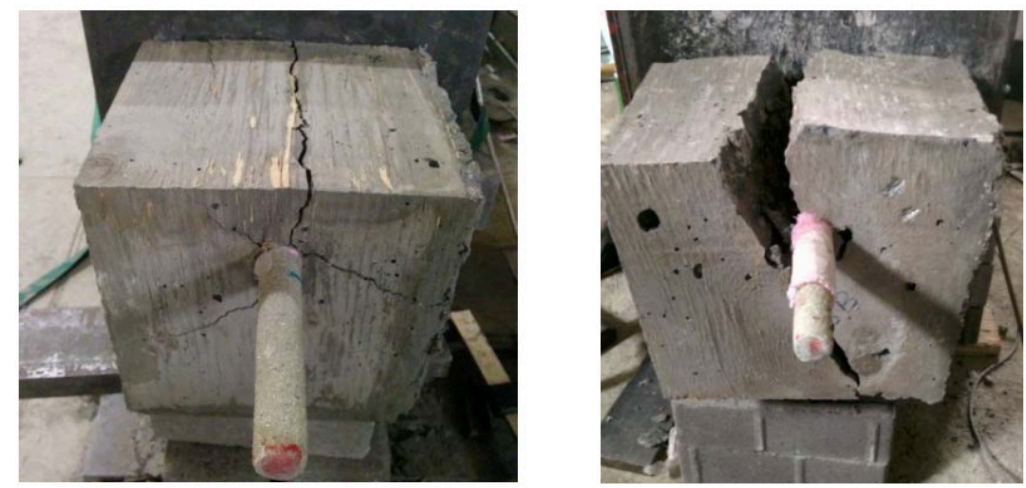

c) Bar Slippage followed by Side Concrete Cover Crack (BS-SCCC)

Figure 4.2: Failure Modes for Concrete Blocks with $40 \mathrm{~mm}$ Eccentric GFRP Bars 


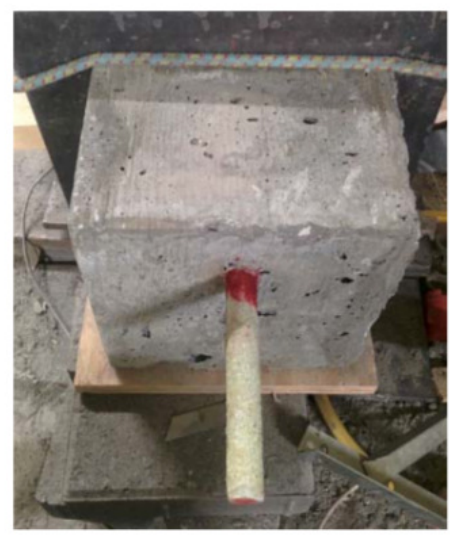

a) Pure Bar Pullout Failure (BP)
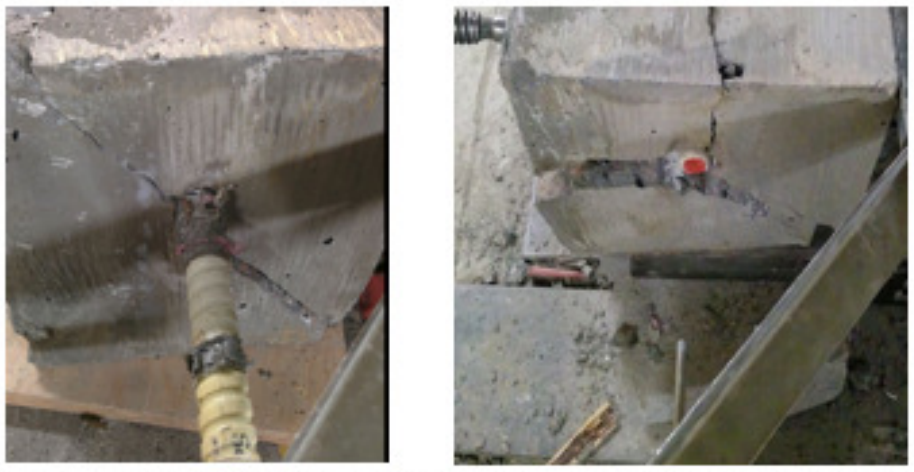

b) Bar Slippage followed by Diagonal Concrete Crack (BS-DCC)

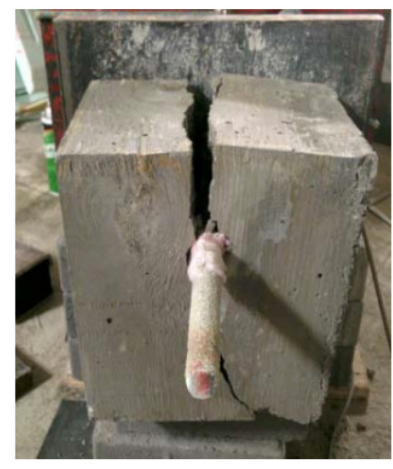

c) Bar Slippage followed by Side Concrete Cover Crack (BS-SCCC)

Figure 4.3: Failure Modes for Concrete Blocks with $60 \mathrm{~mm}$ Eccentric GFRP Bars 
Figures 4.2 to 4.3 demonstrate typical failure modes for concrete blocks with $40 \mathrm{~mm}$ and $60 \mathrm{~mm}$ eccentric GFRP bars. For these two groups, bar slippage followed by concrete cover crack was the dominating failure mode. Observed bar slippage (BS) followed by concrete cover crack patterns were designated herein as side concrete cover crack (BS-SCCC), v-notch concrete cover crack (BS-VCCC), and diagonal concrete cover crack (BS-DCC). During the visual inspection of these two groups of specimens, it was noted that specimens with embedment length of $4 \mathrm{~d}_{\mathrm{b}}$ of the ribbed-surface GFRP bar with $40 \mathrm{~mm}$ concrete cover and specimens with embedment length of $6 \mathrm{~d}_{\mathrm{b}}$ of the sand-coated GFRP bar with $60 \mathrm{~mm}$ concrete cover deviated from this trend by having a failure mode of pure bar pullout. Tables $4-1 \mathrm{c}$ through A-1e summarize the failure modes for each specimen with eccentric bar location.

Figures 4.4(a) and 4.4(b) show concrete splitting failure for both the ribbed-surface bar and the sand-coated bar, respectively, along with views of the bar surface along the embedment length after failure. For sand-coated bars, the surface of the bar was left bare. The sand particles and the membrane are completely stripped off as the specimen failed in concrete splitting. For majority of the ribbedsurface GFRP bars, the ribbed-surface completely stripped from the bar near the loaded end, with portion of the surface remaining intact further away from the loaded end. Comparing the two types of GFRP bars, the sand-coated surface bars experienced complete stripping of both the membrane and sand particles, whereas the ribbed-surface GFRP bars experienced partial stripping of the ribs off the surface. It was also noted that some of the ribs were sheared off, but not completely ripped off.

The sand particles on the GFRP bars are the main component that attributes to the bond behaviour between GFRP bars and the concrete. The sand particles on the bar provide frictional forces as a load is being applied to it, and provide a relatively higher surface area for the surrounding concrete to adhere to it. The bare stripping of the bar and the concrete split failure explains that there was a successful bonding mechanism between the sand particles and the surrounding concrete, which also resulted in a higher average ultimate load. However, the bond failure was very abrupt and brittle in most cases. As for the ribbed-surface bar, the successively ribbed geometry on the bar is responsible for the bond properties. The surrounding concrete fills in the trough between the rib crests to provide an interlocking mechanism. 

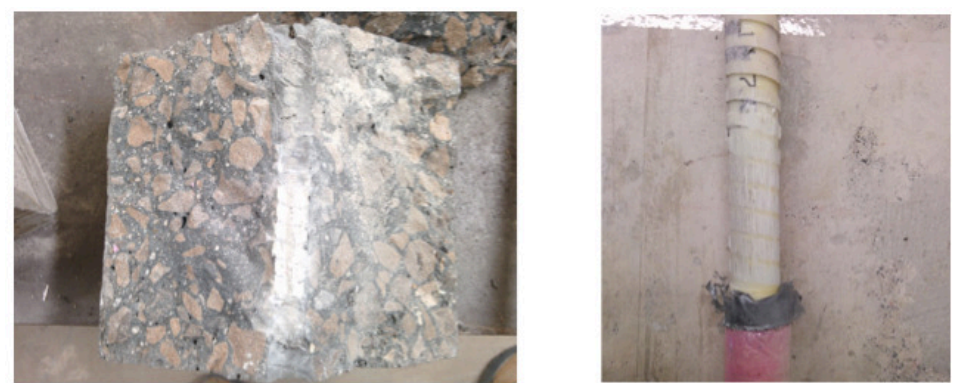

a) Results Shown on Schock ComBAR GFRP Bar
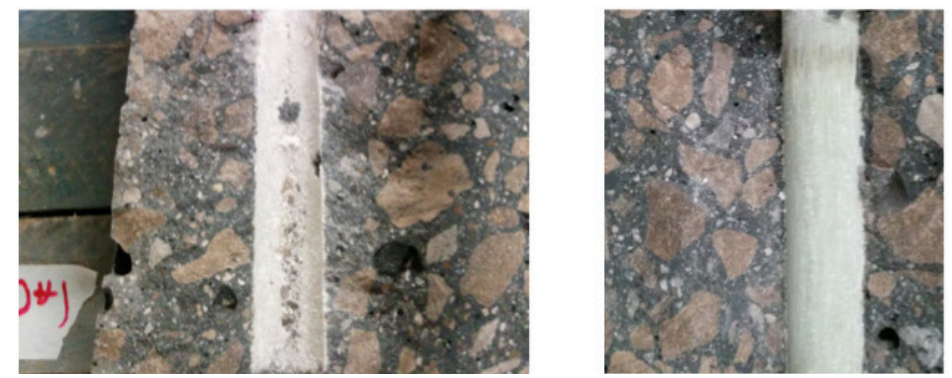

b) Results Shown on VROD GFRP Bar

Figure 4.4: Straight GFRP bar slippage followed by concrete splitting failure, showing shear failure at the rib-bar interface for ribbed and at the sand coating-bar interface in case of sand-coated bars

\subsubsection{Pullout Test Specimen Results for the Headed GFRP bars}

Figures 4.5 and 4.6 show the failure modes for concrete blocks with concentric and eccentric sand-coated GFRP bars with headed ends, respectively.

For the concrete blocks with concentrically positioned GFRP bars, the common failure mode was either bar slippage from the head (BS) or bar head breakage followed by bar slippage and concrete splitting (HB-BS-CS) as depicted in Figure 4.5. In the first stage, as the ultimate load is achieved, the anchorage head ruptures due to the wedging effect that the anchorage head produces followed by bar slippage. Then, concrete splitting occurs to the specimen. As for concrete blocks with eccentric GFRP bars, three common failure modes were noted, namely: bar slippage from the anchorage head followed by concrete splitting (BS-CS) as depicted in Figure 4.6(a), bar slippage from the anchorage head followed by a V-notch side concrete crack (BS-VSCCC) ad depicted in Figure 4.6b, and bar slippage from the anchorage head and concrete cover splitting (BS-CCS), shown in Figure 4.6c. 

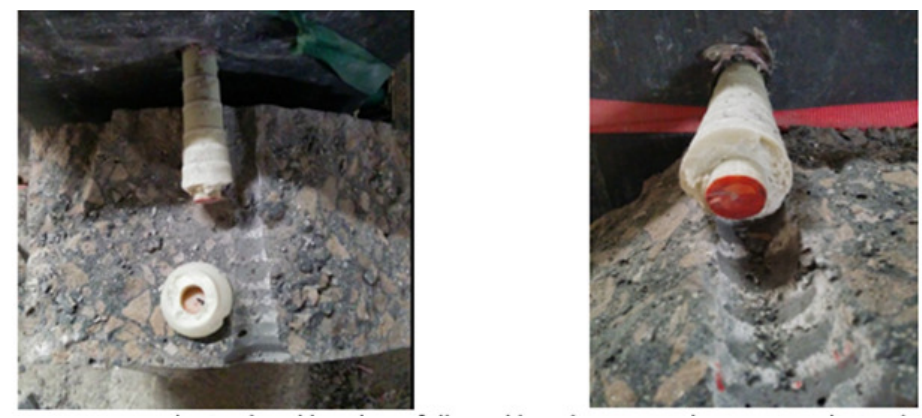

a) Bar Head Breakage followed by Bar Slippage and Concrete Splitting (HB-BS-CS)
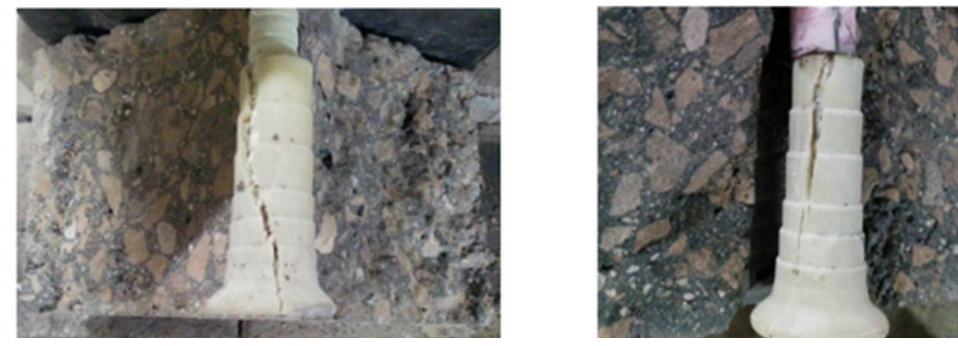

b) Bar Head Breakage through Longitudinal Crack followed by Bar Slippage and Concrete Splitting (HB-BS-CS)

\section{Figure 4.5: Failure Modes for Concrete Blocks with $60 \mathrm{~mm}$ Concentric GFRP with Sand-Coated Surface}

During the analysis of the surface condition of headed-end bars installed concentrically in the concrete block, two types of failure were observed in the bar head. The first type of failure happened when the bar head is broken at the largest desk near the bar end, as depicted in 4.5a, at a force exceeding the tensile rupture strength of the material forming the head, followed by concrete splitting. The second type of deformation is when the bar slips from the anchorage head at a force exceeding the shear strength between the bar itself and anchorage head, causing a longitudinal crack in the head, followed by concrete splitting through the entire specimen as depicted in Figure $4.5 \mathrm{~b}$. The length of the anchorage head serves a similar role as the embedment length of straight bars. Also, the anchorage head provides an additional wedging effect that allows the headed specimens to achieve similar bond strength to straight-ended specimens with longer embedment lengths. Thus, this finding confirms that the anchorage head provides adequate adhesive bond properties and is the main component to achieve the successful bond mechanism. 

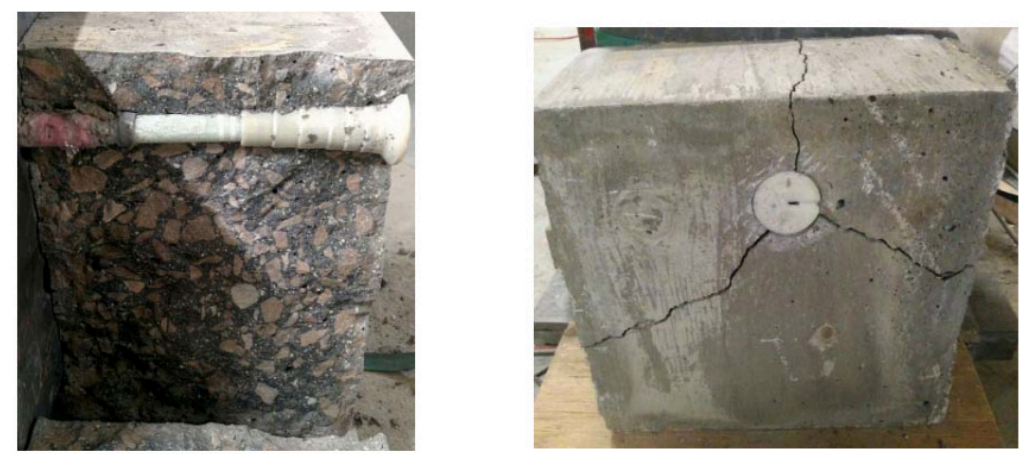

a) Bar Slippage from the Anchorage Head followed by Concrete Splitting (BS-CS)
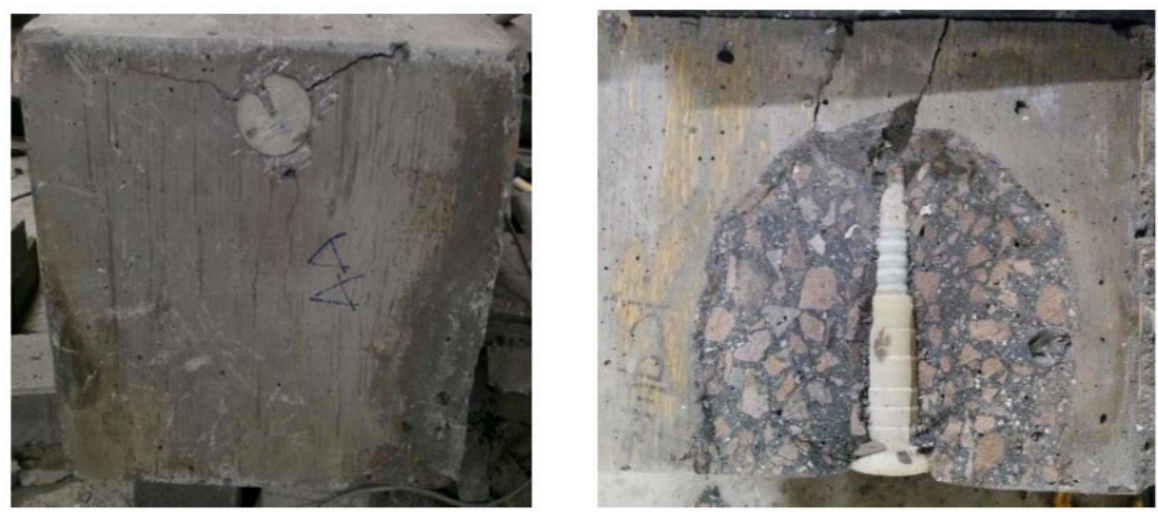

b) Bar Slippage from the Anchorage Head and V-shape Side Concrete Cover Crack in Case of Embedment Length of $76 \mathrm{~mm}$ with Bar Head in \#6 GFRP Bar (BS-VSCCC)

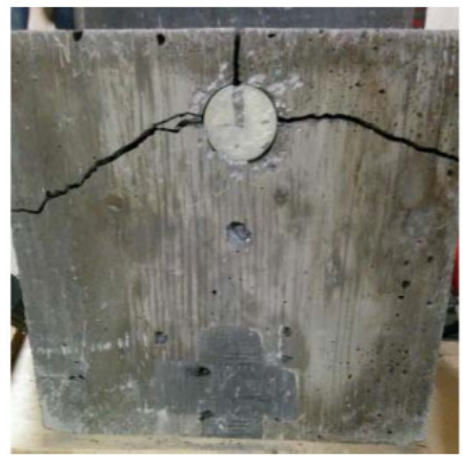

c) Bar Slippage from the Anchorage Head and Concrete Cover Splitting in Case of Zero Embedment Length with Bar Head in \#6 GFRP Bar (BS-CCS)

Figure 4.6: Failure Modes for Concrete Blocks with $60 \mathrm{~mm}$ Eccentric GFRP with Sand-Coated Surface and Headed End 
During the analysis of the surface condition of headed-end bars installed eccentrically in the concrete block, three types of failure were observed in the bar head. The first type of failure is depicted in Figure 4.6 on which the bar slips from the head followed by concrete splitting. The left image in Figure 4.6a shows the portion of the bar to the right of head slipped off the head as identified by the appearance of O-rings introduced to the bar by the manufacturer to provide bond between the bar core and the cast head. Also, the image shows that the straight portion of the embedment length outside the bar has the sand-coating sheared off the bar core as an indication of bar slippage. Similar observation is depicted in right image in Figure 4.6b. The second and third failure modes shown in Figures $4.6 \mathrm{~b}$ and 4.6c are identical to the first failure mode depicted in Figure 4.6a except that concrete splitting was due to V-notch side concrete cover crack and concrete cover splitting, respectively.

\subsection{Experimental Results for Straight-Ended Specimens: Effect of Controlling Parameters on Bond Stress}

Tables A-1 and A-2 in Appendix A include the recorded maximum pullout load, along with the loaded-end slip and free-end slip measurements. The fifth column in the table provides the type of failure that each specimen experienced, which were visually examined and noted after testing each specimen. From these tables, it can be seen that some values may have a large variance from the other identical specimens and it may be due to experimental errors and unexpected failure, which will be discussed in later sections. Tables A-1 and A-2 also present the recorded ultimate load for each specimen in each specimen. The bond stress reported in the last column of these tables is calculated with Equation 4.1 and is averaged with the duplicate specimens and plotted with the controlling parameters for analysis. It should be noted that some specimens failed prematurely so that there were excluded from Table A.

$\mu=\frac{T}{\pi d_{b} l_{d b}}$

Where $\mu$ is the bond stress, $T$ is the experimental failure load, $d_{b}$ is the bar diameter, and $I_{d b}$ is the bar development length. It should be noted that bar development length in case of headed-end bar is the sum of the head length and the straight portion of the bar if bonded to concrete. 


\subsubsection{Experimental Results: Effect of GFRP Bar's Surface Treatment on Ultimate Load and Bond Stress}

Results reported in Table A showed that a higher ultimate load was achieved with the bars that were sand-coated compared to those with ribbed-surface. This relationship can be explained by observing the ultimate load and the failure mode of the specimens with an embedment length of $64 \mathrm{~mm}$ diameter bar positioned concentrically (i.e. S5-C-64-Schöck \& S5-C-64-V-ROD). Figure 4.7a presents such finding through the average ultimate load of \#5 GFRP bars plotted with increasing embedment length for the concentric samples. This phenomenon can be described by the studies of Morales Arias et al. (2012), where the sand-coated surface of GFRP bars provides a larger surface area of contact for surrounding concrete to bond with when compared to ribbed-surface. Figure $4.7 \mathrm{~b}$ presents the average bond stress versus the embedment length for the same two groups of specimens. A similar trend can be seen, where the sand-coated specimens produced a relatively higher bond stress than the ribbedsurface specimens.

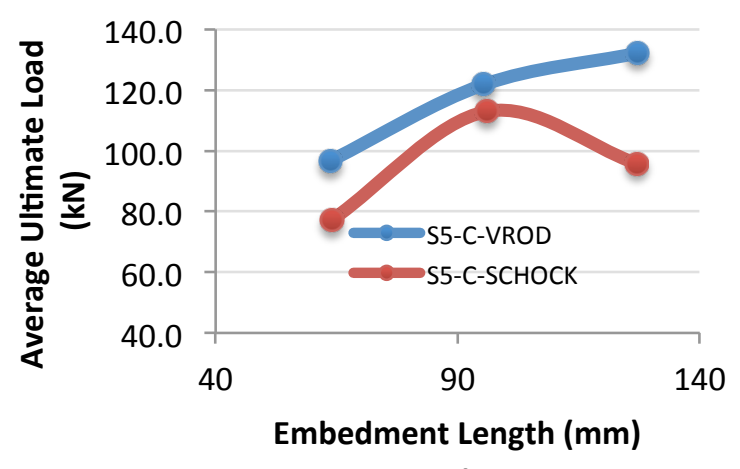

a)

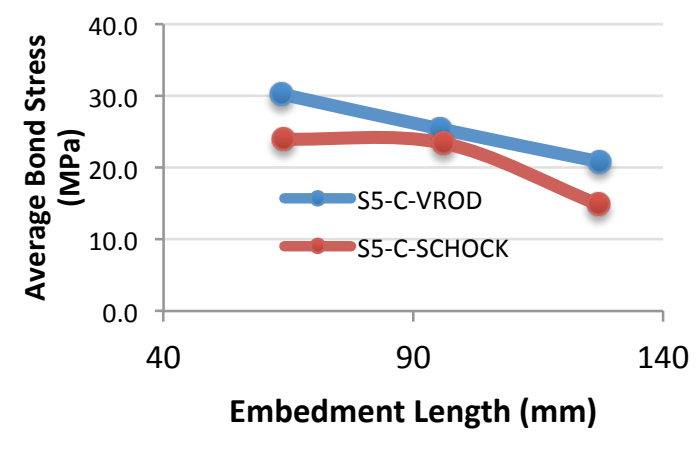

b)

Figure 4.7: Effect of Surface Treatment on a) Ultimate Load and b) Bond Stress

\subsubsection{Experimental Results: Effect of Embedment Length on Ultimate Load and Bond Stress}

As mentioned in the previous chapter, three embedment lengths of $4 d_{b}, 6 d_{b}$, and $8 d_{b}$ were implemented with straight ended GFRP bars. In Figure 4.8, the most obvious trend is the increase of average ultimate load with increase in the embedment length. However, the rate of increase in ultimate load with increase in embedment length is scattered when considering concentric or eccentric bars, irrespective of the surface type of the GFRP bars. Figure 4.9 demonstrates the effect of embedment length on the average bond stress. Overall, the trend lines demonstrate a decline of bond strength with increasing embedment length. This trend verifies the findings from researchers' experimental results, as discussed in Chapter 2. This can be explained by the non-linear distribution of bond stresses along the 
GFRP bar within the concrete when the specimen is subjected to tensile force. To compare the effect of embedment length on the average bond stress between Schöck and V-ROD specimens, reference is made to the groups of specimens with bars concentrically position with bar diameter of \#5, dark blue trend lines in Figure 4.9a and Figure 4.9b. However, this trend is altered in few samples with larger diameter (i.e. \#6 bars). This may be attributed to the type of failure that changed from one group to the other.

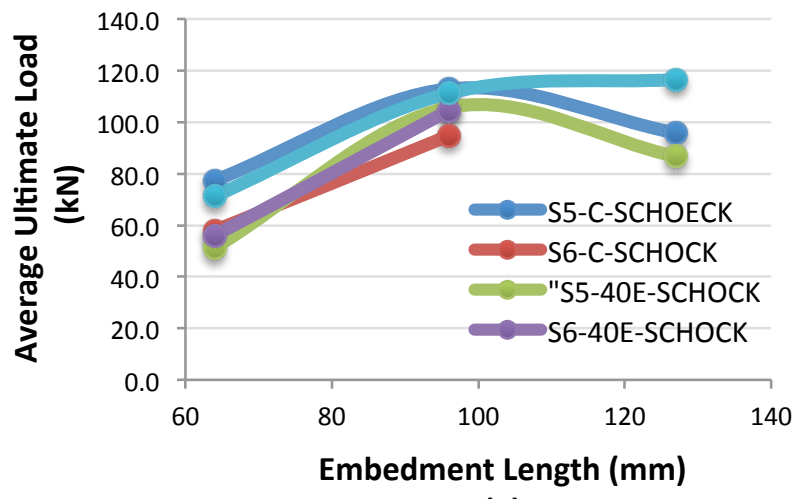

(a)

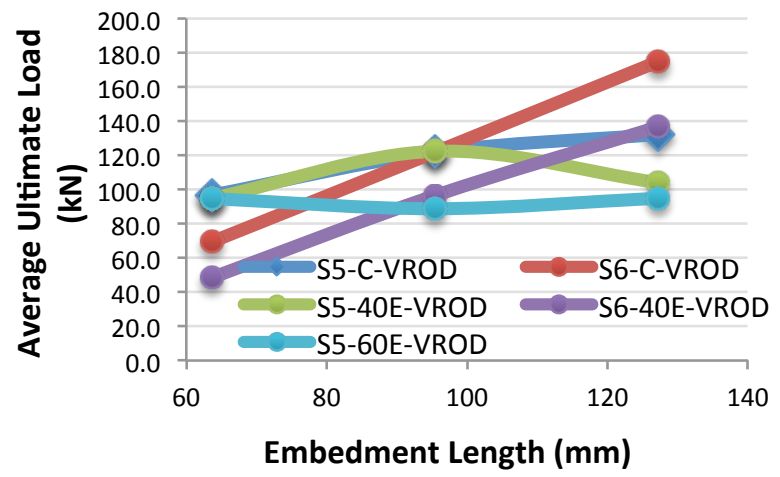

(b)

Figure 4.8: Effect of Embedment Length on Average Ultimate Load for a) Schock ComBAR Specimens and b) V-ROD Specimens

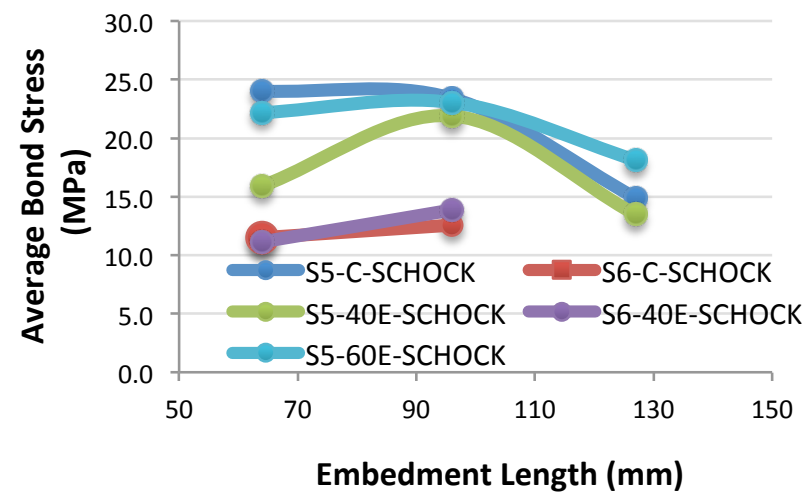

(a)

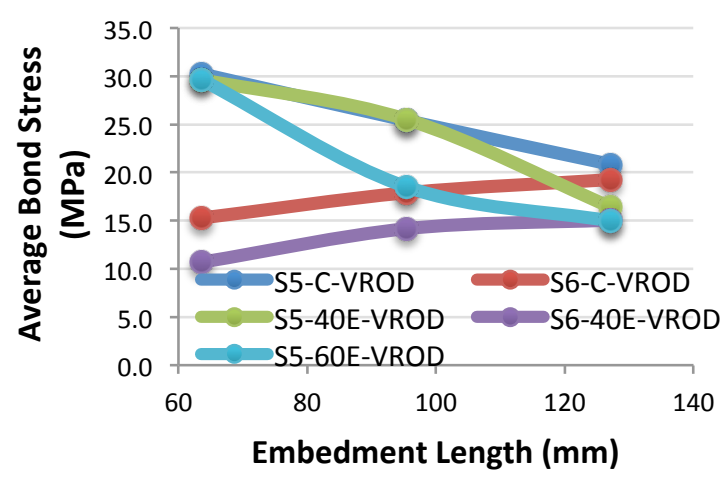

(b)

Figure 4.9: Effect of Embedment Length on Bond Stress for a) Schock ComBAR Specimens and b) VROD Specimens 


\subsubsection{Experimental Results: Effect of GFRP Bar Diameter on Ultimate Load and Bond Stress}

Figure 4.10 show the effect of bar diameter on the average ultimate load with specimens separated by the bar's surface treatment. For V-ROD specimens Figure 4.10a, the trend of the change in ultimate load with increase in bar diameter is rather scattered as half of the trend lines demonstrate an increase of average ultimate load with an increase in bar diameter, and vice versa for the other half of the specimens. Similar trend lines were produced for the group of Schöck specimens. Figure 4.11 demonstrates the relationship between the bar diameter and the bond stress. It can be seen that for both sand-coated and ribbed-surfaced specimens, lower bond strength is produced as the bar diameter increases. As presented by Baena et al. (2008), this relationship is expected to govern for all specimens with straight-end bars due to the migration of stress from the loaded end of the bar to the unloaded end, which results in a lower average bond strength. In addition, Baena et al. (2008) explained the increase of Poisson effect is more pronounced with increasing bar diameter.

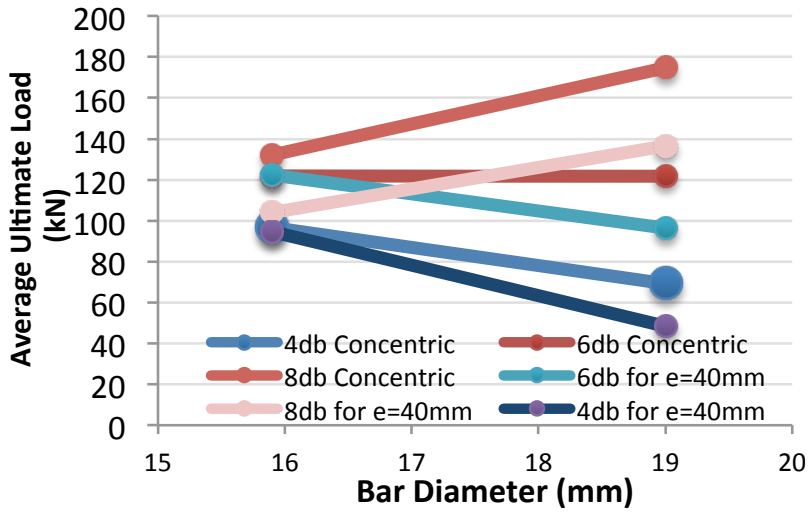

(a)

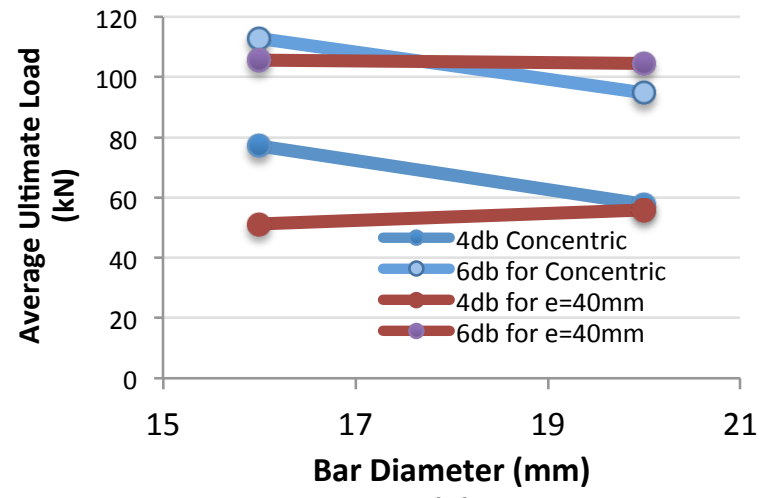

(b)

Figure 4.10: Effect of Bar Diameter on Average Ultimate Load for a) VROD Specimens and b) Shock ComBAR Specimens

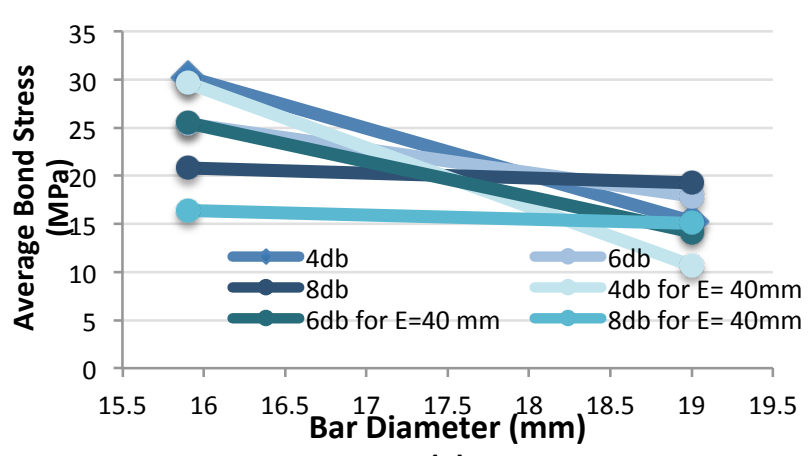

(a)

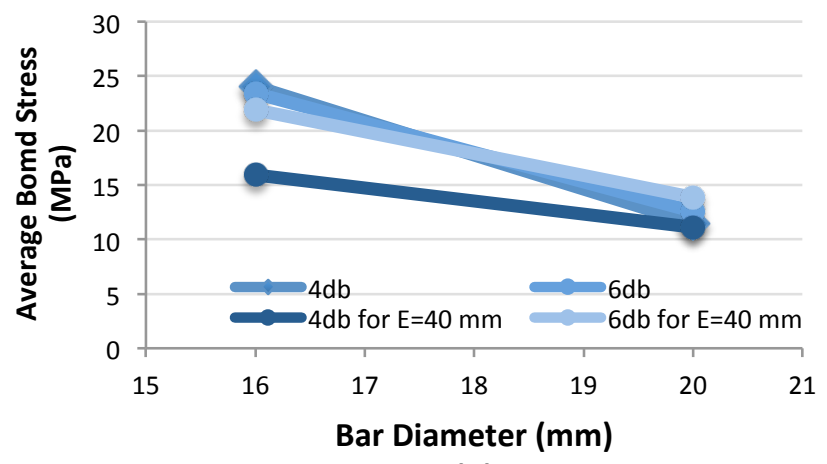

(b)

Figure 4.11: Effect of Bar Diameter on Average Bond Stress for a) Straight VROD GFRP bars and b) Straight ComBAR GFRP bar 


\subsubsection{Experimental Results: Effect of Concrete Cover on Ultimate Load}

The relationship between the concrete cover and ultimate load has been analyzed based on the concrete splitting failure of the specimens. Figures 4.12 through 4.15 illustrate the relationship between the average ultimate load, average bond stress, and concrete cover. The effect of concrete cover on the ultimate load showed scattered trend. For example, for the group of Schöck ComBAR specimens, the trend lines tend to concave downwards, demonstrating that a concrete cover of $60 \mathrm{~mm}$ provided the higher average ultimate load, which is shown in Figure 4.12a. Whereas for groups of V-ROD specimens (Figure $4.12 \mathrm{~b}$ ), the trend lines concaves upwards, indicating that a concrete cover of $60 \mathrm{~mm}$ produced a lower average ultimate load. Thus, these two graphs are not good representations of the effect of concrete cover on the average ultimate load. Although, scattered results are still depicted in the relationship between the average bond stress and concrete cover, as shown in Figures 4.14 and 4.15, some of the graphs lends towards the expected results presented by Ametrano (2011). For example, in Figure $4.14 a$, the trend lines for $4 d_{b}$ and $6 d_{b}$ converges to the findings presented by Ametrano, where the average bond stress increases with concrete cover. Similar trends can be seen in Figure $4.14 \mathrm{~b}$ and Figure 4.15b.

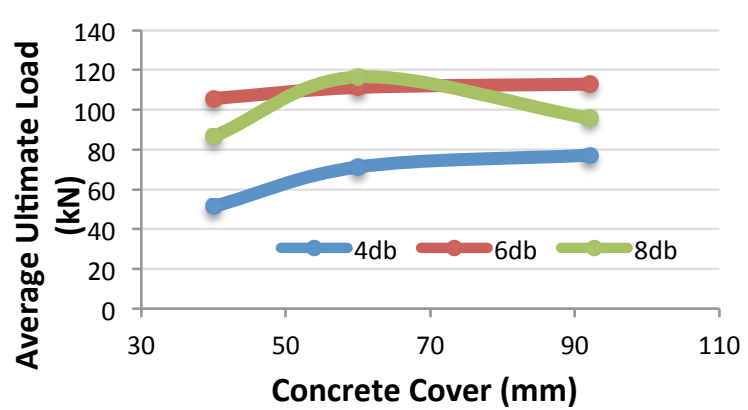

(a)

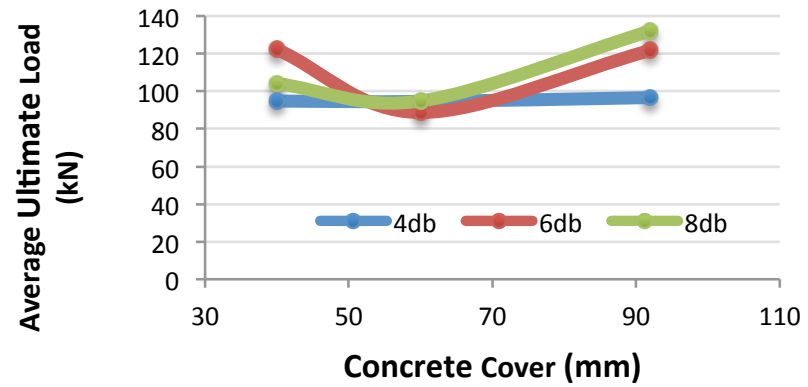

(b)

Figure 4.12: Effect of Concrete Cover on Average Ultimate Load for \#5 Bar for a) Schöck ComBAR Specimens b) VROD Specimens 


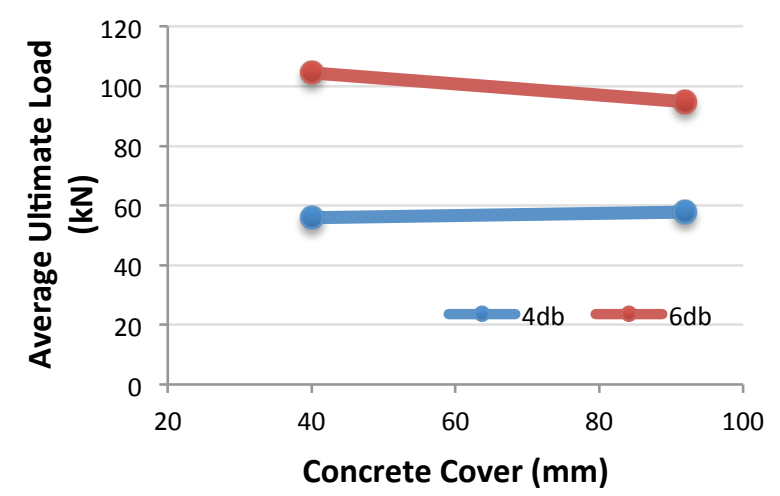

(a)

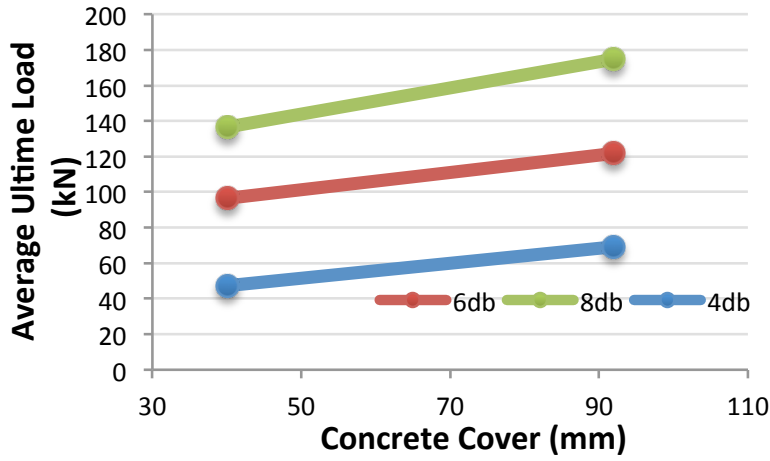

(b)

Figure 4.13: Effect of Concrete Cover on Average Ultimate Load for \#6 bar for a) Schöck ComBAR Specimens b) VROD Specimens

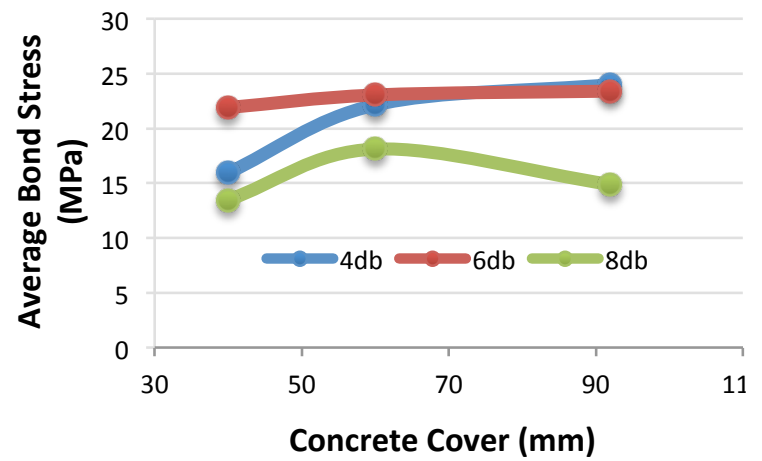

(a)

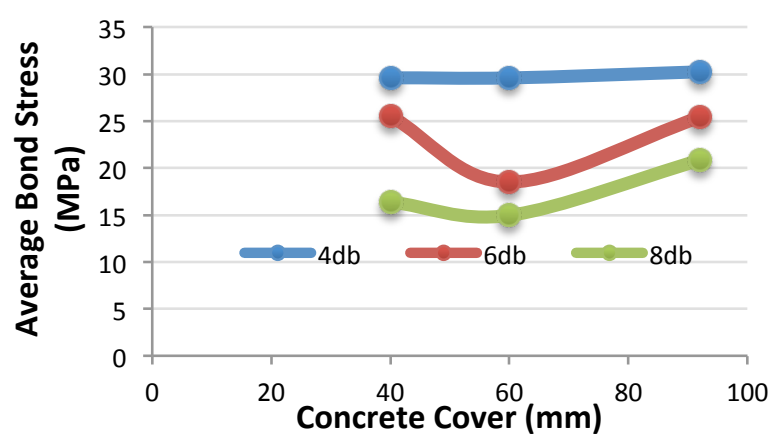

(b)

Figure 4.14: Effect of Concrete Cover on Average Bond Stress for \#5 bar a) Schöck ComBAR Specimens b) VROD Specimens

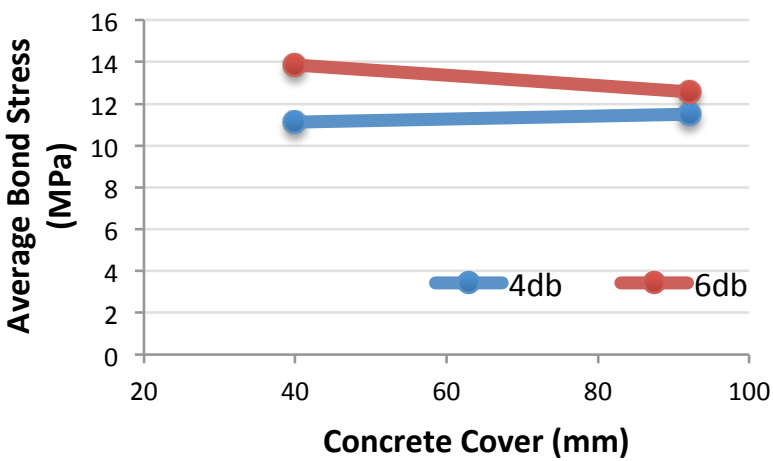

(a)

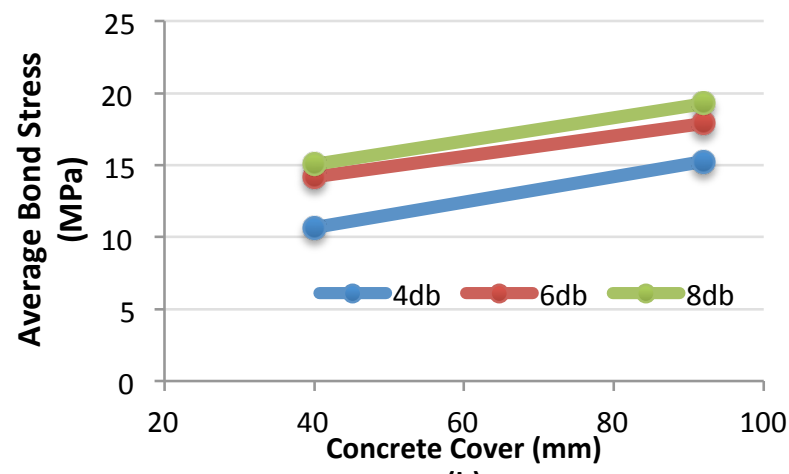

(b)

Figure 4.15: Effect of Concrete Cover on Average Bond Stress for \#6 bar for a) Schöck ComBAR Specimens b) VROD Specimens 


\subsubsection{Summary of the Variables' Influence on Ultimate Load and Bond Stress for Straight-Ended Specimens}

Through sections 4.3.1 to 4.3.4, each of the controlling variables' experimental results were analyzed to determine how it influences the average ultimate load, bond stress, and the governing failure mode. Overall, the parametric studies demonstrated good convergence towards other researchers' findings, which were discussed in the literature review. As a summary, the experimental results demonstrated the following relationships:

- Sand-coated GFRP bars (V-ROD) resulted in higher average ultimate load and bond stress relative to the ribbed-coated GFRP bars (Schöck ComBAR). This is due to the additional physical bond from the sand particles that V-ROD GFRP bars provided. However, most specimens experienced brittle and abrupt failure after ultimate pullout load was achieved.

- In general, a gradual drop in bond stress was experienced with increasing embedment length. Which is similar to the behaviour experienced in other researchers' findings, such as Firas et al. (2009).

- The effect of bar diameter on the average ultimate load produced rather scattered results and was not appropriate to generalize any sort of relationship. As for its effect on average bond stress, overall, an increase in bar diameter led to a drop in bond stress, which validates the expected behaviour of this phenomenon.

- Overall, the increase of concrete cover yielded scattered results. However, a few results did demonstrate a convergence towards expected relationship 


\subsection{Experimental Results for Headed Specimens: Effect of Controlling Parameters on Bond Stress}

Table A-2 in the Appendix includes the recorded maximum pullout load and the loaded-end slip and free-end measurements for specimens with pre-installed sand-coated GFRP bars. The effect of three controlling parameters were analyzed and related to the average ultimate load and bond stress. The three controlling parameters include the embedment length, bar diameter and concrete cover. Each of the variables are analyzed and discussed in the following sections. The bond stress is calculated with Equation 4.1 and is averaged with the duplicate specimens and plotted with the controlling parameters for analysis. There are only two embedment lengths, $0 d_{b}$ and $4 d_{b}$, installed for the specimens with the anchorage heads. In order to calculate the bond stress, the total embedment length is initially calculated. Figure 4.16 demonstrates how the total embedment length of headed bars is calculated. The total embedment length includes both the length of the anchorage head and the installed embedment length. Few specimens failed due to pure bar pullout of bar slippage followed by side concrete cover splitting were sliced at the head location to show the amount of slip of bar from the end of head. The sliced blocks are demonstrated in Figure 4.19.

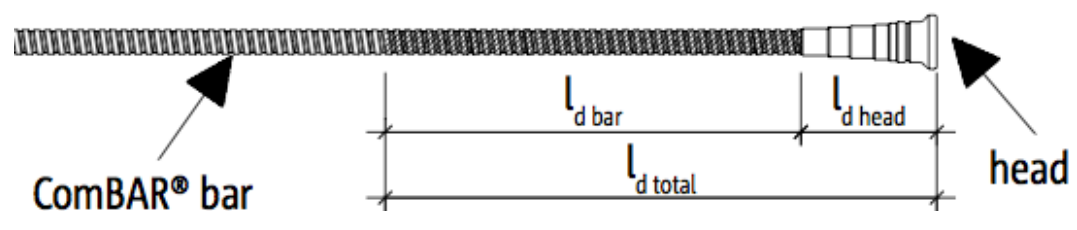

Figure 4.16: Total Embedment Length of Headed Bars ((Source: Schöck ComBAR ${ }^{\circledR}$, April 2013) $^{2}$

\subsubsection{Effect of Embedment Length on Ultimate Load and Bond Stress}

Figure 4.17a illustrates the relationship between the average ultimate load and the embedment length. By analyzing the trend lines, it can observe that the average ultimate load generally increases with an increasing embedment length. Figure $4.17 \mathrm{~b}$ demonstrates the relationship between the average bond stress and embedment length. It can be seen that bond stress decreases with increase in bar embedment length. 


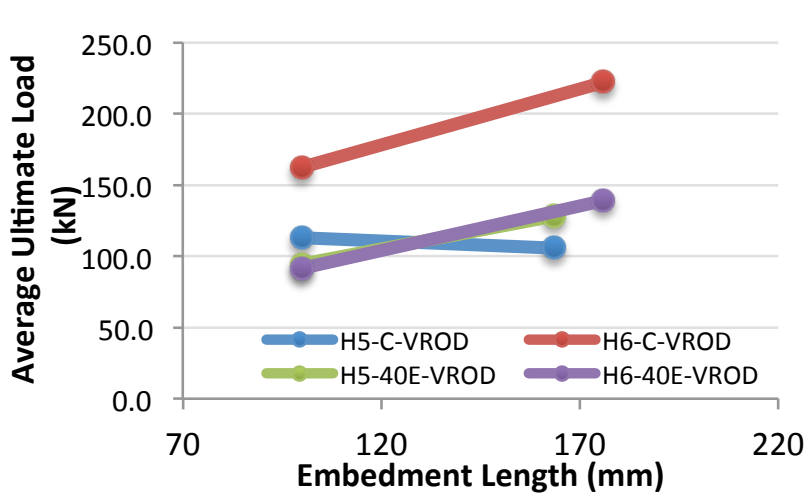

(a)

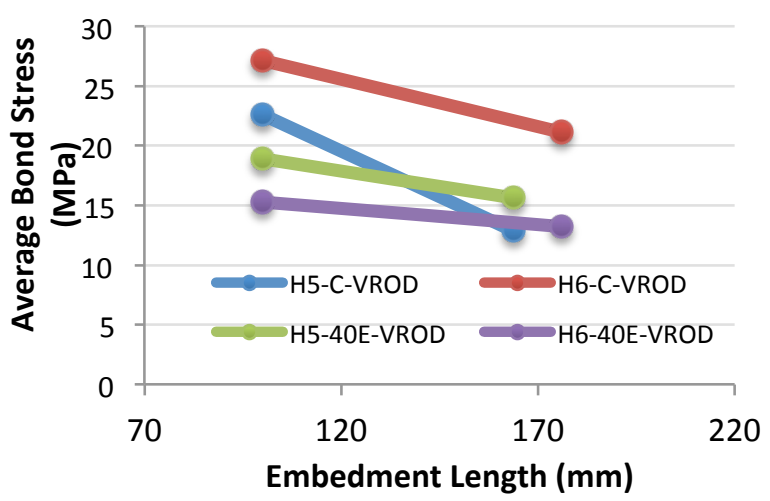

(b)

Figure 4.17: Effect of Embedment Length on a) Average Ultimate Load and b) Average Bond Stress

\subsubsection{Effect of Bar Diameter on Ultimate Load and Bond Stress}

Figures $4.18 \mathrm{a}$ and Figure $4.18 \mathrm{~b}$ demonstrate the effect of bar diameter on both the average ultimate and the average bond stress, respectively. The results are rather scattered with increase in bar diameter as a result of change in bar locations. For example, concentric samples demonstrated an increasing trend in the average ultimate load and average bond stress. As for specimens with an eccentricity of $40 \mathrm{~mm}$, a decline of both average ultimate load and bond stress is shown for increase in bar diameter.

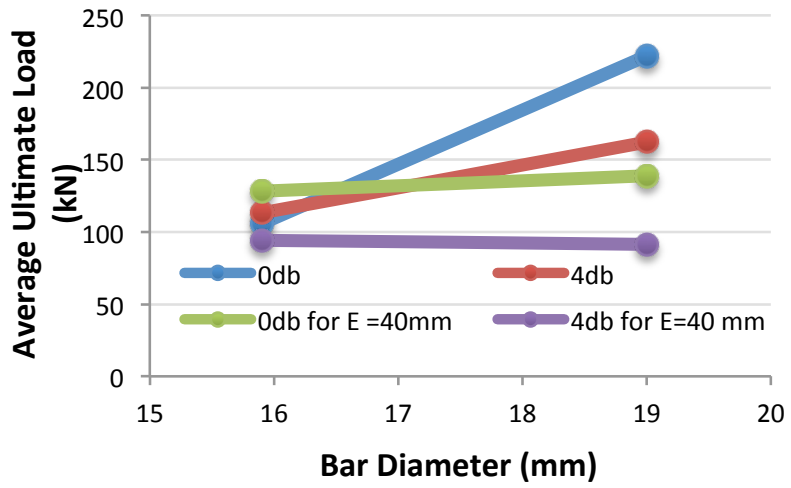

(a)

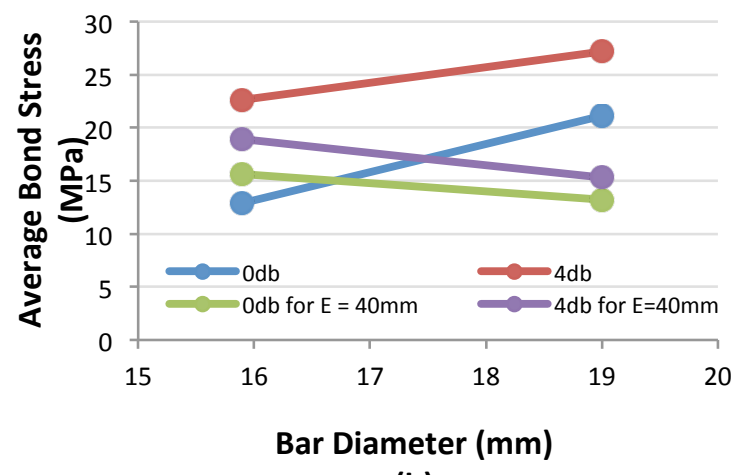

(b)

Figure 4.18: Effect of Bar Diameter on a) Average Ultimate Load and b) Average Bond Stress

\subsubsection{Effect of Concrete Cover on Ultimate Load and Bond Stress}

Figures 4.20 and 4.21 illustrate the effect of the concrete cover on the average ultimate load and average bond stress, respectively. In Figures 4.20a and 4.21a, the red trend line represents the group of specimens with the length of the anchorage head as the total embedment length, labeled as $0 d_{b}$. The blue trend line represents the group of specimens with an embedment length of $4 d_{b}$, plus the length of the anchorage head. Results show that the ultimate load decreases with increase in concrete 
cover over $60 \mathrm{~mm}$ while the trend is altered when the concrete cover is $40 \mathrm{~mm}$. This may be attributed to the mode of failure associated with each amount of concrete cover. On the other hand, Figures $4.20 \mathrm{~b}$ and $4.21 \mathrm{~b}$ show that bond stress increases with increase in concrete cover. Recall that from the studies conducted by Tighiouart et al. (1998 and 1999), for a larger bar diameter, it is more prone for bleeding of water to accumulate, creating interfacial transition zones (ITZ) around the GFRP bar that reduce its bond to the surrounding concrete. It is suggested the ITZ avoided the possible pullout of the GFRP bar from the anchorage head as less stress is accumulated on the GFRP bar and the anchorage head, and resulted in concrete splitting for the concentric specimens.

Figure 4.19 demonstrates the different concrete cover and the resulted GFRP bar slip from the anchorage head. It can easily be seen that a relatively pronounce slip exist for the concentric specimens.
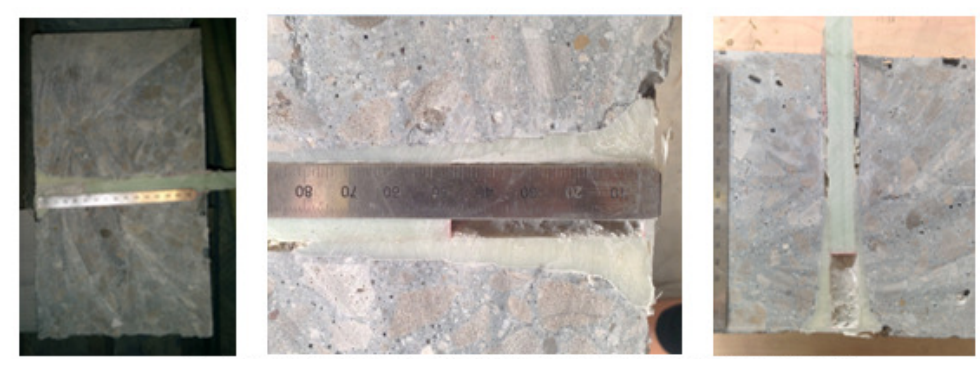

a) Bar Slip from the Head in Concrete Block with Concentric GFRP Bar
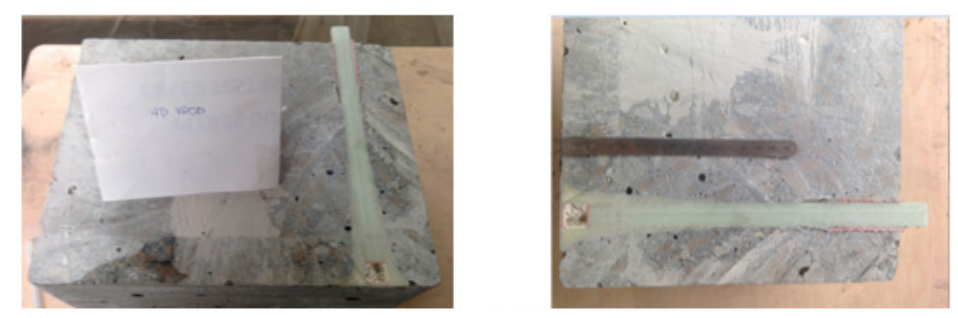

b) Bar Slip from the Head in Concrete Block with $\mathbf{4 0} \mathrm{mm}$ Concrete Cover

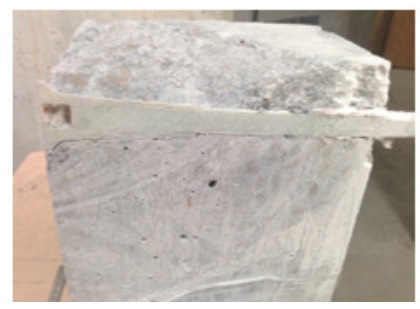

c) Bar Slip from Head and Concrete Side Splitting in Concrete Block with $40 \mathrm{~mm}$ Concrete Cover

Figure 4.19: Images of GFRP bar slip from the head after slicing the concrete block at head location 


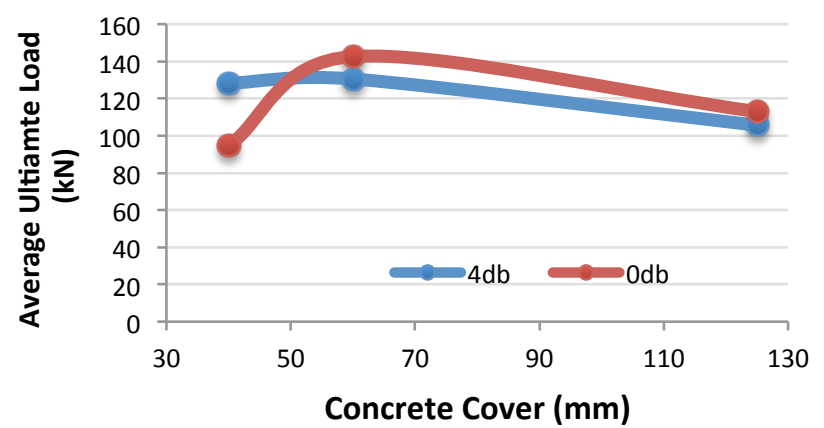

(a)

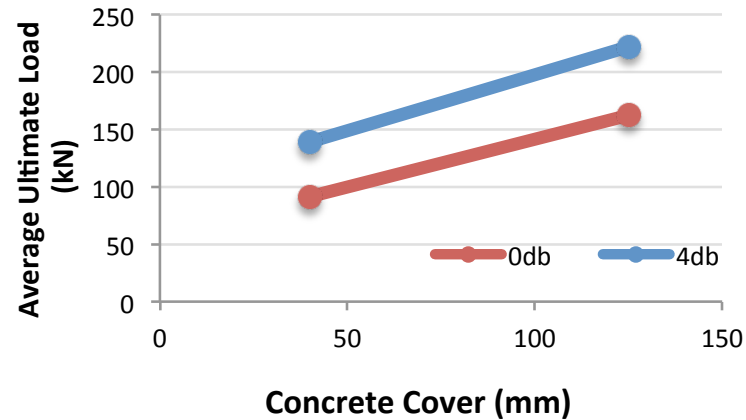

(b)

Figure 4.20: Effect of Concrete Cover on Average Ultimate Load for Specimens with a)

$$
d_{b}=15.875 \mathrm{~mm} \text { and }
$$

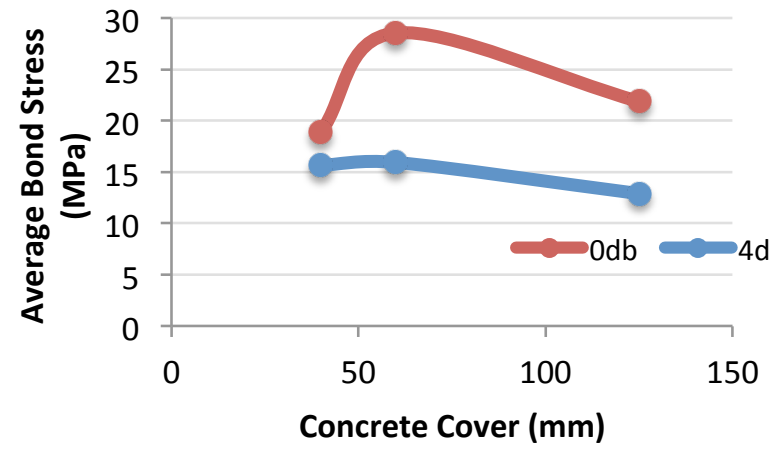

(a)

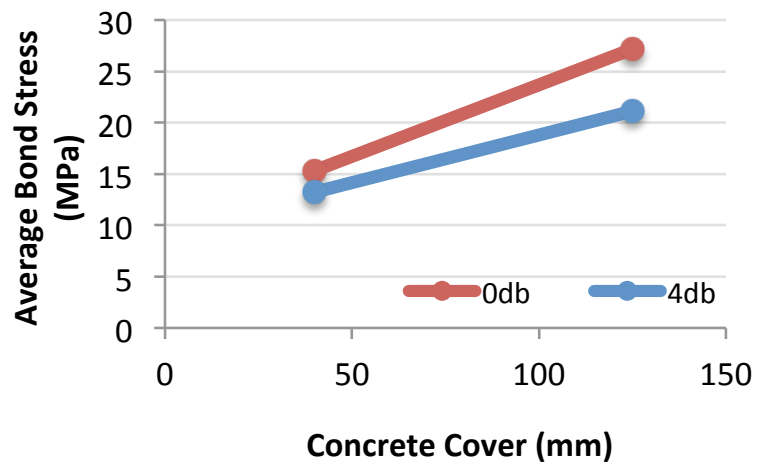

(b)

Figure 4.21: Effect of Concrete Cover on Average Bond Stress for Specimens with a) $d_{b}=15.875 \mathrm{~mm}$ and 


\subsubsection{Summary of the Variables' Influence on Ultimate Load and Bond Stress for Headed bar Specimens}

Through sections 4.4.1 to 4.2.3, each of the controlling variables' experimental results have been analyzed to determine how they influence the average ultimate load and bond stress. As a summary, the experimental results demonstrated the following relationships:

- Similar to straight-end bars, with the increase in bar embedment length, results show scattered results due to the change in failure mode. In most of the tested samples, the ultimate load increases with increase in bar embedment length. Similar observations were observed in case of the change in ultimate load and bond stress with the change in bar diameter as well as the concrete cover to the bar

- The effect of the bar diameter on average ultimate load and bond stress is rather scattered and did not converge to expected results

- Overall, higher average bond stress resulted with increasing concrete cover, which supports researchers' findings and the expected results. Also, figures demonstrated that a larger concrete cover exhibit a relatively larger bar slip within the anchorage head

\subsection{Bond Behaviour Comparison: Straight-End Versus Headed-End Specimens}

The previous two sections covered the effect of each factor on the average ultimate load and bond stress. The results have shown a few resemblances between the groups of specimens. From experimental findings, the anchorage heads can adequately be used to replace traditional exposure of the bar to achieve required embedment lengths. From Tables $A-1$ and $A-2$, it can be seen that a relatively high average ultimate load was achieved. Unlike the straight-end GFRP bars, the anchorage head provides a different bonding mechanism with the surrounding concrete. The anchorage head has an increasing diameter along the length up to the maximum exterior diameter, and it created an additional wedging effect. This allowed the headed specimens to produce higher bond strength similar to those with straight-end bars, with a significantly smaller embedment length. In terms of the bond failure, the headed-end specimens produced similar concrete splitting mechanism as the straight-end specimens. However, when these specimens failed, the surrounding concrete exploded destructively. The failures were rather brittle and destructive damages on the head portion were experienced, as shown in subsection 4.2.2. 


\subsection{Load and Slip Relationship}

The load and slip relationships for the groups of specimens are graphically shown in Figures 4.22 to 4.25. The bond strengths are plotted against the free-end slip, in millimeters, for different types of GFRP bars and embedment lengths.

The bond stress versus slip is graphed for concentric samples with increasing embedment length and the same bar diameter for both sand-coated and ribbed-surfaced specimens, and is shown in Figures $4.22 \mathrm{a}$ and $4.22 \mathrm{~b}$. It can be seen that the increase of embedment length results in a reduction of the average bond stress, which validates the expected results described in section 4.5. Thus, at the same slip value, the bond stress is less for those specimens with the larger embedment length. In Figure 4.22a, the ribbed-surface group of specimens experienced a gradual decrease of bond stress and this is due to the bar slip failure. Figure 4.22b illustrates a sudden loss of bond stress for the group of sand-coated specimens and this is due to concrete splitting bond failure. As for specimens with straight, ribbedsurfaced GFRP bars positioned with a concrete cover of $60 \mathrm{~mm}$, the relationship is represented in the graph shown in Figure 4.23. The trend lines are very similar to those in Figure $4.22 \mathrm{~b}$, also indicating that these groups of specimens have experienced a concrete splitting bond failure. For all three graphs, significantly larger slips were experienced for the specimens that experienced concrete splitting, which is due to the large movement of the LVDT behind the specimens. Some specimens even experienced explosive concrete splitting failure that caused the LVDT to detach itself from the specimens, leading to large free-end slip values.

For the headed-end specimens, a similar trend can also be seen. The specimens with just the length of the anchorage head as embedment length experienced bond stress that is larger than those with both the headed end and length of $4 d_{b}$ as the total embedment length used. This validates the analysis on the effect of embedment lengths on bond stress for headed-end bar specimens. Figures $4.24 \mathrm{a}$ and $4.24 \mathrm{~b}$ show the bond stress versus slip for sand-coated groups of specimens with a bar diameter of $15.875 \mathrm{~mm}$ and concrete covers of $125 \mathrm{~mm}$ (concentric) and $40 \mathrm{~mm}$, respectively. The trend lines in these graphs show a gradual decline of bond stress, verifying the slip of the GFRP bar from the anchorage heads. Specifically in Figure 4.24b, a gradual decrease of bond stress was followed by a sudden loss of bond stress. The trend lines that exhibit this pattern indicate a slip of the GFRP bar from the anchorage, followed by a global concrete spitting failure. Figure 4.25 illustrates more examples of groups of specimens that initially experienced bar slip from the anchorage followed by concrete splitting bond failure. 


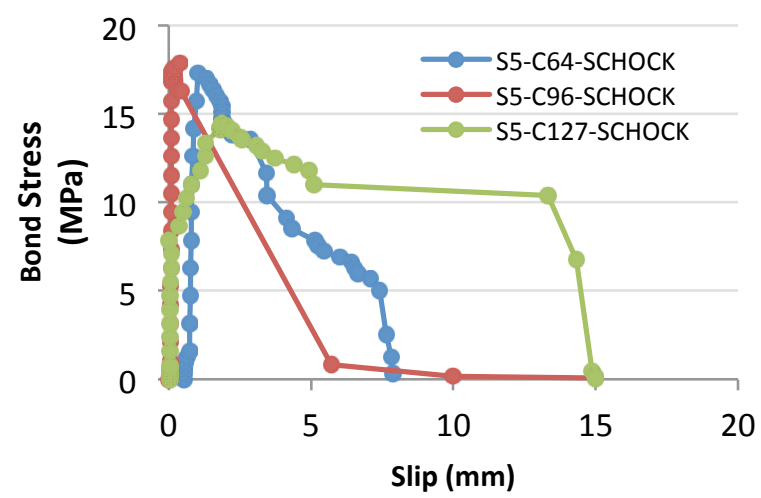

a)

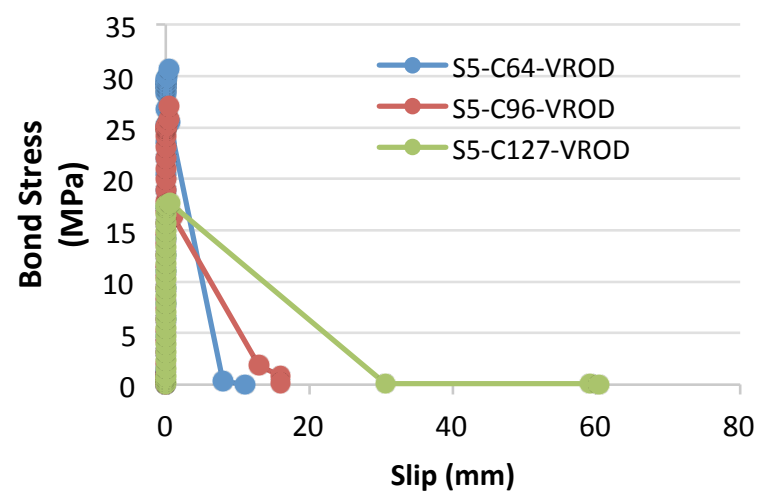

b)

Figure 4.22: Bond Stress vs. Free-End Slip for Concentric, Straight-End Specimens for a) Schöck ComBAR and b) VROD

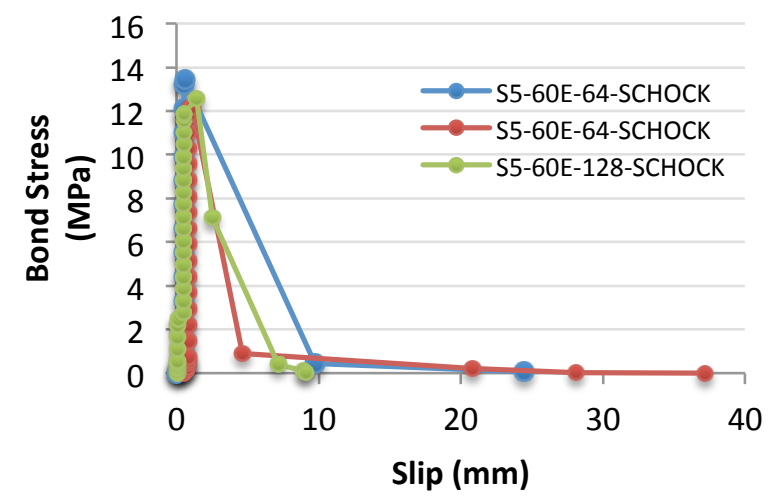

Figure 4.23: Bond Stress vs. Free-End Slip for Schöck ComBAR Specimens with Concrete Cover of $60 \mathrm{~mm}$ 


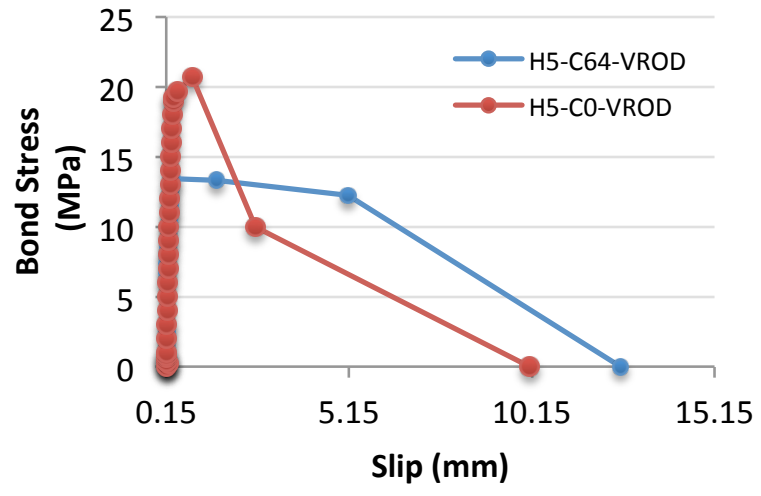

a)

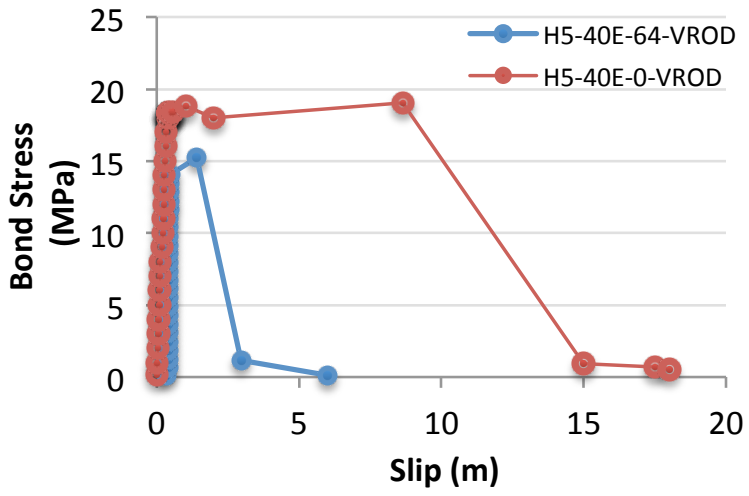

b)

Figure 4.24: Bond Stress -Slip Graph for Headed VROD Specimens with Concrete Cover of a) $125 \mathrm{~mm}$ Concentric and b) $40 \mathrm{~mm}$

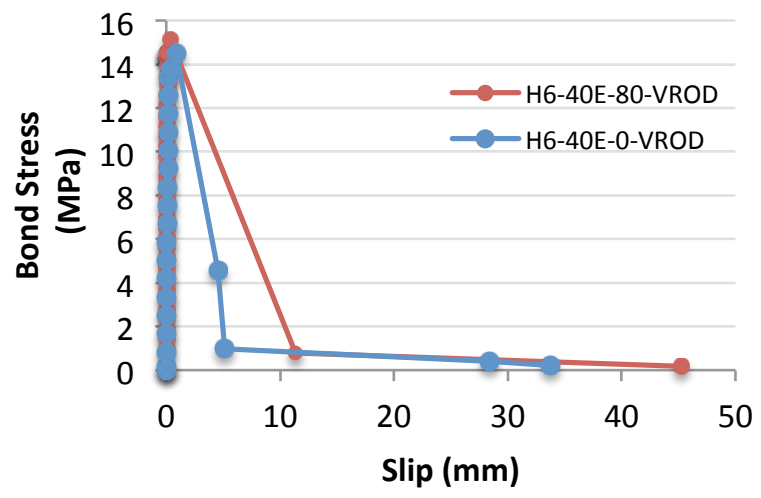

a)

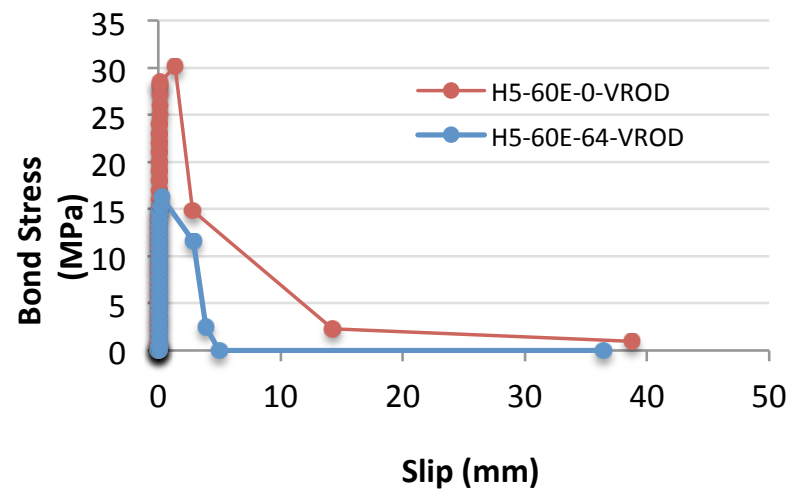

b)

Figure 4.25: Bond Stress-Slip for Headed VROD Specimens with Concrete Cover of a) $40 \mathrm{~mm}$ and b) $60 \mathrm{~mm}$ 


\section{Chapter 5: Comparative Analysis of Experimental Development Length and Code Requirements}

\subsection{Introduction}

This chapter presents the calculation of the required development lengths based on the experimental study for both sand-coated and ribbed-surface GFRP bars. From the experimental test results, bond factors are derived for both straight and headed GFRP bars, which are used to determine the basic required development length. A comparison is conducted between the development lengths derived from the experimental results and the code requirements.

\subsection{Basic Development Length}

As discussed in Chapter 2, the basic development length equation is derived based on the assumption of constant bond stress along the embedded length in the concrete subjected to a pullout force (Khederzadeh et al., 2013). The basic development length equation is calculated as follows:

$L_{d b}=\frac{C_{2} d_{b} F_{f}}{\sqrt{f_{c}^{\prime}}}$

Where $C_{2}$, bond factor constant is represented as,

$C_{2}=\frac{\sqrt{f_{c}^{\prime}}}{4 \mu}$

and $F_{f}$, is represented as,

$F_{f}=\frac{4 T}{\pi d_{b}^{2}}$

Where $T$, is the average ultimate load recorded from the experiment.

For the straight-end specimens, all results reported in Table A-1 in Appendix A were used to develop the bond factor constant, $C_{2}$, and development length, $L_{d}$, as shown in Table 5.1. For the headed -end specimens, all results reported in Table A-2 in Appendix A were used to develop the bond factor constant, $C_{2}$, and development length, $L_{d}$, as shown in Table 5.1. A linear regression analysis is conducted after the calculation of both the bond factor and development length to obtain a single, modified basic development length equation. 


\begin{tabular}{|c|c|c|c|c|c|c|}
\hline $\begin{array}{l}\text { Specimen } \\
\text { Notation }\end{array}$ & $\begin{array}{c}\text { Embedment } \\
\text { Length, } \\
L_{d b}(\mathrm{~mm})\end{array}$ & $\begin{array}{c}\text { Average } \\
\text { Ultimate } \\
\text { Load } \\
T(k N)\end{array}$ & $\begin{array}{c}\text { Average } \\
\text { Bond Stress, } \\
\mu(M P a)\end{array}$ & $\begin{array}{l}\text { Bond Factor } \\
\text { Constant, } C_{2}\end{array}$ & $F_{f},(M P a)$ & $\begin{array}{c}\text { Development } \\
\text { Length, } \\
L_{d}(\mathrm{~mm})\end{array}$ \\
\hline \multicolumn{7}{|c|}{ For Schöck ComBar } \\
\hline $\begin{array}{l}\text { S5-C64-S } \\
\text { (1A) }\end{array}$ & 64 & 77.2 & 24 & 0.093 & 383.96 & 63.99 \\
\hline $\begin{array}{c}\text { S5-C96-S } \\
\text { (1B) }\end{array}$ & 96 & 112.94 & 23.4 & 0.095 & 561.72 & 96.02 \\
\hline $\begin{array}{c}\text { S5-C128-S } \\
\text { (1C) }\end{array}$ & 128 & 95.76 & 14.9 & 0.15 & 476.27 & 127.86 \\
\hline $\begin{array}{c}\text { S6-C80-S } \\
\text { (1D) }\end{array}$ & 80 & 57.8 & 11.5 & 0.19 & 183.98 & 79.99 \\
\hline $\begin{array}{c}\text { S6-C120-S } \\
(1 \mathrm{E})\end{array}$ & 120 & 94.77 & 12.6 & 0.18 & 301.66 & 119.71 \\
\hline $\begin{array}{c}\text { S5-40E-64-S } \\
(3 \mathrm{~A})\end{array}$ & 64 & 51.25 & 15.94 & 0.14 & 254.90 & 63.96 \\
\hline $\begin{array}{c}\text { S5-40E-96-S } \\
\text { (3B) }\end{array}$ & 96 & 105.7 & 21.9 & 0.10 & 525.71 & 96.10 \\
\hline $\begin{array}{c}\text { S5-40E-128- } \\
\text { S (3C) }\end{array}$ & 128 & 86.65 & 13.5 & 0.16 & 430.96 & 127.69 \\
\hline $\begin{array}{c}\text { S5-60E-64-S } \\
(5 \mathrm{~A})\end{array}$ & 64 & 71.25 & 22.15 & 0.10 & 354.37 & 63.99 \\
\hline $\begin{array}{c}\text { S5-60E-96-S } \\
(5 B)\end{array}$ & 96 & 111.25 & 23.05 & 0.09 & 553.31 & 96.01 \\
\hline $\begin{array}{l}\text { S5-60E-128- } \\
\text { S (5C) }\end{array}$ & 128 & 116.55 & 18.11 & 0.12 & 579.67 & 128.03 \\
\hline $\begin{array}{c}\text { S6-40E-80-S } \\
\text { (3D) }\end{array}$ & 80 & 55.9 & 11.12 & 0.20 & 177.94 & 80.00 \\
\hline $\begin{array}{c}\text { S6-40E-120- } \\
\text { S (3E) }\end{array}$ & 120 & 104.56 & 13.87 & 0.16 & 332.82 & 119.98 \\
\hline \multicolumn{7}{|c|}{ For Straight VROD } \\
\hline $\begin{array}{c}\text { S5-C64-V } \\
(1 \mathrm{~A}\end{array}$ & 64 & 96.68 & 30.29 & 0.07 & 488.45 & 64.00 \\
\hline $\begin{array}{c}\text { S5-C96-V } \\
\text { (1B) }\end{array}$ & 96 & 121.8 & 25.43 & 0.09 & 615.36 & 96.04 \\
\hline $\begin{array}{c}\text { S5-C127-V } \\
(1 \mathrm{C})\end{array}$ & 127 & 132.15 & 20.86 & 0.11 & 667.65 & 127.03 \\
\hline $\begin{array}{c}\text { S6-C76-V } \\
\text { (1D }\end{array}$ & 76 & 69.2 & 15.21 & 0.15 & 242.79 & 76.02 \\
\hline $\begin{array}{c}\text { S6-C114-V } \\
(1 \mathrm{E})\end{array}$ & 114 & 121.75 & 17.85 & 0.12 & 427.16 & 113.97 \\
\hline $\begin{array}{c}\text { S6-C152-V } \\
\text { (1F) }\end{array}$ & 152 & 174.77 & 9.3 & 0.24 & 613.18 & 314.01 \\
\hline
\end{tabular}




\begin{tabular}{|c|c|c|c|c|c|c|}
\hline $\begin{array}{c}\text { S5-40E-64-V } \\
(3 \mathrm{~A})\end{array}$ & 64 & 94.75 & 29.68 & 0.07 & 478.7 & 64.01 \\
\hline $\begin{array}{c}\text { S5-40E-96-V } \\
(3 \mathrm{~B})\end{array}$ & 96 & 122.31 & 25.5 & 0.09 & 617.94 & 96.17 \\
\hline $\begin{array}{c}\text { S5-40E-127- } \\
\mathrm{V}(3 \mathrm{C})\end{array}$ & 127 & 104 & 16.4 & 0.14 & 525.43 & 127.15 \\
\hline $\begin{array}{c}\text { S6-40E-76-V } \\
(3 \mathrm{D})\end{array}$ & 76 & 48.38 & 10.64 & 0.21 & 169.74 & 75.98 \\
\hline $\begin{array}{c}\text { S6-40E-114- } \\
\text { V (3E) }\end{array}$ & 114 & 96.38 & 14.12 & 0.16 & 338.15 & 114.05 \\
\hline $\begin{array}{c}\text { S6-40E-160- } \\
\text { V (3F) }\end{array}$ & 152 & 136.56 & 15.1 & 0.15 & 479.12 & 151.11 \\
\hline $\begin{array}{c}\text { S5-60E-64-V } \\
(5 \mathrm{~A})\end{array}$ & 64 & 94.6 & 29.6 & 0.08 & 477.94 & 64.08 \\
\hline $\begin{array}{c}\text { S5-60E-96-V } \\
(5 B\end{array}$ & 96 & 88.75 & 18.5 & 0.12 & 448.38 & 96.19 \\
\hline $\begin{array}{c}\text { S5-60E-127- } \\
\text { V (5C) }\end{array}$ & 127 & 94.88 & 14.98 & 0.15 & 479.36 & 127.00 \\
\hline
\end{tabular}

\begin{tabular}{|c|c|c|c|c|c|c|}
\hline $\begin{array}{l}\text { Specimen } \\
\text { Notation }\end{array}$ & $\begin{array}{c}\text { Total } \\
\text { Embedmen } \\
\text { t Length, } \\
L_{d b}(\mathrm{~mm})\end{array}$ & $\begin{array}{c}\text { Average } \\
\text { Ultimate } \\
\text { Load } T(k N)\end{array}$ & $\begin{array}{l}\text { Average } \\
\text { Bond } \\
\text { Stress, } \\
\mu(M P a)\end{array}$ & $\begin{array}{l}\text { Bond Factor } \\
\text { Constant, } C_{2}\end{array}$ & $F_{f},(M P a)$ & $\begin{array}{c}\text { Development } \\
\text { Length, } \\
L_{d}(\mathrm{~mm})\end{array}$ \\
\hline $\begin{array}{c}\text { H5-C-64-V } \\
(2 A)\end{array}$ & 100 & 113 & 22.66 & 0.10 & 570.9 & 99.99 \\
\hline $\begin{array}{c}\mathrm{H} 5-\mathrm{C}-0-\mathrm{V} \\
(2 \mathrm{~B} \\
\end{array}$ & 164 & 105.65 & 12.92 & .0170 & 533.77 & 163.96 \\
\hline $\begin{array}{c}\text { H5-40E-0-V } \\
\text { (4B) }\end{array}$ & 100 & 94.4 & 18.93 & 0.12 & 476.93 & 99.99 \\
\hline $\begin{array}{c}\text { H5-40E-64- } \\
\text { V (4A) }\end{array}$ & 164 & 128.15 & 15.67 & 0.14 & 647.44 & 163.98 \\
\hline $\begin{array}{c}\text { H5-60E-0-V } \\
\text { (5D) }\end{array}$ & 100 & 142.63 & 28.6 & 0.08 & 720.6 & 100. \\
\hline $\begin{array}{c}\text { H5-60E-64- } \\
V(5 E)\end{array}$ & 164 & 130.56 & 15.96 & 0.14 & 659.62 & 164.03 \\
\hline $\begin{array}{c}\text { H6-C-O-V } \\
\text { (2D) }\end{array}$ & 100 & 162.3 & 27.2 & 0.08 & 569.43 & 99.7 \\
\hline $\begin{array}{c}\text { H6-C-76-V } \\
\text { (2C) }\end{array}$ & 176 & 222 & 21.1 & 0.11 & 778.88 & 175.8 \\
\hline $\begin{array}{c}\text { H6-40E-0-V } \\
\text { (4D) }\end{array}$ & 100 & 91.42 & 15.28 & 0.15 & 320.75 & 99.97 \\
\hline $\begin{array}{c}\text { H6-40E-76- } \\
\text { V (4C }\end{array}$ & 176 & 138.95 & 13.2 & 0.17 & 487.5 & 175.89 \\
\hline
\end{tabular}




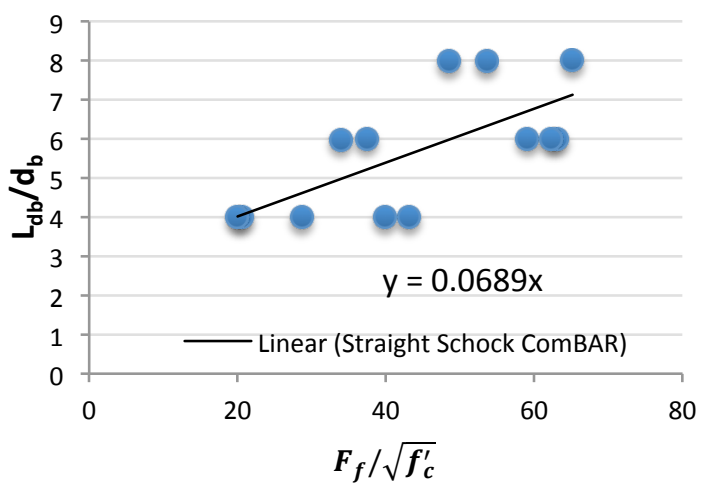

(a)

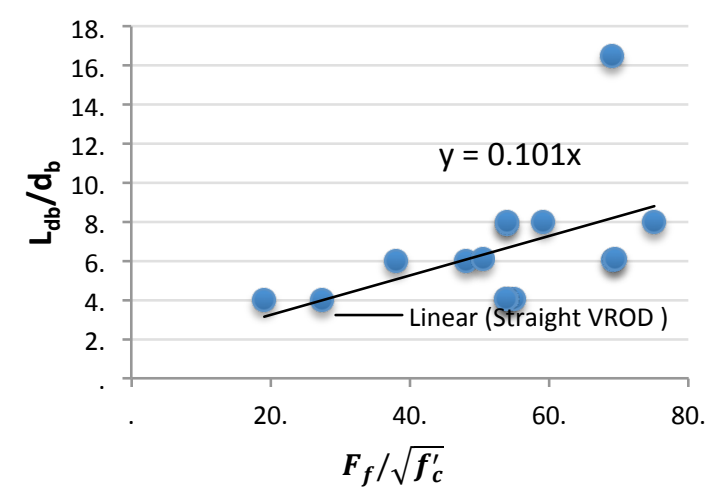

(b)

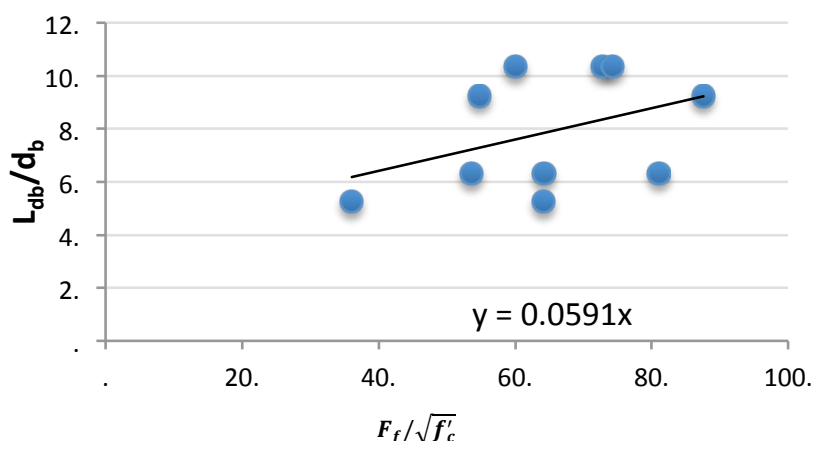

(c)

Figure 5.1: Bond Factor Coefficient, $C_{2}$, for a) Straight ComBAR Bars and b) Straight VROD Bars and c) Headed VROD Bars 
The slope on each graph represents the modified bond factor, $C_{2}$ and it is adopted for the basic development length equations of GFRP straight end and anchorage head GFRP bar as the following:

For straight-end GFRP bars with ribbed surface:

$L_{d b}=\frac{0.0689 d_{b} F_{f u}}{\sqrt{f_{c u}^{\prime}}}$

For straight-end GFRP bars with sand-coated surface:

$L_{d b}=\frac{0.101 d_{b} F_{f u}}{\sqrt{f_{c u}^{\prime}}}$

For headed-end GFRP bars with sand-coated surface:

$L_{d b}=\frac{0.0591 d_{b} F_{f u}}{\sqrt{f_{c u}^{\prime}}}$

Table 5.3 shows the experimental development length calculated with Equations 5.1, 5.2 and 5.3. The ultimate tensile strength, $F_{f}$ values are averaged out based on the values presented in Table 5.1 and Table 5.2.

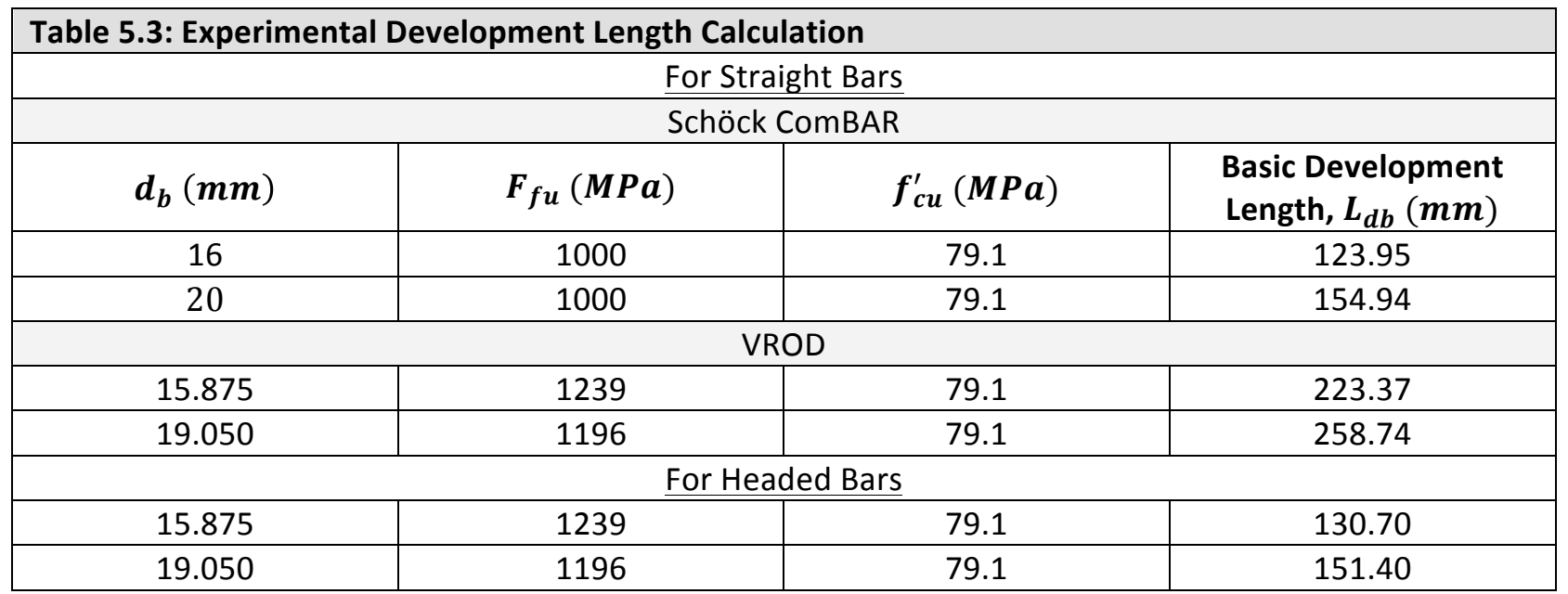




\subsection{Design Codes' Development Length}

\subsubsection{CHBDC 2006 Development Length}

The development length requirement for FRP bars provided by the 2006 CHBSC is shown in Equation 3.2 is presented below.

$l_{d}=\frac{0.45 k_{1} k_{4}}{\left[d_{c s}+K_{t r}\left(\frac{E_{F R P}}{E_{s}}\right)\right]}\left[\frac{f_{F R P u}}{f_{c r}}\right] A$

Table 5.4 includes the values for each parameter used in Equation 5.4 for each bar size and different GFRP bars used in this study.

\begin{tabular}{|c|c|c|}
\hline \multicolumn{3}{|c|}{ Table 5.4: Parameters for CHBDC Development Length Equation for Schöck ComBAR Product } \\
\hline Parameter & 16 mm GFRP Bar & $20 \mathrm{~mm}$ GFRP Bar \\
\hline$k_{1}$ & 1 & 1 \\
\hline$k_{4}$ & 1 & 1 \\
\hline$f_{f r p}(M P a)$ & 1000 & 1000 \\
\hline$A_{f r p}\left(\mathrm{~mm}^{2}\right)$ & 201.0 & 314.0 \\
\hline$d_{c s}+k_{t r}\left(\frac{E_{f r p}}{E_{s}}\right) \leq 2.5 d_{b}$ & 40.0 & 50.0 \\
\hline$f_{c r}(M P a)$ & $3.2^{*}$ & $3.2^{*}$ \\
\hline
\end{tabular}

${ }^{*} \mathrm{HPC}$ has a compressive strength of $79.1 \mathrm{MPa}$ and the maximum permissible value of $f_{c}^{\prime}$ is $64 \mathrm{MPa}$ for calculating $f_{c r}$. Thus, $f_{c r}=0.4 \sqrt{64 M P a}=3.2$

\section{Table 5.5: Parameters for CHBDC Development Length Equation for V-Rod Product}

\begin{tabular}{|c|c|c|}
\hline Parameter & $15.9 \mathrm{~mm}$ GFRP Bar & $19.1 \mathrm{~mm}$ GFRP Bar \\
\hline$k_{1}$ & 1 & 1 \\
\hline$k_{4}$ & 1 & 1 \\
\hline$f_{f r p}$ & 1239 & 1196 \\
\hline$A_{f r p}\left(\mathrm{~mm}^{2}\right)$ & 197.9 & 285.0 \\
\hline$d_{c s}+k_{t r}\left(\frac{E_{f r p}}{E_{S}}\right) \leq 2.5 d_{b}$ & 39.75 & 47.75 \\
\hline$f_{c r}(M P a)$ & $3.2^{*}$ & $3.2^{*}$ \\
\hline
\end{tabular}

*HPC has a compressive strength of $79.1 \mathrm{MPa}$ and the maximum permissible value of $f_{c}^{\prime}$ is $64 \mathrm{MPa}$ for calculating $f_{c r}$. Thus, $f_{c r}=0.4 \sqrt{64 M P a}=3.2$

As mentioned previously, $d_{c s}$ is the distance from the concrete surface to the center of the bar. However, $d_{c s}$ cannot be greater than $2.5 d_{b}$. As seen in Tables 5.4 and 5.5 , the denominator is taken as the limit. Additionally, $f_{c}^{\prime}$ used to calculate $f_{c r}$ cannot be greater than $64 \mathrm{MPa}$, which resulted in 3.2 $\mathrm{MPa}$ that was used to determine the development lengths of the specimens shown in Table 5.6. 


\begin{tabular}{|c|c|c|c|}
\hline \multicolumn{4}{|c|}{$l_{d}(m m)$} \\
\hline \multicolumn{2}{|c|}{ Schöck ComBAR } & \multicolumn{2}{|c|}{ V-Rod } \\
\hline $16 \mathrm{~mm}$ & $20 \mathrm{~mm}$ & $15.9 \mathrm{~mm}$ & $19.1 \mathrm{~mm}$ \\
\hline 706.64 & 883.13 & 867.45 & 1003.84 \\
\hline
\end{tabular}

\subsubsection{CSA S806-12 Development Length}

The development length equation for FRP bars provided by the CSA S806-12 is presented below.

$l_{d}=\frac{1.15 k_{1} k_{2} k_{3} k_{4} k_{5}}{d_{c s}+K_{t r}}\left(\frac{f_{F}}{\sqrt{f_{c}^{\prime}}}\right) A_{b}$

Similarly, $d_{c s}$ in Tables 5.7 and 5.8 shows different values from the distance from the center of the bar to the closest concrete surface and it can be seen that all values were greater than two times the bar diameter. Additionally, $\sqrt{f_{c}^{\prime}}$ cannot be greater than $8 \mathrm{MPa}$, which was taken into account when calculating the development length. As a result, the development lengths in Table 5.9 lean toward a conservative side and increase the amount of development length required.

\begin{tabular}{|c|c|c|c|c|c|c|}
\hline Table 5.7: Parameters for CSA S806-12 Development Length Equation for Schöck ComBAR Product \\
\hline Parameters & \multicolumn{3}{|c|}{$16 \mathrm{~mm}$} & \multicolumn{3}{c|}{$20 \mathrm{~mm}$} \\
\hline$k_{1}$ & 1.0 & 1.0 & 1.0 & 1.0 & 1.0 & 1.0 \\
\hline$k_{2}$ & 1.0 & 1.0 & 1.0 & 1.0 & 1.0 & 1.0 \\
\hline$k_{3}$ & 0.8 & 0.8 & 0.8 & 0.8 & 0.8 & 0.8 \\
\hline$k_{4}$ & 1.0 & 1.0 & 1.0 & 1.0 & 1.0 & 1.0 \\
\hline$k_{5}$ & 1.05 & 1.05 & 1.05 & 1.05 & 1.05 & 1.05 \\
\hline$d_{c s}+K_{t r}(m m)^{*}$ & $40^{*}$ & $40^{*}$ & $40^{*}$ & $50^{*}$ & $50^{*}$ & $50^{*}$ \\
\hline$f_{F}(M P a)$ & 1000 & 1000 & 1000 & 1000 & 1000 & 1000 \\
\hline$f_{c}^{\prime}(M P a)^{* *}$ & $2.83^{* *}$ & $2.83^{* *}$ & $2.83^{* *}$ & $2.83^{* *}$ & $2.83^{* *}$ & $2.83^{* *}$ \\
\hline$A_{b}$ & 201.0 & 201.0 & 201.0 & 314.0 & 314.0 & 314.0 \\
\hline
\end{tabular}

$* d_{c s}$ shall not be greater than $2.5 d_{b}$

$* * \sqrt{f_{c}^{\prime}}$ shall not be greater than $8 \mathrm{MPa}$ 


\begin{tabular}{|c|c|c|c|c|c|c|}
\hline Table 5.8: Parameters for CSA S806-12 Development Length Equation for V-Rod Product \\
\hline Parameters & \multicolumn{3}{|c|}{$15.9 \mathrm{~mm}$} & \multicolumn{4}{c|}{$19.1 \mathrm{~mm}$} \\
\hline$k_{1}$ & 1.0 & 1.0 & 1.0 & 1.0 & 1.0 & 1.0 \\
\hline$k_{2}$ & 1.0 & 1.0 & 1.0 & 1.0 & 1.0 & 1.0 \\
\hline$k_{3}$ & 0.8 & 0.8 & 0.8 & 0.8 & 0.8 & 0.8 \\
\hline$k_{4}$ & 1.0 & 1.0 & 1.0 & 1.0 & 1.0 & 1.0 \\
\hline$k_{5}$ & 1.0 & 1.0 & 1.0 & 1.0 & 1.0 & 1.0 \\
\hline$d_{c S}(\mathrm{~mm})$ & 39.75 & 39.75 & 39.75 & 47.75 & 47.75 & 47.75 \\
\hline$f_{F}(M P a)$ & 1239 & 1239 & 1239 & 1196 & 1196 & 1196 \\
\hline$f_{c}^{\prime}(M P a)$ & $2.83^{* *}$ & $2.83^{* *}$ & $2.83^{* *}$ & $2.83^{* *}$ & $2.83^{* *}$ & $2.83^{* *}$ \\
\hline$A_{b}$ & 197.9 & 197.9 & 197.9 & 285.0 & 285.0 & 285.0 \\
\hline
\end{tabular}

$* d_{c s}$ shall not be greater than $2.5 d_{b}$

$* * \sqrt{f_{c}^{\prime}}$ shall not be greater than $5 \mathrm{MPa}$

Table 5.9: CSA S806-12 Development Length Requirement

\begin{tabular}{|c|c|c|c|}
\hline \multicolumn{4}{|c|}{$l_{d}(m m)$} \\
\hline \multicolumn{2}{|c|}{ Schöck ComBAR } & \multicolumn{2}{|c|}{ V-Rod } \\
\hline $16 \mathrm{~mm}$ & $20 \mathrm{~mm}$ & $15.9 \mathrm{~mm}$ & $19.1 \mathrm{~mm}$ \\
\hline 1716.20 & 2144.82 & 2006.42 & 2321.91 \\
\hline
\end{tabular}

\subsubsection{Design Code Requirements}

Table 5.10 shows the comparison between the two development lengths obtained from the CSA S806-12, CHBDC 2006 and the experimental development length.

Table 5.10: Comparison of Development Length between CSA S806-12 and CHBDC 2006

\begin{tabular}{|c|c|c|c|c|c|c|}
\hline \multirow[b]{3}{*}{ Bar Diameter } & \multicolumn{4}{|c|}{ Straight-Ended Bars } & \multicolumn{2}{|c|}{ Headed Bars } \\
\hline & \multicolumn{2}{|c|}{ Schöck ComBAR } & \multicolumn{2}{|c|}{ V-Rod } & & \\
\hline & $16 \mathrm{~mm}$ & $20 \mathrm{~mm}$ & $15.875 \mathrm{~mm}$ & $19.050 \mathrm{~mm}$ & $\begin{array}{c}15.875 \\
\mathrm{~mm}\end{array}$ & $\begin{array}{c}19.050 \\
\mathrm{~mm}\end{array}$ \\
\hline $\begin{array}{l}\text { Experimental } \\
\text { Results }\end{array}$ & 123.95 & 154.94 & 223.37 & 258.74 & 130.70 & 151.40 \\
\hline CHBDC 2006 & 706.64 & 883.13 & 867.45 & 1003.84 & --- & --- \\
\hline CSA S806-12 & 1716.20 & 2144.82 & 2006.42 & 2321.91 & $\begin{array}{ll}-- \\
-\end{array}$ & --- \\
\hline
\end{tabular}

It can be seen that the experimental development lengths of the straight-end, sand-coated and ribbed-surface, GFRP bars are significantly less than the requirements provided from the design codes. Overall, CSA S806-12 produced the highest development length. This demonstrates that the design codes and provisions provide a much greater minimum requirement of development length for GFRP bars to provide an adequate level of margin of safety. 


\subsection{Experimental Errors}

There were inevitable and avoidable errors that were encountered during this research process. The inevitable errors are those in the experimental stages. Pullout tests are destructive and many specimens experienced significant concrete splitting that skewed some of the readings recorded by the LVDTs. The LVDTs were very sensitive and gave irrelevant and skewed readings when the specimen experienced concrete splitting and broken concrete pieces perturbed and made contact with the LVDTs.

Overall, the experimental results were fairly consistent and as discussed in the previous sections, the majority of the results validated other researchers' findings, which were mentioned in the literature review. As recommendations, it is preferable to have a stable and standard pullout apparatus that could potentially ease the experimental processes and procedures.

\subsection{Conclusion of Experimental Results}

The experimental results were used to analyze the four controlling variables for straight-ended specimens and the three controlling variables for the headed-end specimens that played a significant role in the bond mechanisms, properties, and bond failure modes of GFRP bars cast in HPC. The sandcoated (V-ROD) GFRP bar developed bond strengths with frictional forces, while the ribbed-surface (Schöck ComBAR) GFRP bar used mechanical interlock. It can be seen that the sand-coated GFRP bar specimens produced higher range of bond strength; however, it is accompanied by brittle and sudden failure. As for the headed-end specimens, the anchorage head provided an additional wedging effect that enabled the specimens to achieve similar bond strength as the straight-end GFRP bars achieved, but with much smaller embedment lengths. The basic experimental development lengths were determined based on the assumption that constant stress was achieved along the embedded length of the GFRP bar for all specimens. After a comparative analysis, it was determined that the minimum required development length provided by design codes and provisions resulted in a larger development length than the experimental development length, thus a fairly high discrepancy between the experimental and the theoretical development lengths was observed. 


\section{Chapter 6: Conclusions}

\subsection{General}

This research project consisted of a parametric study of the effect of the controlling variables on the bond behaviour of two different GFRP bar types cast in high-performance concrete (HPC) with a compressive strength of $79.1 \mathrm{MPa}$, and to determine the basic experimental development lengths. Pullout test was conducted during the experimental investigation, the controlling variables, including: bar diameter, concrete cover dimensions, type of GFRP bar and the surface treatment of the bar, were investigated based on the analysis of the experimental results. A comparative analysis was conducted between the experimental development length and the prescribed equations provided by both the CHBDC 200, CSA S806-. The experimental findings discuss in this report is summarized in the following conclusions:

- Two different surface-treated GFRP bars cast in HPC, namely: sand-coated (V-ROD) and ribbedsurface (Schöck ComBAR) were used in this research project. The sand-coated GFRP bars resulted in higher average bond stress and average ultimate load relative to the ribbed-surface GFRP bars as a result of the physical bond that the sand particles provided leading to an increase in frictional stresses with the bar core, compared to the bearing stress on the ribs in case of ribbed-surface bars.

- The effects of embedment length on bond strength results were similar to other researchers' findings. As the embedment length increases from $6 d_{b}$ to $8 d_{b}$, it can be seen that the bond strength decrease. This behaviour is explained by the non-uniform distribution of stress along the bar as the GFRP bar is subjected to increasing tensile forces. As for the headed-end bar specimens, scattered data showed uneven trend as a result of the head breakage and bar slippage from the head.

- For most of the specimens with pre-installed straight-end GFRP bars, the increase in bar diameter was accompanied by a decrease in the bond strength. It was established that an increase of bar diameter, decreases the bond strength due to Poisson effect as discussed in the research done by Firas et al. (2009). As for the headed-end bar specimens, scattered data showed uneven trend as a result of the head breakage and bar slippage from the head.

- For the straight-end specimens, experimental results showed a slight increase in bond strength as the concrete cover increases from 40 to $60 \mathrm{~mm}$. It was expected that specimens with GFRP bars pre-installed concentrically would produce higher bond strength; however, there were few 
cases where this was not the case and resulted in minor scattered plots. As for the headed-end bar specimens, scattered data showed uneven trend as a result of the head breakage and bar slippage from the head.

- The basic experimental development length was determined for all successfully tested specimens experiencing pullout bond failure or bar slippage followed by concrete splitting crack. The basic development length was determined under the assumption of constant bond stress along the embedded length in concrete subjected to a pullout force. Linear regression analysis was conducted to obtain an appropriate bond factor constant, $C_{2}$, which was incorporated in the development equation. A comparison between the experimental and design code's development length was conducted and it was concluded that the design codes and provision provide a significantly greater minimum requirement of development length for GFRP to provide an adequate level of margin of safety.

\subsection{Recommendations for Future Work}

This research has expanded our knowledge of the use of different surface-treated GFRP bars in HPC materials that can potentially be used in the joints of precast bridge decks. However, there is definitely more research in this area still required to expand the knowledge in this topic. The following are some recommendations for future research:

- Conduct beam tests to determine more reliable GFRP bar bond strength and development lengths.

- Conduct long-term creep tests on GFRP bars embedded in HPC.

- Conduct pullout tests on GFRP bars using different exposure to elements such as freeze thaw cycles of concrete and other environmental effects.

- A standardized pullout test apparatus needs to be established for future experimental research. 


\section{Bibliography}

Achillides, Z., \& Pilakoutas, K. (2004). Bond Behaviour of Fiber Reinforced Polymer Bars under Direct Pullout Conditions. Journal of Composites for Construction, 8 (2), 173-181.

ACl-440.3R-04. (2004). Guide Test Methods for Fiber- Reinforced Polymers (FRPs) for Reinfrorcing or Strengthening Concrete Structures. Farmington Hills, Michigan, USA.

ACl 440.1R-03. (2003). Guide for the Design and Construction of Concrete Reinforced with FRP Bars. Reported by ACl Committee 440, American Concrete Institute, Farmington Hills, Michigan, USA.

ACl 355.2R-04. (2004). Qualification of Post-Installed Mechanical Anchors in Concrete. American Concrete Institute, Farmington Hills, Michigan, USA.

Al-Zahrani, M., Nanni, A., \& Al-Dulaijan, S. B. (1996). Bond of FRP to concrete in reinforcement rods with axisymetric deformations. (M. El-Badry, Ed.) Proceedings of the 2nd International Conference on Advanced Composite Materials in Bridge and Structures , 853-860.

Ametrano, D. (2011). Bond Characteristics of Glass Flbre Reinforced Polymer Bars Embedded in High Strength and Ultra-HIgh Performance Concrete. Master of Applied Science, Ryerson University, Civil Engineering, Toronto.

Arias, J., Vazques, A., \& Escobar, M. (2012). Use of Sand Coating to Improve Bonding between GFRP Bars and Concrete. Journal of Composite Materials , 46 (18), 2271-2278.

Azizinamini, A. S. (1993). Bond Performance of Reinforcing Bars Embedded in High-Strength Concrete. ACl Structural Journal, 90 (5) , 826-835.

Baena , M., Torres, L., Turon, A., \& Barris, C. (2008, February). Experimental Study of Bond Behaviour between Concrete and FRP Bars Using a Pull-Out Test . Elsevier , 40 (8), 784-797.

Bisby, L. (2006). FRP Composites for Construction. ISIS Canada Educational Module No. 2, University of Manitoba, Manitoba, Canada.

CAN/CSA S6-06. (2006). Canadian Highway Bridge Design Code. Canadian Standards Association, Rexdale, Ontario, Canada.

CAN/CSA S806-02. (2002). Design and construction of building components with fibre reinforced polymers. Canadian Standards Association. Rexdale, Ontario, Canada.

Canadian Standard Association. (2000). Canadian Highway Bridge Design Code, CAN/CSA-S6-00. Toronto, Ontario, Canada.

Chaallal, O., and Benmokrane, B. (1993). Pullout and bond of glass fibre rods embedded in concrete and cement grout. Materials and Structures, 26(3), 167-175.

Cosenza, E. M. (1997). Behaviour and modelling of bond of FRP rebars to concrete. Journal of Composites for Construction, 1 (2), 40-51. 
Cosenza, E. M. (1996). Bond characteristics and anchorage length of FRP rebars. Proc., 2nd Int. Conf. on Advanced Compos. Mat. in Bridge Structures, 909-916.

Ehsani, M. R., Saadatmanesh, H., \& Tao, S. (1996). Bond Behaviour and Design Recommedations for Fiber-Glass Reinforcing Bars. Proceedings of the First International Conference on Composites in Infrastructure, 466-476.

Ehsani, M., Saadatmanesh, H., \& Tao, S. (1997). Bond Behaviour of Deformed GFRP Bar. Journal of Composite Materials, 31 (14), 1413-1430.

Firas, S., Gilles, F., \& Le Roy, R. (2009). Bond Between Carbon Fibre-Reinforced Polymer (CFRP) Bars and Ultra High Performance Fibre Reinforced Concrete (UHPFRC). Construction and Building Materials, 25(2), 479-485.

Godat, A., L'Hady, A., Chaallal, O., \& Neale, K. (2012). Bond Behaviour of the ETS FRP Bar ShearStrengthening Method. Journal of Composites for Consturction, 16(5), 529-539.

Gopalaratnam, V. S., Meyer, J., De Young, K., Belarbi, A., \& Wang, H. Steel-Free Hybrid Reinforcement System for Concrete Bridge Deck. Deptment of Civil, Architectural and Environmental Engineering, University of Missouri-Rolla,Missouri, USA.

Hanus, J. (2000). Development Length of GFRP Reinforcement in Concrete Bridge Decks. Minnesota Department of Transportation, Minnesota, USA.

Hao, Q., Wang, Y.-L., Zhang, Z.-C., \& Ou, J.P. (2007). Bond Strength Improvement of GFRP Rebars with DIfferent Rib Geometries . Journal of Zhejiang University, 8(9), 1356-1365.

ISIS Canada Research Network. (2007). Reinforcing Concrete Structures with Fibre Reinforced Polymers. ISIS Manual No. 3, University of Manitoba, Manitoba, Canada.

Larraide, J., \& Silva-Rodriguez, R. (1993). Bond and Slip of FRP Rebars in Concrete . Journal of Materials in Civil Engineering, 5 (1), 30-40.

Khederzadeh, H., \& Sennah, K. (2013). Pullout Strength of Pre-installed GFRP Bars in Concrete. CSCE General Conference, Canadian Society for Civil Engineering, Montreal, Quebec, Canada.

Kosmatka, S. H., Kerkhoff, B., \& Panarese, W. C. (2013). Design and Control of Concrete Mixtures. In S. H. Kosmatka, B. Kerkhoff, \& W. C. Panarese, High-Performance COncrete (pp. 299-314). Skokie, Illinois, USA: Portland Cement Association.Pultrall Inc. (2014). History of V-ROD. (Pultrall Inc. ) Retrieved June 14, 2014, from Pultrall Inc.: http://www.pultrall.com/en/vrod.asp.

Pultrall Inc. (2014). V-ROD Downloads. (P. Inc., Producer, \& Pultrall Inc.) Retrieved May 23, 2014, from VROD by Pultrall Inc. : http://www.vrod.ca/en/downloads.asp.

Makitani, E., Irisawa, I., \& Nishiura, N. (1993). Investigation of bond in concrete member with fiber reinforced plastic bars. (A. Nanni, \& C. Dola, Eds.) Proceedings of the International Symposium on FibreReinforced-Plastic Reinforcement for Concrete Structure, 138, 315-331. 
Mohamed, H. (2012). Pullout Capacity of V-ROD GFRP-Headed Rebars Exposed to Alkali Under Sustained Load at 60c. Research and Developmen Department, Pultrall Inc., Quebec, Canada.

Rossetti, V. G., \& Giammatteo, M. (1995). Local bond stress-slip relationships of glass fibre reinforced plastic bars embedded in concrete. Materials and Structures, 28, 340-344.

Schöck Canada Inc. (2014). Schöck Canada: Downloads. Retrieved May 3, 2014, from Schöck Canada Inc: http://www.schoeck-combar.com/comb/download-combar1?type=8\&filter=1.

Tighiouart, B., Benmokrane, B., \& Gao, D. (1998). Investigation of Bond in Concrete Member wtih Fibre Reinforced Polyer (FRP) Bars. Construction and Building Materials, 12(8), 453-462.

Tuakta, C. (2005). Use of Fiber Reinforced Polymere Composite in Bridge Structures. MEng project, Deparment of Civil and Environmental Engineering, Massachusetts Institute of Technology.

Vazquez, A., Arias, J. P., \& Escobar, M. M. (2012). Use of sand coating to improve bonding between GFRP bars and concrete. Journal of Composite Materials, 46(18), 2271-2278.

Vint, L. (2012). Investigation of Bond Properties of Glass Fibre Reinforced Polymer (GFRP) Bars in Concrete Under Direct Tenstion. M.A.Sc. Thesis, University of Toronto, Toronto, Canada.

Wambeke, B. W., and Shield, C. K. (2006). Development Length of Glass Fibre-Reinforced Polymer Bars in Concrete. ACI Structural Journal, 103(1), 11-17.

Zhang, B., Benmokrane, B., \& Chennouf, A. (2000). Prediction of Tensile Capacity of Bond Anchorages for FRP Tendons. Journal of Composites for Construction, 4(2), 39-47.

Zheng, H., \& Tian, G.-W. (2011). Probabilistic Evaluation of the Design Development Length of a GFRP Rod Pull-Out from Concrete. Engineering Structures, 33(10), 2943-2952. 
Appendix 


\begin{tabular}{|c|c|c|c|c|c|c|}
\hline $\begin{array}{l}\text { Specimen } \\
\text { Notation }\end{array}$ & $\begin{array}{l}\text { Failure Load } \\
\qquad(k N)\end{array}$ & $\begin{array}{c}\text { Free End } \\
\text { Slip (LES) } \\
(\boldsymbol{m m})\end{array}$ & $\begin{array}{l}\text { Loaded End } \\
\text { Slip }(\boldsymbol{m m})\end{array}$ & $\begin{array}{l}\text { Type of } \\
\text { Failure }\end{array}$ & $\begin{array}{c}\text { Average } \\
\text { Ultimate } \\
\text { Load }(k N)\end{array}$ & $\begin{array}{c}\text { Average } \\
\text { Bond } \\
\text { Stress } \\
(M P a)\end{array}$ \\
\hline \multirow{4}{*}{ S5-C64-S (1A) } & 69.50 & 0.30 & $\mathrm{~N} / \mathrm{A}$ & $\mathrm{BP}$ & \multirow{4}{*}{77.20} & \multirow{4}{*}{24.00} \\
\hline & 83.30 & 0.31 & 30.00 & $\mathrm{BP}$ & & \\
\hline & 75.20 & 0.34 & 19.50 & $\mathrm{BP}$ & & \\
\hline & 80.80 & 0.51 & 12.60 & $\mathrm{BP}$ & & \\
\hline \multirow{5}{*}{ S5-C96-S (1B) } & 113.00 & 0.50 & 16.60 & BS-CS & \multirow{5}{*}{112.94} & \multirow{5}{*}{23.4} \\
\hline & 113.50 & 0.79 & 16.80 & BS-CS & & \\
\hline & 122.00 & 0.21 & 25.30 & BS-CS & & \\
\hline & 116.20 & 0.39 & 29.10 & BS-CS & & \\
\hline & 100.00 & 0.39 & 10.10 & BS-CS & & \\
\hline \multirow{5}{*}{ S5-C128-S (1C) } & 92.50 & 0.22 & 19.30 & BS-CS & \multirow{5}{*}{95.76} & \multirow{5}{*}{14.9} \\
\hline & 84.50 & 0.22 & 20.40 & BS-CS & & \\
\hline & 91.80 & 1.86 & 14.90 & BS-CS & & \\
\hline & 109.00 & 0.10 & 16.50 & BS-CS & & \\
\hline & 101.00 & 1.38 & 29.40 & BS-CS & & \\
\hline \multirow{5}{*}{ S5-C64-V (1A) } & 97.80 & 0.29 & 17.30 & $\mathrm{BP}$ & \multirow{5}{*}{96.68} & \multirow{5}{*}{30.29} \\
\hline & 109.00 & 0.36 & 20.40 & BS-CS & & \\
\hline & 97.10 & 0.30 & 20.70 & BS-CS & & \\
\hline & 91.80 & 0.30 & 17.30 & BS-CS & & \\
\hline & 87.70 & 0.30 & 17.30 & BS-CS & & \\
\hline \multirow{5}{*}{ S5-C96-V (1B) } & 138.00 & 0.60 & 29.50 & $\mathrm{BP}$ & \multirow{5}{*}{121.80} & \multirow{5}{*}{25.43} \\
\hline & 120.00 & $\mathrm{~N} / \mathrm{A}$ & 20.80 & $\mathrm{BP}$ & & \\
\hline & 129.00 & 0.43 & 23.10 & $\mathrm{BP}$ & & \\
\hline & 123.00 & 0.39 & 21.40 & $\mathrm{BP}$ & & \\
\hline & 99.00 & 0.35 & 27.30 & $\mathrm{BP}$ & & \\
\hline \multirow{4}{*}{ S5-C127-V (1C) } & 151.50 & 0.29 & 21.90 & BS-CS & \multirow{4}{*}{132.15} & \multirow{4}{*}{20.86} \\
\hline & 153.80 & 0.08 & 15.30 & BS-CS & & \\
\hline & 112.30 & 0.20 & 22.20 & BS-CS & & \\
\hline & 111.00 & 0.53 & 14.90 & BS-CS & & \\
\hline
\end{tabular}

(BP): Pure bar pullout failure

(BS-CS): Bar slippage followed by concrete block splitting 


\begin{tabular}{|c|c|c|c|c|c|c|}
\hline \multicolumn{7}{|c|}{ Table A-1b: General Data for Straight Ended GFRP bars } \\
\hline $\begin{array}{l}\text { Specimen } \\
\text { Notation }\end{array}$ & $\begin{array}{l}\text { Failure Load } \\
\qquad(k N)\end{array}$ & $\begin{array}{c}\text { Free End } \\
\text { Slip (LES) } \\
(\mathrm{mm})\end{array}$ & $\begin{array}{l}\text { Loaded End } \\
\text { Slip }(\boldsymbol{m m})\end{array}$ & $\begin{array}{l}\text { Type of } \\
\text { Failure }\end{array}$ & $\begin{array}{c}\text { Average } \\
\text { Ultimate } \\
\text { Load }(k N)\end{array}$ & $\begin{array}{c}\text { Average } \\
\text { Bond Stress } \\
(M P a)\end{array}$ \\
\hline \multirow{5}{*}{ S6-C80-S (1D) } & 53.80 & 0.39 & 17.50 & $\mathrm{BP}$ & \multirow{5}{*}{57.80} & \multirow{5}{*}{11.50} \\
\hline & 59.50 & 0.03 & 19.10 & $\mathrm{BP}$ & & \\
\hline & 57.80 & 0.09 & 25.20 & $\mathrm{BP}$ & & \\
\hline & 58.70 & 0.42 & 17.50 & $\mathrm{BP}$ & & \\
\hline & 59.20 & 0.45 & 20.50 & PB & & \\
\hline \multirow{3}{*}{ S6-C120-S (1E) } & 97.30 & 0.66 & 25.20 & BS-CS & \multirow{3}{*}{94.77} & \multirow{3}{*}{12.60} \\
\hline & 71.00 & 1.32 & 17.10 & BS-CS & & \\
\hline & 116.00 & 1.08 & 16.50 & BS-CS & & \\
\hline \multirow{4}{*}{ S6-C76-V (1D) } & 81.00 & 0.09 & 16.90 & BS-CS & \multirow{4}{*}{69.20} & \multirow{4}{*}{15.21} \\
\hline & 54.50 & 0.40 & 17.90 & BS-CS & & \\
\hline & 70.80 & 0.20 & 21.00 & BS-CS & & \\
\hline & 70.50 & 0.36 & 17.40 & BS-CS & & \\
\hline \multirow{4}{*}{$\begin{array}{l}\text { S6-C114-V } \\
(1 \mathrm{E})\end{array}$} & 113.00 & 0.24 & 27.50 & BS-CS & \multirow{4}{*}{121.75} & \multirow{4}{*}{17.85} \\
\hline & 128.00 & 0.16 & 31.70 & BS-CS & & \\
\hline & 116.00 & 0.16 & 22.10 & BS-CS & & \\
\hline & 130.00 & 0.17 & 29.60 & BS-CS & & \\
\hline \multirow{4}{*}{$\begin{array}{l}\text { S6-C152-V } \\
\text { (1F) }\end{array}$} & 177.75 & 0.234 & 34.18 & BS-CS & \multirow{4}{*}{174.77} & \multirow{4}{*}{19.3} \\
\hline & 172.00 & 0.245 & 24.43 & BS-CS & & \\
\hline & 171.59 & 0.304 & 23.02 & BS-CS & & \\
\hline & 178 & 0.268 & 24.56 & BS-CS & & \\
\hline
\end{tabular}

(BP): Pure bar pullout failure

(BS-CS): Bar slippage followed by concrete block splitting 


\begin{tabular}{|c|c|c|c|c|c|c|}
\hline $\begin{array}{l}\text { Specimen } \\
\text { Notation }\end{array}$ & $\begin{array}{l}\text { Failure Load } \\
\qquad(k N)\end{array}$ & $\begin{array}{l}\text { Free End Slip } \\
\text { (LES) }(\mathrm{mm})\end{array}$ & $\begin{array}{l}\text { Loaded End } \\
\text { Slip }(\boldsymbol{m m})\end{array}$ & $\begin{array}{l}\text { Type of } \\
\text { Failure }\end{array}$ & $\begin{array}{c}\text { Average } \\
\text { Ultimate } \\
\text { Load } \\
(k N) \\
\end{array}$ & $\begin{array}{c}\text { Average } \\
\text { Bond Stress } \\
(M P a)\end{array}$ \\
\hline \multirow{4}{*}{$\begin{array}{c}S 5-40 E-64-S \\
(3 A)\end{array}$} & 64.00 & 36 & 8.00 & $\mathrm{BP}$ & \multirow{4}{*}{51.25} & \multirow{4}{*}{15.94} \\
\hline & 43.00 & 16 & 14.00 & $\mathrm{BP}$ & & \\
\hline & 48.00 & 30 & 16.00 & $\mathrm{~PB}$ & & \\
\hline & 50.00 & 5 & 16.00 & $\mathrm{BP}$ & & \\
\hline \multirow{5}{*}{$\begin{array}{c}\text { S5-40E-96-S } \\
\text { (3B) }\end{array}$} & 109.5 & 0.42 & 19.55 & BS-DCC & \multirow{5}{*}{105.70} & \multirow{5}{*}{21.9} \\
\hline & 104.75 & 0.40 & 17.39 & BS-DCC & & \\
\hline & 87.75 & 0.05 & 18.45 & BS-DCC & & \\
\hline & 105.00 & 0.36 & 20.81 & BS-DCC & & \\
\hline & 121.50 & 0.65 & 21.54 & BS-DCC & & \\
\hline \multirow{5}{*}{$\begin{array}{c}\text { S5-40E-128-S } \\
(3 \mathrm{C})\end{array}$} & 92.75 & 0.73 & 17.86 & BS-DCC & \multirow{5}{*}{86.65} & \multirow{5}{*}{13.5} \\
\hline & 85.50 & 0.16 & 19.93 & BS-DCC & & \\
\hline & 90.25 & 0.40 & 13.21 & BS-DCC & & \\
\hline & 85.25 & 0.15 & 21.86 & BS-DCC & & \\
\hline & 79.50 & 0.20 & 19.48 & BS-DCC & & \\
\hline \multirow{5}{*}{$\begin{array}{c}\text { S5-40E-64-V } \\
\text { (3A) }\end{array}$} & 93.50 & 0.28 & 15.76 & BS-DCC & \multirow{5}{*}{94.75} & \multirow{5}{*}{29.68} \\
\hline & 95.00 & 0.11 & 22.72 & BS-DCC & & \\
\hline & 105.50 & 0.13 & 22.68 & BS-DCC & & \\
\hline & 85.00 & 0.90 & 19.35 & BS-DCC & & \\
\hline & 62.50 & 1.14 & 13.60 & BS-DCC & & \\
\hline \multirow{4}{*}{$\begin{array}{c}\text { S5-40E-96-V } \\
\text { (3B) }\end{array}$} & 121.00 & 0.18 & 15.20 & BS-VCCC & \multirow{4}{*}{122.31} & \multirow{4}{*}{25.5} \\
\hline & 124.00 & 0.48 & 17.25 & BS-VCCC & & \\
\hline & 122.75 & 0.42 & 19.54 & BS-VCCC & & \\
\hline & 121.50 & 0.65 & 21.54 & BS-VCCC & & \\
\hline \multirow{4}{*}{$\begin{array}{c}\text { S5-40E-127-V } \\
\text { (3C) }\end{array}$} & 128.00 & 0.02 & 16.52 & BS-VCCC & \multirow{4}{*}{104.00} & \multirow{4}{*}{16.4} \\
\hline & 85.50 & 0.03 & 18.27 & BS-VCCC & & \\
\hline & 98.50 & 0.12 & 21.57 & BS-VCCC & & \\
\hline & 104.00 & 0.23 & 15.18 & BS-VCCC & & \\
\hline
\end{tabular}

(BP): Pure bar pullout failure

(BS-DCC): Bar slippage followed by diagonal concrete crack

(BS-VCCC): Bar slippage followed by V-shape concrete cover crack 


\begin{tabular}{|c|c|c|c|c|c|c|}
\hline $\begin{array}{l}\text { Specimen } \\
\text { Notation }\end{array}$ & $\begin{array}{l}\text { Failure Load } \\
\qquad(k N)\end{array}$ & $\begin{array}{l}\text { Free End Slip } \\
\text { (LES) }(\mathbf{m m})\end{array}$ & $\begin{array}{l}\text { Loaded } \\
\text { End Slip } \\
(\boldsymbol{m m})\end{array}$ & $\begin{array}{l}\text { Type of } \\
\text { Failure }\end{array}$ & $\begin{array}{c}\text { Average } \\
\text { Ultimate } \\
\text { Load }(k N)\end{array}$ & $\begin{array}{c}\text { Average } \\
\text { Bond Stress } \\
(M P a)\end{array}$ \\
\hline \multirow{5}{*}{$\begin{array}{c}\text { S6-40E-80-S } \\
\text { (3D) }\end{array}$} & 46.50 & 1.11 & 18.62 & BS-CS & \multirow{5}{*}{55.90} & \multirow{5}{*}{11.12} \\
\hline & 47.75 & 0.94 & 16.54 & BS-CS & & \\
\hline & 59.75 & 0.16 & 24.02 & BS-CS & & \\
\hline & 58.25 & 0.29 & 22.76 & BS-CS & & \\
\hline & 67.25 & 0.05 & 23.72 & BS-CS & & \\
\hline \multirow{4}{*}{$\begin{array}{c}\text { S6-40E-120-S } \\
\text { (3E) }\end{array}$} & 126.00 & 4.57 & 19.52 & BS-CS & \multirow{4}{*}{104.56} & \multirow{4}{*}{13.87} \\
\hline & 88.00 & 0.72 & 25.28 & BS-CS & & \\
\hline & 111.75 & 0.14 & 26.30 & BS-CS & & \\
\hline & 92.5 & 2.30 & 17.62 & BS-CS & & \\
\hline \multirow{4}{*}{$\begin{array}{c}\text { S6-40E-76-V } \\
\text { (3D) }\end{array}$} & 44.00 & 0.02 & 25.12 & BS-SCCC & \multirow{4}{*}{48.38} & \multirow{4}{*}{10.64} \\
\hline & 46.75 & 0.15 & 26.80 & BS-SCCC & & \\
\hline & 49.25 & $\mathrm{~N} / \mathrm{A}$ & 23.08 & BS-SCCC & & \\
\hline & 53.5 & 0.71 & 27.50 & BS-SCCC & & \\
\hline \multirow{4}{*}{$\begin{array}{c}\text { S6-40E-114-V } \\
\text { (3E) }\end{array}$} & 99.00 & 0.26 & 14.73 & BS-SCCC & \multirow{4}{*}{96.38} & \multirow{4}{*}{14.12} \\
\hline & 97.25 & 0.34 & 15.30 & BS-SCCC & & \\
\hline & 86.75 & 0.81 & 15.19 & BS-SCCC & & \\
\hline & 102.50 & 0.17 & 15.94 & BS-SCCC & & \\
\hline \multirow{4}{*}{$\begin{array}{c}S 6-40 E-160-V \\
\text { (3F) }\end{array}$} & 124.00 & 0.70 & 27.11 & BS-CS & \multirow{4}{*}{136.56} & \multirow{4}{*}{15.1} \\
\hline & 136.50 & 1.70 & 22.39 & BS-CS & & \\
\hline & 152.25 & 0.96 & 16.96 & BS-CS & & \\
\hline & 133.50 & 0.10 & 23.15 & BS-CS & & \\
\hline
\end{tabular}

(BP): Pure bar pullout failure

(BS-DCC): Bar slippage as a result of shear failure in the grooves in case of ribbed bars and in the sandcoating in case of sand-coated bars, followed by diagonal concrete crack

((BS-CS): Bar slippage followed by concrete block splitting BP-SCCC): Bar pullout (slippage) followed by side concrete cover crack 


\begin{tabular}{|c|c|c|c|c|c|c|}
\hline $\begin{array}{l}\text { Specimen } \\
\text { Notation }\end{array}$ & $\begin{array}{l}\text { Failure Load } \\
\qquad(k N)\end{array}$ & $\begin{array}{l}\text { Free End Slip } \\
\text { (LES) (mm) }\end{array}$ & $\begin{array}{l}\text { Loaded } \\
\text { End Slip } \\
(\boldsymbol{m m})\end{array}$ & $\begin{array}{l}\text { Type of } \\
\text { Failure }\end{array}$ & $\begin{array}{c}\text { Average } \\
\text { Ultimate } \\
\text { Load } \\
(k N)\end{array}$ & $\begin{array}{l}\text { Average } \\
\text { Bond Stress } \\
(M P a)\end{array}$ \\
\hline \multirow{5}{*}{$\begin{array}{c}\text { S5-60E-64-S } \\
(5 A)\end{array}$} & 67.25 & 0.20 & 13.91 & BS-DCC & \multirow{5}{*}{71.25} & \multirow{5}{*}{22.15} \\
\hline & 70.50 & 0.07 & 16.27 & BS-DCC & & \\
\hline & 61.00 & 0.61 & 15.24 & BS-DCC & & \\
\hline & 74.25 & 1.05 & 13.89 & BS-DCC & & \\
\hline & 83.25 & 0.15 & 15.97 & BS-DCC & & \\
\hline \multirow{5}{*}{$\begin{array}{c}\text { S5-60E-96-S } \\
(5 B)\end{array}$} & 105.25 & 0.21 & 34.77 & BS-DCC & \multirow{5}{*}{111.25} & \multirow{5}{*}{23.05} \\
\hline & 125.75 & 0.08 & 13.36 & BS-DCC & & \\
\hline & 123.00 & 0.22 & 13.26 & BS-DCC & & \\
\hline & 119.25 & 0.12 & 15.64 & BS-DCC & & \\
\hline & 83.00 & 0.21 & 11.77 & BS-DCC & & \\
\hline \multirow{5}{*}{$\begin{array}{l}\text { S5-60E-128-S } \\
(5 \mathrm{C})\end{array}$} & 121.00 & 1.29 & 20.13 & PS-DCC & \multirow{5}{*}{116.55} & \multirow{5}{*}{18.11} \\
\hline & 132.75 & 0.18 & 19.24 & BS-DCC & & \\
\hline & 104.00 & 0.20 & 18.58 & BS-DCC & & \\
\hline & 110.75 & 1.28 & 19.99 & BS-DCC & & \\
\hline & 114.25 & 0.38 & 22.77 & BS-DCC & & \\
\hline \multirow{5}{*}{$\begin{array}{c}\text { S5-60E-64-V } \\
(5 A)\end{array}$} & 100.00 & 0.46 & N/A & $\mathrm{BP}$ & \multirow{5}{*}{94.60} & \multirow{5}{*}{29.6} \\
\hline & 97.00 & 0.81 & N/A & $\mathrm{BP}$ & & \\
\hline & 91.00 & 0.55 & N/A & BP & & \\
\hline & 93.00 & 0.49 & N/A & $\mathrm{BP}$ & & \\
\hline & 92.00 & 1.01 & N/A & $\mathrm{BP}$ & & \\
\hline \multirow{4}{*}{$\begin{array}{c}\text { S5-60E-96-V } \\
(5 B)\end{array}$} & 103.00 & N/A & 17.00 & BS-SCCC & \multirow{4}{*}{88.75} & \multirow{4}{*}{18.5} \\
\hline & 96.00 & N/A & 18.00 & BS-SCCC & & \\
\hline & 79.00 & 0.11 & 16.00 & BS-SCCC & & \\
\hline & 77.00 & 0.34 & 18.00 & BS-SCCC & & \\
\hline \multirow{2}{*}{$\begin{array}{c}\text { S5-60E-127-V } \\
\text { (5C) }\end{array}$} & 97.50 & 0.06 & 18.80 & BS-DCC & \multirow{2}{*}{94.88} & \multirow{2}{*}{14.98} \\
\hline & 92.25 & 1.67 & 18.47 & BS-DCC & & \\
\hline
\end{tabular}

(BP): Pure bar pullout failure

(BS-DCC): Bar slippage as a result of shear failure in the grooves in case of ribbed bars and in the sandcoating in case of sand-coated bars, followed by diagonal concrete crack

(BS-SCCC): Bar slippage followed by side concrete cover crack 


\begin{tabular}{|c|c|c|c|c|c|c|}
\hline $\begin{array}{l}\text { Specimen } \\
\text { Notation }\end{array}$ & $\begin{array}{l}\text { Failure Load } \\
\qquad(k N)\end{array}$ & $\begin{array}{l}\text { Free End Slip } \\
\text { (LES) (mm) }\end{array}$ & $\begin{array}{l}\text { Loaded End } \\
\text { Slip (mm) }\end{array}$ & $\begin{array}{l}\text { Type of } \\
\text { Failure }\end{array}$ & $\begin{array}{c}\text { Average } \\
\text { Ultimate } \\
\text { Load } \\
(\boldsymbol{k N})\end{array}$ & $\begin{array}{c}\text { Average } \\
\text { Bond Stress } \\
(M P a)\end{array}$ \\
\hline \multirow{4}{*}{$\mathrm{H} 5-\mathrm{C}-\mathrm{O}-\mathrm{V}(2 \mathrm{~B})$} & 144.75 & 0.11 & 13.40 & BS & \multirow{4}{*}{113.00} & \multirow{4}{*}{22.66} \\
\hline & 101.25 & 1.42 & 25.11 & BS & & \\
\hline & 102.50 & 0.33 & 19.25 & BS & & \\
\hline & 103.50 & 0.87 & 19.87 & BS & & \\
\hline \multirow{5}{*}{$\begin{array}{c}\text { H5-C-64-V } \\
(2 A)\end{array}$} & 105.25 & 0.19 & 23.17 & BS & \multirow{5}{*}{105.65} & \multirow{5}{*}{12.92} \\
\hline & 105.00 & 0.10 & 24.72 & BS & & \\
\hline & 98.00 & 0.09 & 20.29 & BS & & \\
\hline & 111.00 & 0.24 & 22.47 & BS & & \\
\hline & 109.00 & 0.31 & 23.46 & BS & & \\
\hline \multirow{5}{*}{$\begin{array}{c}\mathrm{H} 5-40 \mathrm{E}-0-\mathrm{V} \\
\text { (4B) }\end{array}$} & 95.25 & 1.99 & 21.65 & BS-CCS & \multirow{5}{*}{94.40} & \multirow{5}{*}{18.93} \\
\hline & 88.00 & 0.01 & 21.69 & BS-CCS & & \\
\hline & 94.00 & 1.03 & 17.49 & BS-CCS & & \\
\hline & 97.75 & 0.69 & 22.54 & BS-CCS & & \\
\hline & 97.00 & 0.27 & 25.55 & BS-CCS & & \\
\hline \multirow{5}{*}{$\begin{array}{c}\mathrm{H} 5-40 \mathrm{E}-64-\mathrm{V} \\
(4 \mathrm{~A})\end{array}$} & 137.00 & 0.97 & 25.64 & BS-VSCCC & \multirow{5}{*}{128.15} & \multirow{5}{*}{15.67} \\
\hline & 150.00 & 0.57 & 24.53 & BS-VSCCC & & \\
\hline & 124.50 & 1.42 & 25.85 & BS-VSCCC & & \\
\hline & 120.75 & 0.94 & 20.67 & BS-VSCCC & & \\
\hline & 108.50 & 2.61 & 26.81 & BS-VSCCC & & \\
\hline \multirow{4}{*}{$\begin{array}{c}\text { H5-60E-0-V } \\
\text { (5D) }\end{array}$} & 150.75 & 0.42 & 30.56 & BS-CS & \multirow{4}{*}{142.63} & \multirow{4}{*}{28.60} \\
\hline & 141.25 & 1.06 & 15.00 & BS-CS & & \\
\hline & 155.75 & 0.65 & 15.26 & BS-CS & & \\
\hline & 122.75 & 0.14 & 25.68 & BS-CS & & \\
\hline \multirow{4}{*}{$\begin{array}{c}\text { H5-60E-64-V } \\
\text { (5E) }\end{array}$} & 148.00 & 0.81 & 19.17 & BS-CS & \multirow{4}{*}{130.56} & \multirow{4}{*}{15.96} \\
\hline & 136.25 & 0.05 & 16.46 & BS-CS & & \\
\hline & 133.00 & 0.12 & 16.42 & BS-CS & & \\
\hline & 105.00 & 0.29 & 16.30 & BS-CS & & \\
\hline
\end{tabular}

(BS): Bar slippage from the head

(BS-CS): Bar slippage from the head followed by concrete splitting

(BS-VSCCC): Bar slippage from the head and V-shape side concrete cover crack in case of embedment length of $76 \mathrm{~mm}$ with the bar head in \#6 GFRP bar

(BS-CCS): Bar slippage from the head and concrete cover splitting in case of zero embedment length with the bar head in \#6 GFRP bar 


\begin{tabular}{|c|c|c|c|c|c|c|}
\hline \multicolumn{7}{|c|}{ Table A-2b: General Data for Headed GFRP bars } \\
\hline $\begin{array}{l}\text { Specimen } \\
\text { Notation }\end{array}$ & $\begin{array}{l}\text { Failure Load } \\
\qquad(k N)\end{array}$ & $\begin{array}{c}\text { Free End Slip } \\
\text { (LES) ( } \mathrm{mm} \text { ) }\end{array}$ & $\begin{array}{l}\text { Loaded End } \\
\text { Slip ( } \mathrm{mm})\end{array}$ & $\begin{array}{l}\text { Type of } \\
\text { Failure }\end{array}$ & $\begin{array}{c}\text { Average } \\
\text { Ultimate } \\
\text { Load } \\
(k N)\end{array}$ & $\begin{array}{l}\text { Average } \\
\text { Bond Stress } \\
(M P a)\end{array}$ \\
\hline \multirow{5}{*}{ H6-C-0-V (2D) } & 135.75 & 0.91 & 19.40 & HB-BS-CS & \multirow{5}{*}{162.30} & \multirow{5}{*}{27.2} \\
\hline & 173.00 & 1.37 & 19.74 & HB-BS-CS & & \\
\hline & 203.25 & 0.12 & 24.00 & HB-BS-CS & & \\
\hline & 161.50 & 1.80 & 26.32 & HB-BS-CS & & \\
\hline & 138.00 & 0.95 & 25.22 & HB-BS-CS & & \\
\hline \multirow{2}{*}{$\begin{array}{c}\mathrm{H} 6-\mathrm{C}-76-\mathrm{V} \\
(2 \mathrm{C})\end{array}$} & 219 & 4.056 & 32.32 & $\mathrm{BP}$ & \multirow{2}{*}{222.0} & \multirow{2}{*}{21.10} \\
\hline & 225 & 5.056 & 25.87 & $\mathrm{BP}$ & & \\
\hline \multirow{3}{*}{$\begin{array}{c}\text { H6-40E-0-V } \\
\text { (4D) }\end{array}$} & 100.5 & 2.283 & 14.78 & HB-BS-CS & \multirow{3}{*}{91.42} & \multirow{3}{*}{15.28} \\
\hline & 86.5 & 0.86 & 22.09 & HB-BS-CS & & \\
\hline & 87.25 & 0.268 & 20.00 & HB-BS-CS & & \\
\hline \multirow{5}{*}{$\begin{array}{c}H 6-40 E-76-V \\
(4 C)\end{array}$} & 150.50 & 0.34 & 32.20 & BS-CS & \multirow{5}{*}{138.95} & \multirow{5}{*}{13.20} \\
\hline & 122.25 & 1.09 & 28.36 & BS-CS & & \\
\hline & 112.00 & 0.56 & 29.75 & BS-CS & & \\
\hline & 147.50 & 1.16 & 19.73 & BS-CS & & \\
\hline & 162.50 & 0.19 & 27.29 & BS-CS & & \\
\hline
\end{tabular}

(BS-CS): Bar slippage from the head followed by concrete splitting (HB-BS-CS): Bar head breakage followed bar slippage and concrete splitting (BP): Pure bar pullout 


\begin{tabular}{|c|c|c|c|}
\hline Specimen & Failure Mode & Specimen & Failure Mode \\
\hline $\begin{array}{l}\text { S5-C64- Schöck } \\
(1 \mathrm{~A})\end{array}$ & Pullout & S5-C64-V (1A) & \\
\hline $\begin{array}{l}\text { S5-C96- Schöck } \\
\text { (1B) }\end{array}$ & & S5-C96-V (1B) & \\
\hline $\begin{array}{c}\text { S5-C128- Schöck } \\
\text { (1C) }\end{array}$ & & S5-C127-V (1C) & \\
\hline $\begin{array}{l}\text { S6-C80- Schöck } \\
\text { (1D) }\end{array}$ & & S6-C76-V (1D) & \\
\hline $\begin{array}{c}\text { S6-C120- Schöck } \\
\text { (1E) }\end{array}$ & & S6-C114-V (1E) & \\
\hline
\end{tabular}




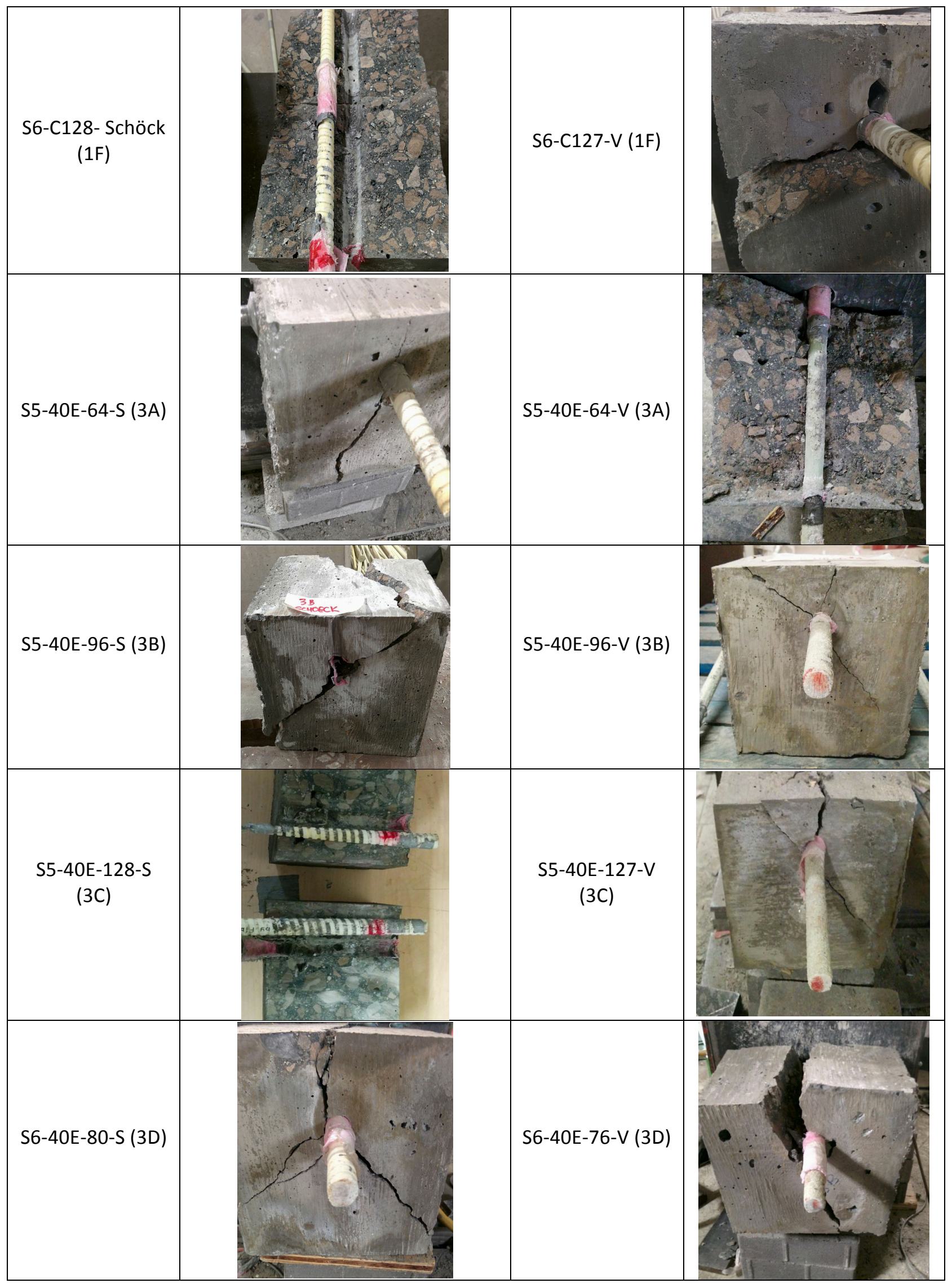




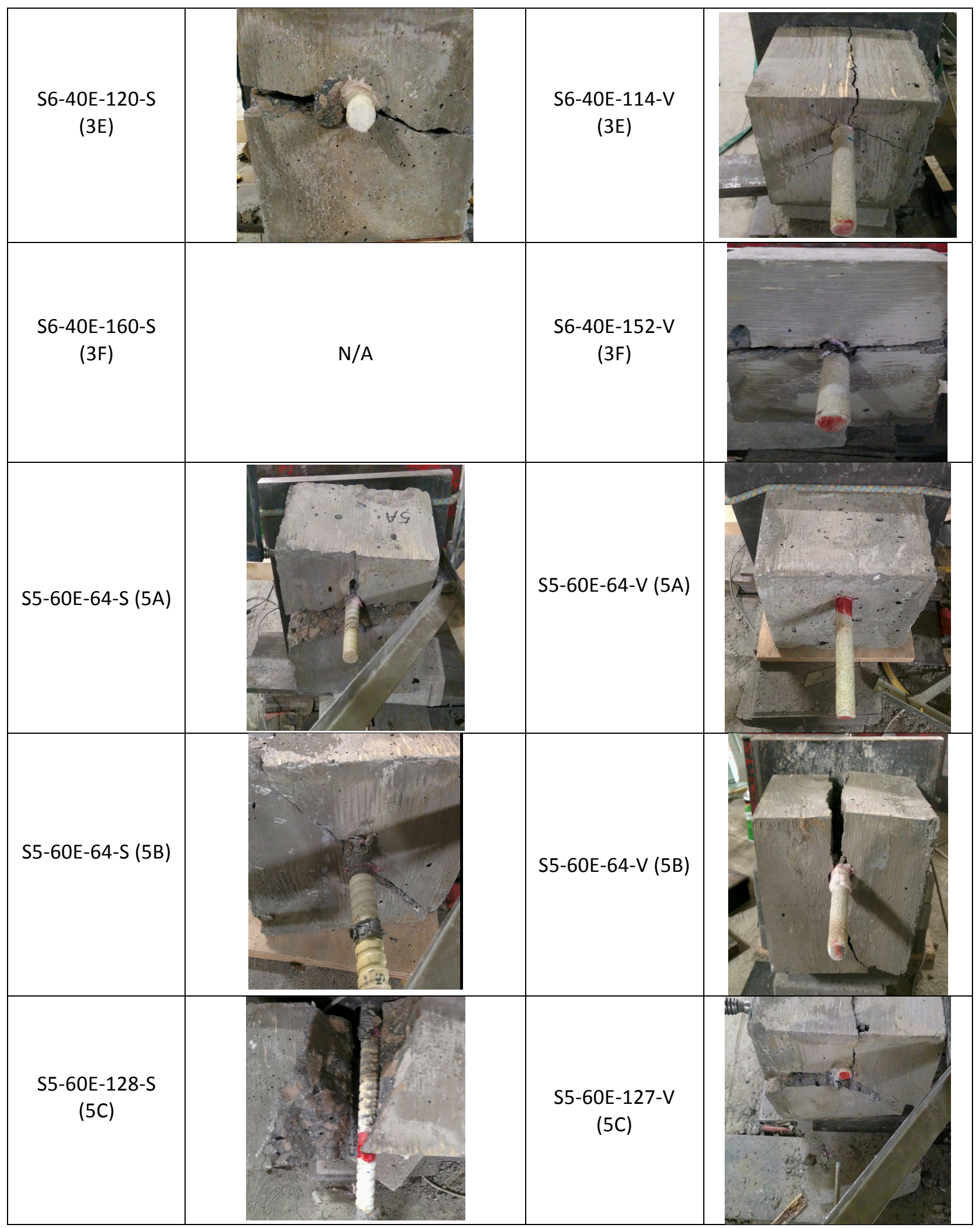




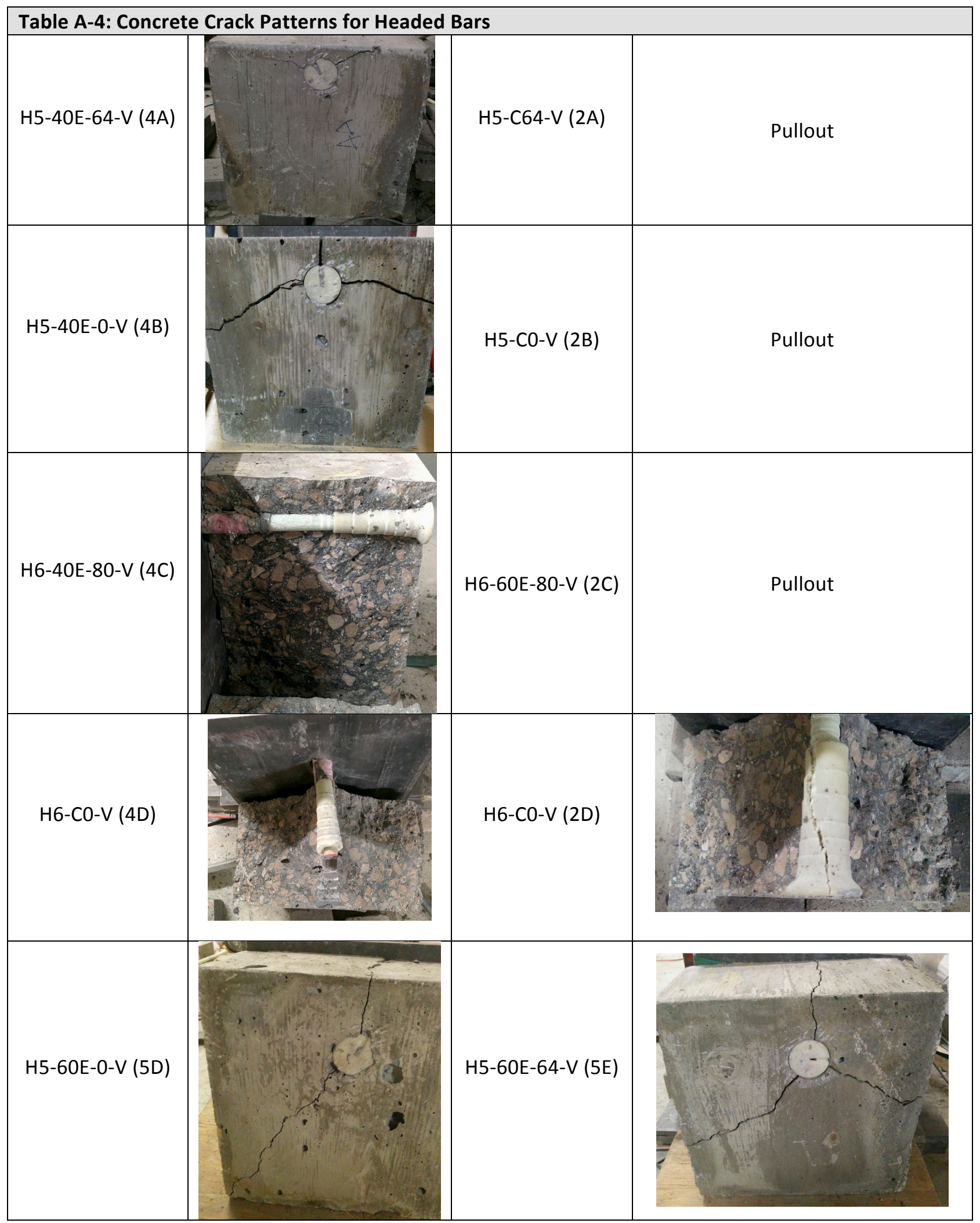

